MAESTRÍA EN DIRECCIÓN DE EMPRESAS

FACULTAD DE CIENCIAS ECONÓMICAS

UNIVERSIDAD NACIONAL DE LA PLATA

Trabajo de tesis para optar al título de Magister

Tema:

\title{
EXIGENCIAS NORMATIVAS EN MATERIA DE GESTIÓN AMBIENTAL. SU IMPACTO EN EL PROCESO DECISORIO DE LAS PEQUEÑAS Y MEDIANAS EMPRESAS
}

AUtOR: NicolÁs AlfRedo BARDelLA

DIRECTOR DE TESIS: GUILLERMO JELINSKY 


\section{Indice}

1 Justificación del problema de investigación ........................................... 1

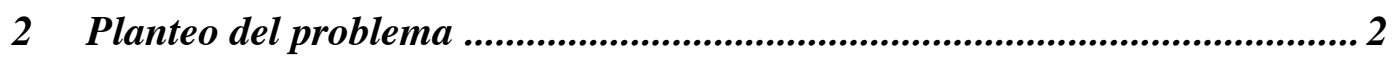

3 Objetivos de la investigación...................................................................... 3

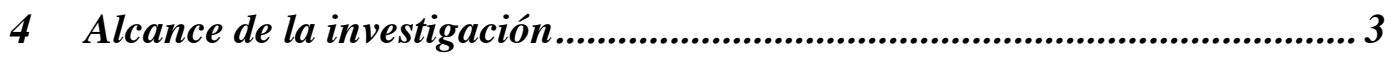

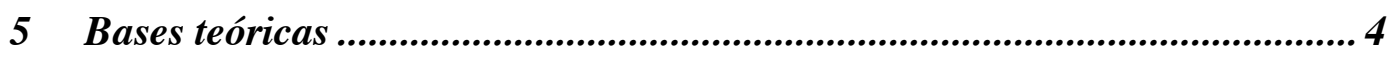

5.1 Requerimientos ambientales en el sector industrial...................................................... 4

5.1.1 Comentarios iniciales.................................................................. 4

5.1.2 Las exigencias legales en el tratamiento ambiental .......................... 4

5.1.3 Las ramas de diferenciación del derecho ambiental ........................... 7

5.1.4 El de acceso a un ambiente sano como derecho consagrado en la

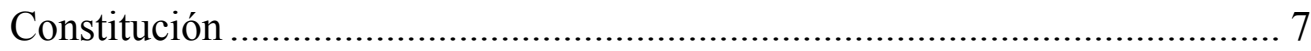

5.1.5 Protección del derecho al ambiente sujeta al acceso a la justicia ....... 10

5.1.6 El concepto de daño ambiental .................................................. 12

5.1.7 La responsabilidad civil en la gestión ambiental ............................. 13

5.1.8 Jurisdicción nacional y provincial en materia ambiental.................. 15

5.1.9 Situación en las provincias y en los municipios ............................. 18

5.1.10 Mínimos inderogables e indisponibles de Protección Ambiental (presupuestos mínimos en la materia)....................................................... 20

5.1.11 El bien jurídico protegido (la protección penal del ambiente)........... 21

5.1.12 Referencias sobre el Control Ambiental Industrial.......................... 34

5.2 Normativas complementarias................................................................................................36

6 Metodología y técnicas aplicadas a la investigación ...............................40

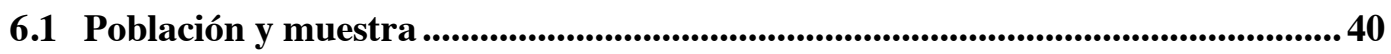

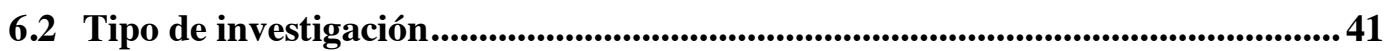

6.3 Técnicas de relevamiento de datos ........................................................................ 41 


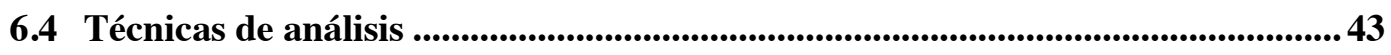

$7 \quad$ Resultados de la investigación ...............................................................44

7.1 Relevamiento de datos de fuentes secundarias .....................................................4 44

7.1.1 Organismo Provincial para el Desarrollo Sostenible....................... 44

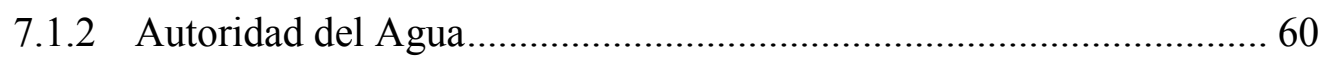

7.1.3 Fuentes complementarias........................................................... 72

7.2 Relevamiento de datos de fuentes primarias .............................................................. 76

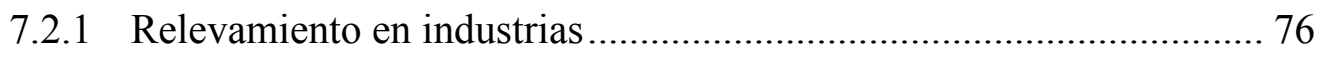

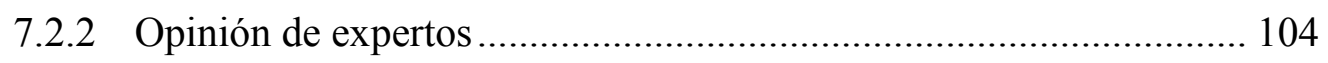

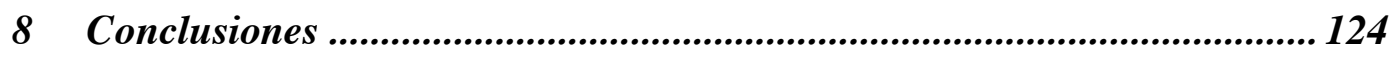

8.1 Influencia de la gestión ambiental en la toma de decisiones de las empresas.. 124

8.2 Causas del compromiso que toma la gestión general de la empresa con la gestión ambiental..........................................................................................126

8.3 Gestión ambiental y ventajas competitivas empresariales ...................................128

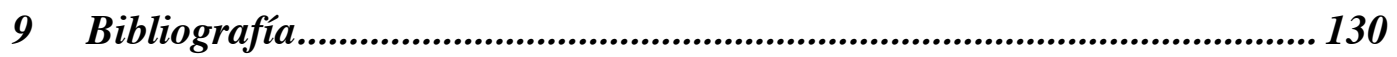

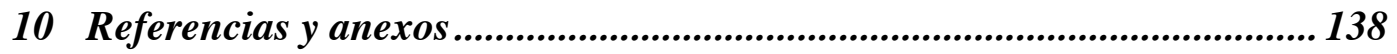

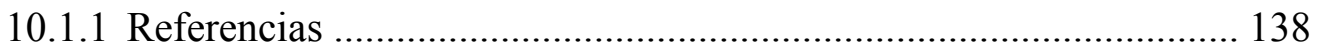

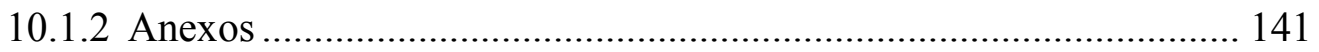




\section{Justificación del problema de investigación}

El entendimiento del ambiente en el sentido amplio del concepto, requiere internalizar un saber emergente en todo un conjunto de disciplinas, tanto de las ciencias naturales como sociales, para construir un conocimiento capaz de captar la interdependencia de los factores y procesos que integran el ambiente.

Los temas ambientales son una preocupación que cada vez está teniendo más importancia dentro de la toma de decisiones de las empresas, y todas las actividades industriales deben cumplir con una serie de requisitos obligatorios y específicos de acuerdo con su actividad en relación a la Gestión Ambiental.

Los mismos se enmarcan en normativas asociadas principalmente al control de los procesos que realizan y de los residuos (sólidos, líquidos o gaseosos) que generan. Para esto, se deben realizar estudios, análisis, declaraciones juradas, monitoreos de contaminantes y demás presentaciones ante las Autoridades de Aplicación (Municipios, Organismo Provincial para el Desarrollo Sostenible -OPDS-, Autoridad del Agua -ADA-). Estas acciones tienen la finalidad del cuidado del ambiente en sentido amplio, y el no cumplimiento con las exigencias que se plantean, conllevan a distintas sanciones civiles o penales según lo establezca la Ley.

A su vez, una gestión ambiental eficiente seguramente evite gastos innecesarios (multas o clausuras, repetición de estudios, ineficiencia en la contratación de los servicios, etc.) y optimice los procesos, redundando en una mejora de los productos, así como una reducción de los residuos generados.

Además, cada día se observan más presiones de la sociedad en cuanto a la gestión ambiental que llevan adelante las Industrias. Por lo tanto, dar cumplimiento con las obligaciones normativas, es el primer paso para evitar conflictos ambientales con la comunidad, entendiendo que los mismos pueden tomar dimensiones que afecten notablemente la imagen de la empresa.

También existe la posibilidad de realizar acciones superadoras al simple cumplimiento de lo establecido por Ley. Estas se relacionan principalmente con un compromiso mayor con la gestión ambiental del establecimiento, 
implementando planes de Sustentabilidad, Responsabilidad Social Empresaria o Certificación de Sistemas de Gestión normalizados avalados por distintas instituciones (por ejemplo, el IRAM -Instituto Argentino de Normalización y Certificación-). Estas acciones muchas veces permiten ganar mercado, tanto interno como externo.

La problemática ambiental es uno de los elementos que configuran el escenario económico en que están inmersas las empresas, con una innegable incidencia sobre los procesos administrativos de las mismas. Este análisis enfoca directamente sobre el proceso decisorio de las pequeñas y medianas industrias.

Por lo tanto, caracterizar la influencia de la gestión ambiental en la toma de decisiones de las empresas, nos permitirá establecer las causas de tales decisiones, así como analizar si la gestión ambiental puede generar ventajas competitivas generales.

Teniendo en cuenta que la gestión ambiental en una Industria debe cumplir con exigencias reglamentarias, del mercado y sociales en crecimiento continuo, ¿cómo influye la gestión ambiental en el proceso decisorio de las pequeñas y medianas empresas?

Por lo dicho, se considera que existe justificación para tomar como tema de tesis de un programa MBA el de Exigencias normativas en materia de gestión ambiental. Su impacto en el proceso decisorio de las pequeñas y medianas empresas

\section{Planteo del problema}

En el área considerada para el estudio (la provincia de Buenos Aires) y tomando en cuenta el objeto de la investigación (la gestión ambiental y el proceso decisorio en PyMES), se puede proponer que existe una profunda brecha entre el deber ser de las exigencias normativas en materia de gestión ambiental y el ser en concreto que se registra; esto es, entre lo que debiera ser la gestión ambiental y lo que se registra en concreto como prácticas de las 
empresas consideradas. Analizando legislación y normativas, objetivos y valores que tal marco legal llevan implícitos, situación ambiental y experiencias exitosas de otras partes del mundo referidas a la cuestión, permite apreciar que está lejos de lo idea, del deber ser, el cómo gestionan las empresas la cuestión ambiental y en qué grado cumplen con el marco regulatorio vigente.

Como problema de investigación existen entonces deficiencias en el cumplimiento del marco normativo en materia de gestión ambiental por parte de las empresas, lo que tiene incidencia directa en el proceso por el cual las mismas toman decisiones.

\section{Objetivos de la investigación}

- Identificar y analizar los efectos del cumplimiento de las normativas sobre gestión ambiental en el proceso decisorio de las empresas definidas como objeto de la investigación.

- Identificar causas que generen compromiso por parte de las empresas en favor de una gestión ambiental responsable y con cumplimiento de las exigencias normativas vigentes.

- Analizar y definir si una gestión con compromiso ambiental puede ser generadora de algún tipo de ventajas competitivas.

\section{Alcance de la investigación}

Se planteará el estricto alcance de la investigación, en función de estas definiciones:

- El estudio se realizará sobre pequeñas y medianas empresas, ubicadas en un radio de menos de $350 \mathrm{Km}$ de la ciudad de La Plata, y que no se encuentren en la Cuenca Matanza - Riachuelo.

- El proceso administrativo que se analizará es el proceso de toma de decisiones en la gestión de las empresas. 
- Se considerará el marco legal y normativo regulatorio vigente para las empresas que operan en ámbito geográfico definido como alcance.

\section{Bases teóricas}

\subsection{Requerimientos ambientales en el sector industrial}

\subsubsection{Comentarios iniciales}

El derecho, como fenómeno regulador de las conductas sociales deviene un instrumento fundamental en la articulación de las dinámicas natural y social en todas las instancias. Cabe reflexionar que si bien es cierto que la importancia de la legislación en la gestión ambiental suele verse oscurecida por no ver en la realidad cumplidos los objetivos para los que es creada, esta circunstancia debe verse como una situación transitoria que no debe hacer perder de vista el hecho de que, en definitiva, el derecho es una condición más pero no la única, para la ordenación del ambiente que se persigue mediante toda gestión ambiental.

Es que las insuficiencias de la legislación ambiental y su defectuosa aplicación son elementos integrantes de la problemática ambiental y deben ser tratados como tales. Por eso, la comprensión de la problemática ambiental requiere el conocimiento de la manera como está organizada jurídicamente la relación sociedad-naturaleza.

\subsubsection{Las exigencias legales en el tratamiento ambiental}

Resulta ser responsabilidad del Estado, dentro del marco de un derecho establecido, la solución de los problemas ambientales que puedan existir en una sociedad. En este sentido, la legislación es un componente esencial de 
toda gestión ambiental a ser desarrollada por los órganos estatales. En efecto, el derecho se encuentra tanto en el origen mismo de esa función pública como en su organización, siendo además la fuente principal de la política ambiental y sus mecanismos de aplicación.

La gestión ambiental fue incorporada a la función pública como resultado directo del hecho de que la ordenación del ambiente en un momento dado pasó a ser considerada un fin estatal, y por lo tanto un nuevo cometido del Estado. En tanto la calificación de un objetivo social como un fin estatal requiere también de una norma que así lo establezca. La legislación ambiental es, en primer término, la fuente de la incorporación de la gestión ambiental a la función pública del estado, así como de la organización que esta asume. Asimismo, la política ambiental del Estado, es decir el conjunto de acciones que éste diseña para lograr la ordenación del ambiente que estima apropiada, es formulada mediante normas en forma más o menos detallada. De este modo la legislación ambiental es, en segundo término, la fuente principal de la política ambiental.

Por otro lado, la aplicación de la política ambiental requiere de un conjunto de mecanismos, la mayoría de los cuales deben ser establecidos por el sistema jurídico estatal. Por eso, la legislación ambiental es, en tercer término, la fuente principal de los mecanismos para la aplicación de la política ambiental. De este modo el quehacer del Estado en materia ambiental está regido principalmente desde el origen mismo de la función que ejerce en este campo, por el derecho.

El derecho ambiental también es un conjunto de propuestas sobre política legislativa para la protección del ambiente. En consecuencia, su conocimiento nos permite insertarnos en el centro de una discusión que es esencial para el destino del ambiente. Siguiendo a Brañes (1994), se puede afirmar que "Se trata de un debate que sólo puede llegar a feliz término con base en un profundo conocimiento interdisciplinario de lo ambiental, en el que lo jurídico es sólo una variable del debate, pero en todo caso la forma que asumirán sus conclusiones. Por eso la comprensión de la problemática ambiental exige, entro otras tantas cosas, el conocimiento del derecho ambiental". Resulta necesario 
entonces identificar las principales contribuciones del derecho ambiental en el estudio de procesos y problemas ambientales.

En este sentido, la doctrina que se ha formado entiende que el derecho ambiental es algo más que una disciplina constituida en torno del estudio de la legislación ambiental o, incluso, de una legislación ambiental determinada. Tendría más que ver con una identificación con un cuerpo de ideas que se organiza a partir de la percepción de un problema social que debe ser regulado por el derecho y, en consonancia con esa percepción -y también según Brañes (1994)- se ocupa de:

- identificar las respuestas que hasta ahora ese problema tiene en la legislación vigente $y$, por tanto, determinar la capacidad formal de esa legislación para enfrentar los desafíos que plantea la problemática ambiental;

- examinar la manera como se aplica la legislación ambiental vigente y, en consecuencia, detectar sus grados de ineficacia y, hasta donde es posible sus causas;

- formular propuestas para el perfeccionamiento de la legislación ambiental y su aplicación; y,

- en general, construir una teoría jurídica cuyos principios y técnicas permitan impulsar el desarrollo de la legislación ambiental y su aplicación, a la luz de las evaluaciones que se hagan de los asuntos ambientales desde las diversas perspectivas de análisis que son propias de esos asuntos. En el derecho ambiental son especialmente importantes los enfoques internacionales de los asuntos ambientales y los análisis de derecho comparado.

En conclusión, el derecho ambiental es algo más que un cuerpo de ideas jurídicas, pues es el campo de un estudio interdisciplinario del que son responsables todas las ciencias que tienen que ver con la problemática ambiental. 


\subsubsection{Las ramas de diferenciación del derecho ambiental}

En principio, en tres grandes ramas puede ser diferenciado el derecho ambiental. A saber:

- Legislación propiamente ambiental: normas contenidas en los ordenamientos jurídicos y que parten de una concepción holística y sistémica del ambiente. Por ejemplo, la Ley General del Ambiente.

- Legislación sectorial de relevancia ambiental: normas contenidas en algunos ordenamientos jurídicos que se ocupan sólo de la protección de ciertos elementos ambientales o de la protección del ambiente frente a los efectos que pueden generar determinadas actividades humanas. Por ejemplo, Leyes sobre industrias.

- Legislación de relevancia ambiental casual: normas contenidas en ordenamientos jurídicos que han sido expedidos sin ningún propósito ambiental pero que regulan conductas que inciden significativamente en la protección del ambiente. Por ejemplo, leyes de procedimiento administrativo regulando el derecho a la información ambiental.

\subsubsection{El de acceso a un ambiente sano como derecho consagrado en la Constitución}

La Constitución Nacional es el punto de partida para el estudio del ordenamiento jurídico que hace al derecho a un ambiente sano, y eso por ser la "ley fundamental" el origen de todo el marco legal al respecto. La norma constitucional argentina reconoce dentro del orden jurídico positivo la tutela del ambiente como un derecho humano, previendo además mecanismos específicos de protección, e introduce un régimen innovador en la distribución de competencias entre la Nación y las Provincias ${ }^{1}$.

1 Cabe recordar que nuestra Constitución al igual que todas las inspiradas en el constitucionalismo clásico, está dividida en dos partes. La primera, denominada también parte dogmática, 
El reconocimiento expreso de los derechos otorga al sujeto activo la posibilidad de exigir coactivamente su cumplimiento, ya sea frente a los demás individuos o grupos, ya sea frente al propio Estado. Antes de la reforma constitucional de 1994 la doctrina consideraba que los derechos referidos al ambiente se encontraban implícitamente contenidos en el Artículo 33 y como una derivación del derecho a la salud y la vida en general, justificándose su ausencia en la juventud de estos nuevos derechos. Este debate finalizó con su inclusión expresa en la norma constitucional ${ }^{2}$. La incorporación de normas tendientes a la protección del ambiente en la Constitución Nacional recién se produjo en la reforma constitucional de 1994, como consecuencia del interés creciente de la sociedad en la preservación de su calidad de vida y del entorno natural.

Resulta ser un fenómeno propio de las últimas décadas el reconocimiento jurídico del medio ambiente, y reconoce como antecedente más relevante las Conferencias de las Naciones Unidas de Estocolmo (1972), Río de Janeiro (1992), Johannesburgo (2002) y Río + 20 (2012). En razón de su origen relativamente reciente, los derechos vinculados al ambiente son dominados por

contiene una serie de preceptos que en su conjunto tienden a colocar un dique de contención al poder, tratando de limitarlo, confinarlo, evitando que se desmesure y usurpe así el espacio de libertad.

Esta primera parte contiene declaraciones (afirmaciones expresas que implican la adopción de determinada postura en relación a cuestiones políticas fundamentales (forma de estado, sostén culto católico); así como derechos (facultados o prerrogativas que se reconoce a sus titulares, ya sean individuos o grupos sociales) y garantías (mecanismos o instrumentos especiales que se crean para amparar y asegurar el ejercicio de ciertos derechos fundamentales a los titulares de éstos como ser el amparo, habeas data, el habeas corpus).

${ }^{2}$ La doctrina distingue entre derechos constitucionales explícitos e implícitos. Resultan explícitos cuando se encuentran expresamente reconocidos en el texto constitucional, e implícitos cuando se los encuentra enumerados en forma genérica en el Artículo 33. Esta norma refiere que "Las declaraciones, derechos y garantías que enumera la Constitución, no serán entendidos como negación de otros derechos y garantías no enumerados, pero que nacen del principio de la soberanía del pueblo y de la forma republicana de gobierno". 
la doctrina como derechos de tercera generación. Según este criterio la primera generación de derechos humanos corresponde a los civiles y políticos, receptados por las revoluciones americana y francesa. Su formulación contempla esencialmente a las libertades del individuo frente al Estado. La segunda generación corresponde al constitucionalismo social del siglo $X X$, reconociendo los derechos sociales y económicos de las personas, requiriendo por lo general, una acción positiva por parte del Estado para su concreción. Por último, como de tercera generación se agrupa un conjunto de derechos más recientes tanto que algunos aún no tienen consagración en el derecho positivo.

Entre estos últimos tipos de derechos están por ejemplo el derecho a la calidad de vida, a la defensa de los ecosistemas, a la autodeterminación, a la integridad territorial, al desarrollo, a la paz, o a la explotación de los propios recursos. Este grupo de derechos responde a los cambios profundos que se están produciendo en la comunidad internacional y en las relaciones entre sus integrantes, con un especial énfasis en la justicia y la solidaridad.

Enumerando puntualmente algunos de los derechos referidos al ambiente, están contenidos en nuestra Constitución Nacional en el Artículo 41, el cual dice "Todos los habitantes gozan del derecho a un ambiente sano, equilibrado, apto para el desarrollo humano y para que las actividades productivas satisfagan las necesidades presentes sin comprometer las de las generaciones futuras; $y$ tienen el deber de preservarlo...". La inclusión expresa de este derecho tiene consecuencias prácticas de suma importancia. Así, a la hora de crear o aplicar restricciones o limitaciones a otros derechos a fin de implementar políticas protectoras del medio, tanto los legisladores como la administración encuentran el sustento legal adecuado para hacerlo. Esta inclusión también constituye pauta valorativa para los jueces cuando deben resolver conflictos donde se ven involucrados distintos derechos (por ejemplo el de ejercer industria lícita, de propiedad versus el derecho a un ambiente sano). 


\subsubsection{Protección del derecho al ambiente sujeta al acceso a la justicia}

El primer responsable en velar por la protección del derecho al ambiente es el Estado (Artículo 41, segundo párrafo). Sin embargo, teniendo en cuenta que el reconocimiento que hace la norma constitucional de este derecho es para cada habitante de la Nación, se debe analizar si éstos pueden individualmente reclamar ante un Juez la defensa del ambiente. Este tema resulta importante pues implica la habilitación para los miembros de una comunidad de solicitar la tutela judicial cuando resultan infructuosos los reclamos ante la administración. Con la reforma constitucional y la sanción expresa de este derecho nos encontramos frente a un derecho de carácter operativo y no programático.

El reconocimiento que la Constitución hace de estos derechos subjetivos está tanto en doctrina como en jurisprudencia, y otorga al titular la facultad de exigir coactivamente que se cumpla, pudiendo concurrir a la justicia para lograr tal cumplimiento de su prestación (acción u omisión) que es la sustancia de su derecho. En esto consiste la operatividad de la respectiva cláusula constitucional: es esa capacidad del titular de poder exigir judicialmente el respeto a su derecho, en forma coactiva si es necesario. Por el contrario, una disposición constitucional es programática, cuando la prerrogativa o facultad que ella otorga no basta para otorgar al beneficiario de ella la protección jurisdiccional contra quienes pretendan desconocerla. Necesita otra norma inferior que la reglamente y que regule aspectos necesarios para su aplicación (obligaciones de dar, no hacer).

Con anterioridad a la reforma este tema había sido arduamente discutido tanto doctrinaria como jurisprudencialmente, pues no existían normas positivas que lo previeran y nuestro sistema procesal judicial no estaba organizado para receptar causas de esta naturaleza. Cabe recordar que la doctrina tradicional le otorgaba a los derechos subjetivos, un enfoque casi exclusivamente individualista. Sin embargo, actualmente se considera que los derechos pueden y deben ser ejercidos fundamentalmente por los individuos, pero no se agota en el ejercicio de ellos por parte de los individuos, sino que éstos pueden ser 
compartidos comunitariamente por ciertos grupos o categorías de individuos. En efecto, hay derechos cuya titularidad no corresponde a los individuos (o al menos solamente a ellos) sino que es ejercida (exclusivamente o en forma compartida con los individuos) por ciertos grupos sociales más o menos amplios, más o menos difusos, o incluso, por toda la sociedad. Como se expresara anteriormente, la doctrina administrativista y procesalista tradicional eran reticentes a reconocer acción judicial para la protección de los intereses difusos, con el argumento de que en nuestro derecho no existe la acción popular, y solamente al Estado, como representante del bien común, correspondía velar por su preservación.

Para su procedencia consideraban que el que invocaba la jurisdicción debía reunir "en su cabeza" un daño diferenciado del resto de la comunidad, un agravio concreto, independiente del mero rompimiento del contrato social distintivo, no participado por el resto del cuerpo político. Salvo algún precedente aislado la justicia solamente entendía en aquellas causas que el iniciador hubiese sufrido o pudiere sufrir un daño particularizado y concreto. La reforma constitucional modificó el esquema vigente hasta ese entonces, pues no sólo incorporó el derecho ambiental de modo expreso para cada habitante, sino que fue más allá al reconocer el derecho a interponer un tipo de acción, la denominada acción de amparo al “...afectado, el defensor del pueblo y las asociaciones que propendan a estos fines, registradas conforme a la Ley, la que determinará los requisitos y formas de su organización”. De este modo quedó consagrada la posibilidad de accionar de las Organizaciones no Gubernamentales (ONG's), el Defensor del Pueblo (u Ombudsman) y el afectado.

Ha creado dudas, respecto a quienes comprende, el empleo del término "afectado", de novedosa utilización en nuestro derecho. Aparentemente, bajo este concepto quedarían comprendidas situaciones que exceden la esfera de los derechos subjetivos individuales, asimilándose al concepto de vecino. En general la jurisprudencia consideró legitimados a las personas que por el hecho de su proximidad con el lugar podrían sufrir las consecuencias ambientales dañosas. En definitiva, pareciera que la legitimación que acuerda el Artículo 43 
de la Constitución Nacional se configura cuando se lesiona el llamado ámbito vital de las personas, el cual viene determinado por una relación de proximidad física, esto es, por una vinculación derivada de la localización especial y no de la pertenencia a una determinada jurisdicción política.

Por su parte, la Ley General del Ambiente contiene previsiones determinando la calidad requerida para acceder a la justicia, distinguiendo dos pretensiones distintas:

- Una, tendiente a obtener una actividad positiva del demandado que es la recomposición del ambiente (obligación de hacer);

- otra, cuyo objetivo es el de obtener el cese de la actividad generadora del daño (obligación de dejar de hacer).

Para cada uno de estos supuestos la calidad requerida del actor es diferente. Así, tendrán legitimación para obtener la recomposición del ambiente dañado, reiterando los conceptos de la Constitución, el afectado, el Defensor del Pueblo y las asociaciones no gubernamentales de defensa ambiental, agregando además al Estado Nacional, Provincial o Municipal y a la persona directamente damnificada por el hecho dañoso. Por otro lado, cuando la pretensión está orientada a hacer cesar una actividad generadora de un daño ambiental (y no la recomposición) dentro de una acción de amparo, la Ley habilita para solicitarlo a "toda persona", es decir que la legitimación sin duda en este caso es amplia y no requiere ninguna calificación para ello.

\subsubsection{El concepto de daño ambiental}

La Constitución incorpora una importante premisa novedosa en el modo que se debe actuar ante el daño ambiental. En su artículo 41 se expresa esto: "El daño ambiental generará prioritariamente la obligación de recomponer, según lo establezca la Ley". De este modo la reforma constitucional incorpora este verbo "recomponer" que no tiene antecedentes en el derecho argentino. La norma delega al Congreso Nacional que deberá legislar sobre responsabilidad por daños ambientales, debiendo establecer prioritariamente la 
obligación de recomponer el ambiente degradado. La experiencia comparada ha demostrado que las tareas de recomposición o remediación ambiental, pueden ser sumamente costosas, ya sea para los particulares que deben afrontar tales gastos o para la sociedad, cuando las mismas son asumidas por el Estado.

\subsubsection{La responsabilidad civil en la gestión ambiental}

Es el régimen de responsabilidad civil el que determina el modo en que el derecho provee al resarcimiento o reparación de los daños causados al ambiente. La doctrina especializada distingue dos tipos de daño ambiental, los cuales normalmente se dan en forma simultánea:

- El primero de ellos es el daño causado a las personas o cosas a través del ambiente por una alteración del mismo provocada por el obrar humano. Estos casos, en principio son asimilables a las diversas hipótesis de daños reconocidas por el derecho clásico en cuanto a las reglas para atribuir responsabilidades y asignar resarcimientos, aplicándose los Artículos. 1109, 1113 y 2618 del Código Civil, con las particularidades que la materia imprime a los casos.

- La segunda noción de daño ambiental es el denominado "daño ambiental propiamente dicho" consistente en el perjuicio o menoscabo soportado directamente por los elementos de la naturaleza o el medio ambiente, que puede recaer o no sobre personas o cosas.

Es la Ley $25.675^{3}$ (Ley General del Ambiente), que reglamenta el Artículo 41 de la Constitución Nacional, la que contiene preceptos que deben ser aplicados en todo el territorio nacional, por ser una ley dictada por el Congreso

${ }^{3}$ Sancionada el 6/11/2002, publicada en el Boletín Oficial el 28/11/2002. 
en virtud de la delegación de competencias que han realizado las Provincias a la Nación y tratarse de una norma de Derecho Civil. Esta Ley determina que toda alteración relevante que modifique negativamente el ambiente, sus recursos, el equilibrio de los ecosistemas o los bienes o valores colectivos constituye daño ambiental (Artículo 27). Asimismo, determina que el causante del daño ambiental será objetivamente responsable de su restablecimiento al estado anterior de su producción. Se mantiene el criterio de responsabilidad objetiva que ya se reconocía tanto por la jurisprudencia como por la doctrina como de necesaria aplicación en la materia (Artículo 28). La norma contempla también el supuesto en que la remediación no sea técnicamente factible, en cuyo caso habilita al juez interviniente a fijar una indemnización que deberá depositarse en un Fondo de Compensación Ambiental que se crea por esta Ley, el que deberá ser administrado por la autoridad competente de cada jurisdicción y estará destinado a garantizar la calidad ambiental, la prevención y mitigación de efectos nocivos y peligrosos sobre el ambiente y la atención de emergencias ambientales.

La Ley establece un sistema de responsabilidad civil agravado. La exención de responsabilidad sólo se producirá acreditando que, a pesar de haberse adoptado todas las medidas destinadas a evitarlo y sin mediar culpa concurrente del responsable, los daños se produjeron por culpa exclusiva de la víctima o de un tercero por quien no debe responder (Artículo 29). La norma también prevé aquellos supuestos donde el daño es producido por más de una persona, y resulta difícil la determinación del grado de responsabilidad que le corresponde a cada uno, estableciendo la solidaridad de la reparación. Todos son responsables, sin perjuicio del derecho de repetición entre sí para lo que el Juez interviniente podrá determinar el grado de responsabilidad de cada persona responsable (Artículo 31). Asimismo, para el supuesto de que el daño sea producido por personas jurídicas, la responsabilidad se hace extensiva a sus autoridades y profesionales, en la medida de su participación (Artículo 31). 


\subsubsection{Jurisdicción nacional y provincial en materia ambiental}

En materia ambiental se verifica que la función normativa se encuentra desdoblada entre la Nación y las Provincias. Así, en virtud del Artículo 41 de la Constitución Nacional, corresponde a la Nación de manera exclusiva la función de citar normas que contengan los presupuestos mínimos de protección ambiental y a las Provincias la función de dictar las normas necesarias para complementarlas. Por su parte, la función ejecutiva, por aplicación de los Artículos 122, 41 (tercer párrafo) y 75 (incisos 13 y 19) se puede afirmar como principio (con algunas excepciones particulares), que pertenece a las Provincias. En éste ámbito también cobran relevancia el federalismo de concertación y los pactos ambientales suscriptos entre las Provincias. Finalmente, la función judicial, rigen los principios generales de la competencia de los órganos judiciales en razón de la materia, las personas y el territorio. A ello se suma el Artículo 7 de la Ley 25.675 que dispone como principio general la competencia de los Jueces Provinciales y sólo excepcionalmente la intervención del fuero de excepción, en los supuestos enumerados en el Artículo 116 de la Constitución Nacional.

Tal como se refiriera, la reforma constitucional del año 1994 introdujo una importante variación en el esquema de distribución de competencias entre Nación y Provincias. En efecto, el Artículo 41 establece que "Corresponde a la Nación dictar las normas que contengan los presupuestos mínimos de protección, y a las provincias, las necesarias para complementarlas, sin que aquellas alteren las jurisdicciones locales". La incorporación de esta previsión obedeció a la necesidad de establecer los umbrales mínimos de protección ambiental como modo de garantizar el derecho a la igualdad entre todos los habitantes de la República, y en especial, a fin de evitar la creación de desventajas comparativas comerciales y de radicación de industrias entre las provincias más protectoras del ambiente de aquellas que no lo son.

Las atribuciones de la Provincia en el sentido de complementar los presupuestos mínimos, permite suponer que las provincias pueden establecer umbrales de calidad más exigentes que los establecidos por la Nación, pero 
nunca inferiores a éstos. Bajo este criterio, a normas ambientales locales más exigentes que las dictadas por la Nación no puede oponérseles el principio de la supremacía de las normas regulado en el Artículo 31 de la Constitución Nacional. Cabe recordar también que por el artículo 124 de la Constitución Nacional reformada, se reafirma el principio del dominio provincial originario de los recursos naturales existentes en su territorio. Por lo tanto la regulación de estos recursos permanece en el ámbito provincial, con las excepciones explícitamente establecidas mediante delegación al Estado Federal, como ser la establecida en el Artículo 41 respecto de la determinación de los presupuestos mínimos de protección ambiental.

El Estado Federal retiene por su parte amplias facultades, ejercidas algunas de ellas en concurrencia con las Provincias, en virtud de las denominadas cláusulas de la prosperidad, para "Proveer lo conducente a la prosperidad del País, al adelanto y bienestar de todas las provincias..." y "Proveer lo conducente al desarrollo humano...". Las mismas brindan sustento constitucional a la elaboración de políticas ambientales nacionales ${ }^{4}$. Debemos recordar también la presencia de facultades que originariamente fueron delegadas a la Nación por la Provincia, y que ésta ejerce en forma exclusiva, no pudiendo las Provincias dictar normas al respecto. Ello sucede con la jurisdicción sobre los ríos en materia de navegación (Artículo 75, inciso 10), la regulación del comercio interprovincial (inciso 13$)^{5}$ y respecto del dictado de los Códigos de fondo: Civil, Penal, de Minería. ${ }^{6}$

${ }^{4}$ Estas facultades conferidas al Estado Nacional a fin de proveer al bienestar general dieron sustento a numerosas normas que avanzaron sobre las autonomías provinciales, como ser la Ley de Nacionalización de hidrocarburos. La dificultad radica principalmente en que no existe un límite definido por la Constitución para el ejercicio de esta potestad por parte del gobierno nacional.

${ }^{5}$ Así por ejemplo el transporte de residuos peligrosos de una provincia a otra es regulado por la Nación por ser considerada la actividad transporte, un acto de comercio.

6 De este modo la determinación o tipificación de las conductas dañosas al ambiente y el establecimiento de la respectiva sanción corresponde al Congreso Nacional, por ejemplo el delito de contaminación de aguas contenido en el Código Penal (Artículo 299), o de contaminación por residuos peligrosos, contenidos en la Ley 24.051 (B.0.3-5-93). 
Por otra parte, no podemos olvidar que las Provincias establecen sus propias instituciones y se rigen por ellas (Artículo 122 de la Constitución Nacional). Bajo este principio constitucional ellas organizan su gobierno dictando sus normas administrativas, sin que el Estado Nacional pueda interferir. Lo mismo sucede con el derecho procesal, normas que son de competencia exclusiva de las Provincias (Artículos 75 -inciso 12-, 121 y 126 de la Constitución Nacional) quienes en este ámbito posen la facultad de desplazar la actuación de la Nación cuando violando este reparto dicte directivas de esta naturaleza ${ }^{7}$. Sin embargo, en esta materia también existen modificaciones introducidas por las leyes de presupuestos mínimos las cuales contienen previsiones procesales y administrativas. Las mismas han sido convalidadas por la Corte Suprema de Justicia Nacional (CSJN), quien ha dicho que "la Ley General del Ambiente, establece en su Artículo 6 los presupuestos mínimos que el Artículo 41 de la Constitución Nacional anticipa, fija los objetivos y los principios rectores de la política ambiental, y los instrumentos de gestión para llevarla a cabo (Artículos. 2, 4 y 8). La referida Ley ha instaurado un régimen jurídico integrado por disposiciones sustanciales y procesales (destinadas a regir las contiendas en las que se discute la responsabilidad por daño ambiental), y ha consagrado principios ordenatorios $y$ procesales aplicables al caso, y que deben ser estrictamente cumplidos, resguardando y concretando así la vigencia del principio de legalidad que impone a ciudadanos y autoridades la total sujeción de sus actos a las previsiones contenidas en la Ley" (sentencia de la CSJN del 8/04/2008.

Asimismo, la responsabilidad civil emergente de las actividades dañosas al ambiente se rigen por el régimen general de responsabilidad civil establecido en el Código Civil o en el caso de daños por la operación con residuos peligrosos por la Ley 24.051 anteriormente citada.

${ }^{7}$ Vale aclarar que la Corte Suprema Nacional ha exceptuado esta competencia de manera notoria, sosteniendo que la facultad local de dictar normas procesales no es absoluta y que no cabe desconocer al Congreso Nacional como órgano competente para dictar normas procesales cuando sea pertinente establecer ciertos recaudos de esa índole a fin de asegurar la eficacia de las instituciones reguladas por los Códigos de fondo. 
Asociación Argentina de Abogados Ambientalistas c/Buenos Aires, Provincia de y otros s/acción de recomposición y saneamiento del Río Reconquista s/medida cautelar" causa A.1722.XLII).

Existen numerosos conflictos entre el Estado Nacional y las provincias para determinar sus competencias en distintas situaciones donde un recurso natural o actividad referida al mismo, perteneciente y regulado por una Provincia presenta aspectos que hacen al interés de la Nación o puede afectar a otras jurisdicciones ${ }^{8}$.

Además no se debe perder de vista que cada provincia se asienta en uno o más sistemas particulares, y que puede un mismo ecosistema, ser compartido por más de una provincia. En definitiva resulta evidente que las cuestiones ambientales desconocen toda frontera política? ${ }^{9}$.

\subsubsection{Situación en las provincias y en los municipios}

Cada Provincia organiza su régimen municipal (Artículo 5 de la Constitución Nacional), por lo tanto dependerá de cada Constitución Provincial y Leyes reglamentarias la naturaleza de cada comuna y las potestades que detenten. En la Provincia de Buenos Aires en particular, los municipios revisten el carácter de autárquicos, en tanto es la Legislatura Provincial la que determina las atribuciones y responsabilidades de cada municipio (Artículo 190,

${ }^{8}$ Por ejemplo el establecimiento de gasoductos atravesando áreas protegidas por una Provincia, donde las consecuencias ambientales preocupan a los locales (el poder de policía sobre el área protegida pertenece a la Provincia) y a su vez el interés general de la Nación en el transporte de gas (comercio interjurisdiccional, además de la cláusula de prosperidad: competencia de la Nación).

${ }^{9}$ Por ello se ha dicho que lo principal a lo que tienden los presupuestos mínimos de protección es:

a. Asegurar que los principios rectores del ordenamiento jurídico ambiental rijan en toda la Nación.

b. Impedir que las provincias o municipalidades atraigan inversiones disminuyendo las exigencias de tutela ambiental.

c. Permitir que las particularidades locales o regionales sean tratadas conforme a criterios adecuados por los órganos municipales, provinciales o interprovinciales (Hutchinson, T. 1999). 
Constitución Provincial). Es decir que la Provincia mantiene todas las competencias que no ha delegado al municipio, aunque no se puede ignorar que la tendencia actual se orienta en el sentido de reconocer en cabeza del municipio ciertas potestades de orden local que le son inherentes. Ello ha sido organizado principalmente por la Ley 6769 y sus modificatorias (Ley Orgánica de Municipalidades de la Provincia de Buenos Aires), entre otras normas, la cual confiere a los municipios competencia en temas como sanidad, conservación y seguridad locales (Artículo 25).

En efecto, corresponde a los municipios:

- el trazado, construcción y conservación de las calles, plazas y paseos públicos (Artículo 27 inciso 2);

- la conservación de monumentos, paisajes y valores locales de interés tradicional, turístico e histórico (Artículo 27 inciso 3);

- las condiciones de higiene y salubridad que deben reunir los sitios públicos (Artículo 27 inciso 8);

- la sanidad vegetal en las situaciones no comprendidas en la competencia Nacional o Provincial (Artículo 27 inciso 12);

- la prevención y eliminación de contaminación ambiental y de los cursos de agua y aseguramiento de los recursos naturales (Artículo 27 inciso 17, esto obviamente en tanto no fuere de competencia Provincial);

- la determinación de zonas industriales y residenciales del partido, imponiendo restricciones y límites al dominio para la mejor urbanización (Artículo 27 inciso 7).

Respecto a este último ítem, cabe destacar que la zonificación corresponde a los municipios, pero las pautas para ello están determinadas en el Decreto-Ley 8.912/77 de Ordenamiento Territorial y Uso del Suelo que regula el uso, ocupación subdivisión y equipamiento del suelo para todos los municipios de la Provincia. Esta normativa contempla la distribución del territorio entre áreas rurales, urbanas y complementarias y las distintas actividades que pueden tener lugar en cada una, además de la proporción de 
espacios verdes o libres públicos que debe contener cada núcleo urbano en función de la población existente y potencial.

Respecto del rol de estas normas es necesario destacar que la organización del espacio es una de técnicas ambientales más importantes. Así se ha afirmado en la Conferencia de Estocolmo en 1972 que "La planificación racional constituye un instrumento indispensable para conciliar las diferencias que puedan surgir entre las exigencias del desarrollo y la necesidad de proteger y mejorar el medio".

\subsubsection{Mínimos inderogables e indisponibles de Protección Ambiental (presupuestos mínimos en la materia)}

La modificación introducida por el Artículo 41 de la Constitución Nacional en el reparto de competencias entre la Nación y las Provincias resulta trascendente en la materia. Allí se establece un mínimo inderogable e indisponible de protección ambiental, en tanto se encuentra categorizado como normas de orden público ambiental. Como tal, ninguna norma en nuestro sistema jurídico puede válidamente oponerse, ni los particulares, en sus contrataciones privadas pueden soslayarlas. La Ley General del Ambiente define en su Artículo 6 el concepto de "presupuesto mínimo". La norma reza así: "se entiende por presupuesto mínimo, a toda norma que concede una tutela ambiental uniforme o común para todo el territorio nacional, y tiene por objeto imponer condiciones necesarias para asegurar la protección ambiental. En su contenido debe prever las condiciones necesarias para garantizar la dinámica de los sistemas ecológicos, mantener su capacidad de carga, y en general, asegurar la preservación ambiental y el desarrollo sustentable”.

Por su parte, en su Artículo 4 la ley establece el principio de congruencia, por el cual la legislación Provincial y Municipal referida a lo ambiental deberá ser adecuada a los principios y normas fijadas por esta Ley. En caso de que así no fuera, ésta prevalecerá sobre toda otra norma que se le oponga. Además, la Ley fija el principio interpretativo de protección del ambiente, de modo que en 
caso de conflicto prevalecen los principios y reglas protectoras del ambiente. Resulta importante destacar que la misma norma reconoce que su aplicación corresponde a los tribunales ordinarios según corresponda por territorio, la materia o las personas. Solamente en aquellos casos en que el acto, omisión o situación generada provoque efectivamente degradación o contaminación en recursos ambientales interjurisdiccionales, la competencia será Federal (Artículo 7). Respecto de las normas locales vigentes y preexistentes a las leyes de presupuestos mínimos de protección ambiental, aquellas mantienen su vigencia en la medida que no se opongan y sean más exigentes que éstas.

\subsubsection{El bien jurídico protegido (la protección penal del ambiente)}

Es necesario determinar cuál es el concepto de ambiente que resulta directamente protegido por las normas penales, en particular en nuestro régimen jurídico, pues existen múltiples acepciones del ambiente que pueden tener relevancia jurídica. En general, la doctrina penalista reconoce al ambiente su propia sustantividad como bien jurídico autónomo, diferenciado de otros como la salud, con propia entidad penal. Bajo esa premisa, la mayoría de los autores penalistas ( $\mathrm{y}$ administrativistas) coinciden en una comprensión física del ambiente. En este sentido, "es un concepto fundamentalmente físico, en cuanto entorno natural de los sujetos y propiciador de la vida, aunque puede ser modificado por el hombre dentro de ciertos límites que remiten a su vez a cánones conservacionistas históricamente cambiantes" (Mateo, R. 1991). Mateo deja así de lado conceptos socioeconómicos, políticos o culturales, que requieren de la aplicación de otras medidas sustancialmente diferentes. Otros autores, por su parte, incluyen el ambiente urbano. Sin embargo, en nuestro derecho positivo, no existe una norma penal cuyo objeto sea la protección del ambiente por sí mismo, sino que en forma indirecta se logra su tutela a través de algunas figuras establecidas para la protección de la vida y la salud de las personas, donde el ambiente es protegido como presupuesto o condición para ello. Se puede afirmar por tanto que los bienes jurídicos tutelados por el derecho penal ambiental son la vida y la salud humanas a través de la 
protección de los elementos que hacen posible esa vida como son el aire, el agua y el suelo.

Cabe destacar que el derecho penal tiene una función subsidiaria y fortalecedora de la eficacia normativa de otras ramas del derecho que tienen por objeto proteger el ambiente y su influencia en la salud y en la calidad de vida del hombre. Atendiendo la naturaleza preventiva del derecho ambiental, debe verse que el derecho penal no puede constituirse como un instrumento de política del Estado exclusivo para proteger el medio, pues deben prevalecer aquellas administrativas y civiles que operan previamente a que se produzca un daño ambiental. En el caso, tal vez su mayor aporte constituya el desalentar las conductas contaminantes ante la amenaza de la gravedad de una sanción del tipo penal.

Antes de introducirnos en las principales normas penales vigentes, se diferenciarán y caracterizarán las definiciones de "dolo" y "culpa". Así, se interpreta dolo como la determinación de la voluntad hacia el delito. Implica una resolución delictuosa, la cual, como tal exige que el autor comprenda la criminalidad de su acto y que dirija su acción. A diferencia de la culpa, en el dolo el núcleo esencial reside en la volición delictiva. Se lo puede definir entonces como la intención de cometer el delito o, por lo menos, la indiferencia de cometerlo frente a su representación como probable.

Tres son las formas de la voluntad delictiva:

a. Dolo directo: El autor dirige su acción hacia el delito cuando la ejecución de éste es el objeto directo de su intención. El delito es lo que el autor se ha propuesto, persigue o pretende. El autor quiere matar a otro, apoderarse de lo ajeno, desacreditar a un tercero, etc.

b. Dolo indirecto: La acción también se dirige de manera decidida hacia el delito, cuando éste no representa el deseo, propósito o pretensión del autor, se le presenta como algo que, aunque no deseado, está necesariamente ligado a lo querido directamente por el mismo. 
c. Dolo eventual: El autor no tiene la intención directa o indirecta de delinquir sino que se limita a tomar a su cargo lo que, por presentársele como probable, puede, frente a su conciencia, eventualmente ocurrir.

La imputación delictiva a título de culpa apunta a la precaución del autor del delito. Constituye un vicio de la voluntad y no del intelecto. Se funda en la previsibilidad del daño, es una omisión de cuidado en el obrar o en el omitir. La omisión tampoco es un no hacer en el vacío, sino la infracción de un deber. El deber de cuidado se fundamenta en la previsibilidad de que de la propia conducta pueda derivar un daño para los terceros. Incurre en culpa aquel que no prevé lo que debió prever.

Existen cuatro formas de conducta culposa:

a. Negligencia: es la omisión del autor al obrar u omitir, de los cuidados debidos que o le permitieron tener conciencia de la peligrosidad de su conducta para la persona, bienes o intereses de terceros. El autor no ha previsto, debiendo hacerlo, el verdadero carácter de su comportamiento. "El autor no se dio cuenta por no revisar el arma, del peligro que implicaba apuntar con ella, el olvido de que dejó enchufada la plancha eléctrica no le permitió al autor advertir el peligro de incendio que había creado". La ligereza del negligente, a diferencia del imprudente, no es en sí misma peligrosa, sin que su peligrosidad es siempre relativa a otro acto del autor, conducta de tercero o hecho externo.

b. Imprudencia: La omisión de los cuidados por el autor se manifiesta en una conducta cuya peligrosidad para las personas, bienes o intereses ajenos reside en sí misma. La ligereza del autor no es como en la negligencia, inofensiva en sí, sino que es la causa activa del peligro: "conducir a velocidad excesiva en estado de ligera alcoholización o hacerlo en condiciones de mala visibilidad, construir una loza de cemento con menos espesor que el necesario y sobre vigas deficientemente asentadas, etc." 
c. Impericia: Se trata de una forma de culpa susceptible de producirse sólo en el oficio propio, arte (cocinero, mecánico, guía de montaña, conductor, etc.) o profesión (presuponen una carrera y una autorización estatal). Es una culpa profesional. Constituye una falta de saber teórico o práctico de la materia del propio oficio. Es falta de sabiduría o experiencia reprochable. No se puede exigir un saber excepcional, sino el normal en el tiempo y lugar ocurridos. No ocurre cuando la actuación se mueve dentro de lo opinable y disputable. Por ejemplo, un médico que realiza un error en el diagnóstico que caiga fuera del marco de lo opinable y discutible, debe ser grosero e inadmisible por obedecer a una falta de saber mínimo.

d. Inobservancia de los reglamentos: Es una forma de culpa que se caracteriza porque la precaución o la prudencia exigible está predeterminada por normas reglamentarias $\mathrm{u}$ ordenatorias de ciertas actividades. Ocurrida la inobservancia, la Ley presume la culpa.

\subsection{Lo que establece el Código Penal}

El Código Penal no reprime genéricamente el daño al ambiente, pero específicamente incrimina diferentes acciones relacionadas con algunos elementos de aquel. En el Título VII "Delitos contra la seguridad pública", capítulo IV "Delitos contra la salud pública" se encuentran los tipos penales que más estrechamente se relacionan con la tutela de algunos de los elementos que integran el ambiente y a través de los cuales se puede poner en peligro la salud humana. Estas normas tienen como objetivo proteger la salud de las personas, pero en forma indirecta también a algunos elementos integrantes del ambiente.

Los tipos penales de mayor trascendencia son los siguientes:

a) El artículo 200 del Código Penal, que reprime "al que envenenare 0 adulterare, de un modo peligroso para la salud, aguas potables o 
sustancias alimenticias o medicinales destinadas al uso público o al consuma de una colectividad de personas".

Respecto de esta figura penal, la jurisprudencia ha dicho que se trata de un delito de peligro, que no exige que el daño a la salud de las personas se haya materializado.

El elemento subjetivo requerido para configurar el delito es el doloso, el que puede ser directo o eventual.

La jurisprudencia dice que se requiere que el agente haya obrado con la intención de adulterar o envenenar el objeto protegido por la norma, sabiendo o debiendo saber que esto era peligroso para la salud. Pero no es necesario que el responsable haya tenido la intención de causar la enfermedad o la muerte. El solo hecho de envenenar o adulterar está penado, y si además se produjese la muerte de alguien la pena se agrava considerablemente.

Esta norma ha sido útil y ampliamente utilizada en causas ambientales.

b) El Artículo 202 del Código Penal reprime "al que propagare una enfermedad peligrosa y contagiosa para las personas".

Esta figura tiene gran significancia desde el punto de vista de la represión penal ambiental ya que la contaminación de las aguas o del aire o del suelo puede ser un medio idóneo para propagar una enfermedad peligrosa y contagiosa para las personas.

Parte de la doctrina critica a este artículo, aduciendo que sufriría de deficiencias en su técnica legislativa. Ello en tanto supuestamente se ha construido como figura de peligro, pero sobre la base de un daño. Es decir que a este delito puede considerárselo consumado cuando se haya enfermado alguien. Según los argumentos de esta doctrina, este tipo penal será aplicable cuando por cualquier medio, incluso los previstos en el artículo 200, lo que se propague sea una enfermedad peligrosa y 
contagiosa y se haya producido la enfermedad de alguna persona (Libster, M. 1993). Sin embargo, la jurisprudencia tiene pronunciamientos en diferente sentido.

Así en la causa "Constantini y otros s/Averiguación de contaminación Río Reconquista" de la Cámara Federal de San Martín (Sala $1^{\circ}$ ) sentencia del 26/8/92, se sostuvo que "el delito del Artículo 202 del Código Penal es una figura de peligro, bastando con acreditar la acción y su idoneidad o aptitud a la luz del bien jurídico protegido" también dice que "La propagación de una enfermedad implica la reproducción de los agentes del morbo, al margen de la comprobación de que tales agentes hayan enfermado a persona alguna. Una cosa es la enfermedad y otra el enfermo; una la actividad de los agentes patógenos y otra su éxito sobre un organismo concreto" y luego agrega que "El Artículo 202 del Código Penal exige propagar una enfermedad por lo que de acuerdo a las palabras de la Ley, no se requiere un cuerpo enfermo sino la sola existencia de enfermedad y de un acto propagador, además de las condiciones de contagiosa y peligrosa. En ese sentido debe señalarse la efectiva posibilidad de enfermedades sin organismos afectados".

Por otro lado, la interpretación jurisprudencial clásica ha dicho que esta norma no castiga al que contagia una enfermedad por un hecho singular sino a aquel que propaga, disemina, multiplica por medio de la producción de hechos múltiples.

c) El artículo 203 del Código Penal prevé la figura culposa de los hechos previstos en los artículos anteriores, "cuando fueren cometidos por imprudencia, negligencia en el propio arte 0 profesión o por inobservancia de los reglamentos u ordenanzas".

\subsection{Normativa sobre Residuos Peligrosos. La Ley $\mathbf{2 4 . 0 5 1}$}

Esta Ley ha sido considerada por la jurisprudencia "compleja, de naturaleza mixta pues contiene disposiciones federales, disposiciones de 
derecho común e incluso algunas que se emplean en uno y otro carácter. También contiene disposiciones de carácter administrativo a aplicase únicamente en el territorio sometido a jurisdicción Federal" (Cámara Federal de San Martín, sentencia16/10/92 "Wentzel Jochen E. y otro" JA 1993-III-10). Ha sido derogada en gran parte por la Ley 25.612 de Presupuestos Mínimos para la Gestión de Residuos Industriales y Actividades de Servicio. Sin embargo, esta última Ley, por su parte, fue vetada en el capítulo que establecía un régimen de responsabilidad penal. De este modo subsisten las normas de la Ley 24.051 que establecen un régimen penal para aquellos que contaminen con los Residuos Peligrosos.

Las disposiciones penales de la Ley 24.051 se encuentran en el Capítulo IX (Artículos 55 a 58), siendo muy utilizadas en materia ambiental.

a) Figura dolosa:

El Artículo 55 prevé la figura dolosa de un tipo delictivo penal ambiental por "utilización" de residuos peligrosos.

Dice la norma "será reprimido con las mismas penas establecidas en el artículo 200 del Código Penal, el que utilizando los residuos a que refiere la presente Ley, adulterare o contaminare de un modo peligroso para la salud, el agua, la atmósfera o el ambiente en general. $\mathrm{Si}$ el hecho fuere seguido de la muerte de alguna persona, la pena será de diez (10) a veinticinco (25) años de reclusión o prisión".

Se ha dicho que la innovación de mayor trascendencia del Artículo 55 de la Ley de Residuos Peligrosos no es la "utilización de residuos peligrosos" (lo que podía quedar comprendido en el Artículo 200 del Código Penal), sino más bien que la nueva figura penal amplía los objetos sobre los cuales recae la acción de envenenar, contaminar o adulterar mediante la utilización de residuos peligrosos, antes era sólo el agua potable y las sustancias alimenticias y medicinales destinadas a consumo humano, a partir de ahora el objeto protegido 
es el ambiente en general y cualquiera de los elementos que lo integran: el suelo, el aire o el agua ${ }^{10}$.

Las acciones típicas son:

- Envenenar. implica la idea de agregar o mezclar algo que resulta venenoso.

- Adulterar. la transformación de las sustancias.

- Contaminar. es el acto o resultado de introducir a un medio dado cualquier elemento o factor que altere negativamente las propiedades básicas del mismo, superando provisoria 0 definitivamente, parcial 0 completamente, la capacidad defensiva y regenerativa del sistema para digerir o reciclar elementos extraños, por no estar neutralizados por mecanismos compensatorios naturales o ratifícales.

El bien jurídico tutelado es la salud pública. Para la existencia de un delito contra la salud pública es indispensable la existencia de un peligro común para la salud. Por ello el delito no se configura con el sólo hecho de envenenar, contaminar o adulterar, es necesario que de dichas acciones resulte un peligro común para la salud. Si no existe peligro para la salud no existe delito, aun cuando exista una verdadera adulteración de sus componentes ${ }^{11}$.

10 "La acción típica se trata de envenenar, contaminar o adulterar de un modo peligroso para la salud, el suelo, el agua la atmósfera o el ambiente en general, es decir se trata de un delito de peligro que amplía notablemente la punibilidad del art. 200 del Código Penal" (Cámara Federal de San Martín sala $1^{\circ}$ 16-10-92 "Wentzel, Jochen E y otro" JA 1993-III-10).

11 "No cualquier peligro determinará la penalización de la conducta, sino que debe tratarse de un peligro grave y de tal magnitud que razonablemente autorice la adecuación al tipo penal, que en definitiva debe ser evaluado por el juzgador sobre la base de los datos indubitables que le proporcionen las ciencias auxiliares en relación al caso concreto" Cámara Federal de San Martín sentencia 17-9-93 "Alba SA" JA 1993-II-470).- 
Las personas jurídicas (sociedades, fundaciones, etc.) también pueden ser penalmente responsables. Esto está previsto en el artículo 57 que dice: "Cuando alguno de los hechos previstos en los dos artículos anteriores se hubiesen producido por decisión de una persona jurídica, la pena se aplicará a los directores, gerentes, síndicos, miembros del consejo de vigilancia, administradores, mandatarios o representantes de la misma que hubiesen intervenido en el hecho punible, sin perjuicio de las demás responsabilidades penales que pudiesen existir".

Sin embargo con relación a la jurisdicción, también ha sido derogada esta Ley por la 25.612 que determina en su Artículo 55 que "será competente para conocer de las acciones que derivan de la presente Ley la Justicia ordinaria que corresponda", por lo tanto, en principio corresponde entender en este tipo de delitos los tribunales penales de la Provincia donde se suscitó el hecho delictivo.

b) Figura culposa:

El artículo 56 prevé la figura culposa: "Cuando alguno de los hechos previstos en el artículo anterior fuere cometido por imprudencia o por impericia en el propio arte o profesión o por inobservancia de los reglamentos u ordenanzas, se impondrá prisión de un (1) mes a dos (2) años. Si resultare enfermedad o muerte de alguna persona, la pena será de seis (6) meses a tres (3) años.

Esta figura en la práctica resulta de mayor aplicación, por las dificultades que puede plantear la prueba del dolo.

c) Elemento instrumental:

En cuanto al elemento instrumental la Ley reprime las conductas que describen los Artículos 55 y 56 a partir de la utilización de los residuos a que se refiere la Ley 24.051 en su Artículo 2.

El residuo es peligroso cuando pueda causar daño, directa o indirectamente a seres vivos, o cuando pueda contaminar el suelo, el agua, la atmósfera o el ambiente en general. 
En particular considera peligrosos los residuos indicados en el Anexo I, o que posean algunas de las características enumeradas en el Anexo II de esta Ley. Incluye a los residuos peligrosos que puedan usarse como insumos para otros procesos industriales y excluye a los domiciliarios, radioactivos y provenientes de las operaciones normales de los buques.

Es decir que la Ley 24.051 define los residuos peligrosos de dos maneras:

- en el artículo 2 brinda un concepto general de residuo peligroso, muy amplio ya que comprende a todo residuo que potencialmente sea causante de daños a los seres vivos y al ambiente en general;

- luego en dos anexos formula una enumeración particularizada en las que describe los tipos de residuos y características peligrosas. Estos listados son meramente enunciativos y pueden ser modificados por la autoridad de aplicación de acuerdo con los avances científicos y tecnológicos.

Para la aplicación de la figura penal se ha discutido si un residuo que no figure en los Anexos, puede igualmente ser considerado peligroso, ya que puede quedar comprendido en la designación genérica del primer párrafo del Artículo 2 de dicha Ley.

Algunos autores justifican esa solución en razón de que los residuos peligrosos en general son de naturaleza química y día a día aparecen nuevos productos químicos que pueden amenazar la salud humana o el ambiente natural. Pero esto ha dado lugar que se objete la constitucionalidad de los delitos creados por la Ley de residuos peligrosos porque la configuración del tipo penal podría depender de una pericia que determine la peligrosidad o falta de ésta de un residuo utilizado en la comisión de un presunto hecho ilícito (Albano, O. 1994). Al respecto se puede señalar que la pericia verifica la existencia del 
hecho tipificado y lo que se cuestiona, es que esta complete el tipo penal. Según esta posición, los Artículos 55 y 56 de la Ley de residuos peligrosos sólo serían aplicables en los supuestos previstos en los Anexos I y II, por contrariar los principios del artículo 18 de la Constitución Nacional. Cabe señalar que la descripción de la acción reprimida penalmente que realiza el Artículo 55 de la Ley 24.051 no presupone falta administrativa. Se trata de una sanción penal desconectada del derecho administrativo, se trata de un delito de peligro en el que, en principio no puede tomarse en cuenta ninguna autorización permiso, estándar o parámetro administrativo, en la medida en que la situación de peligro prevista en este tipo penal exista y esté debidamente comprobada ${ }^{12}$.

d) Personas jurídicas:

El artículo 57 dispone que si los hechos previstos en los artículos anteriores se hubiesen producido por decisión de una persona jurídica, la pena se aplica a aquellas personas que ejerciendo cargos de relevancia hubiesen intervenido en el hecho punible.

De hecho se desprende que es necesaria una intervención personal del directivo en la conducta incriminada por la Ley.

Se refiere a los delitos de comisión por omisión en los cuales el agente tiene la obligación de actuar en determinado sentido (la llamada posición de garante) y mediante una omisión permite que el resultado material se produzca.

Se ha sostenido que las limitaciones que derivan del principio de legalidad permiten fundar la responsabilidad del director de una

12 "no cabe admitir la legalidad de vertidos contemplados en la norma administrativa, si al mismo tiempo constituyen conductas punibles para la ley represiva..."puesto que la autorización administrativa “...no implica una autorización o disculpa para quien por dicha vía cometa un delito previsto en la ley penal" (Cámara Federal de San Martín (Sala $1^{\circ}$ ) sentencia del 26/8/92 “Constantini y otros s/Averiguación de contaminación Río Reconquista"). 
persona jurídica sólo en aquellos casos en que existe una relación de dominio efectivo sobre la causa del resultado.

La jurisprudencia, principalmente en la sentencia del 26/8/92 "Constantini y otros s/Averiguación de contaminación Río Reconquista" de la Cámara Federal de San Martín (Sala $1^{\circ}$ ), se ha pronunciado en el sentido que "si en una empresa el dominio material sobre las cosas se da escalonadamente, cada cotitular de la custodia será responsable según la parte de dominio que mantenga sobre ella (gerente de área, jefe de planta, encargado de mantenimiento, etc.) lo cual supone un ámbito espacial de influencias acotado para el garante, en el que se encuentra el objeto peligroso".

También se debe tener en cuenta que los superiores jerárquicos tienen siempre el deber de control sobre sus subordinados, por lo tanto no pueden delegar completamente su responsabilidad. Así se ha advertido que "sólo a condición de que el titular o directivo de una empresa tome los recaudos de seguridad necesarios para evitar riesgos respecto de los bienes o las personas, es que la sociedad autoriza el establecimiento y la operación de instalaciones altamente complicadas y peligrosas. De aquí se deriva para los directivos de las personas jurídicas y empresas un deber de control sobre las cosas peligrosas y en caso de delegación, un deber de cuidado en la elección de su personal según su capacidad y un deber de supervisión general. Él no puede liberarse de esta posición de garante mediante la designación de garantes auxiliares“.

\subsubsection{Ampliación de las facultades del juez penal por aplicación de la Ley 25.575}

Actualmente podría decirse, en función de algunos precedentes jurisprudenciales, que se estaría reconociendo al juez penal (cuando se encuentra investigando presuntos delitos vinculados al ambiente), facultades excepcionales establecidas en la Ley General del Ambiente. 
En particular, se ha hecho referencia a las potestades previstas en el Artículo 32 de esa norma que prevé que en cualquier estado del proceso, aún con carácter de medida precautoria, el juez podrá disponer medidas de urgencia, como ser clausura de un establecimiento.

Así se ha dicho "el Derecho Ambiental requiere de una participación activa del juez, que debe traducirse en un obrar preventivo acorde con la naturaleza de los derechos afectados y a la medida de sus requerimientos. Será así función del órgano judicial, en el marco de los autos que se presentan a su conocimiento, desplegar aquellos medios que resulten necesarios para evitar el daño temido, o bien para neutralizar o disminuir en lo posible las consecuencias lesivas que puedan producirse con su advenimiento" (Cámara Federal de Apelaciones de La Plata -Sala 2- "Asociación Coordinadora de Usuarios, Consumidores y Contribuyentes c. Enre Edesur s/cese de obra de cableado y traslado de subestación transformadora" 08/07/03; Cámara Federal San Martín -Sala $1^{\circ}$ - "Averiguación presunta infracción a la Ley 24.051, Felici Octavio, Felici Nicolás" sentencia 14-06-2005).

\subsubsection{Jurisdicciones respecto de la materia penal ambiental}

En relación a la competencia de la justicia penal interviniente en materia ambiental coexisten en la actual tres criterios jurisprudenciales diferentes. Esta situación se ha generado a partir del veto del Artículo 60 y de las disposiciones penales de la Ley General del Ambiente, quedando la materia penal regulada en la actualidad por la antigua Ley 24.051.

a) La Corte Suprema de Justicia de la Nación, en el caso "Lubricentro Belgrano" (L.L. 29-5-2000), interpretó que resultaba competente la justicia local, en el caso, la Provincia de Buenos Aires, sino se acreditaba en la causa que los residuos encontrados pudieron haber afectado a las personas o al ambiente fuera de los límites de la Provincia en que fueron hallados. De este modo, para la intervención de la justicia federal se exigió la interjurisdiccionalidad del daño provocado por el delito. 
b) Este criterio fue confirmado en la causa "Echeverría Crenna, Mario s/denuncia" sentencia del 4-07-2006, donde la Corte Nacional entendió que era competente la justicia federal en la causa en razón de la interjurisdiccionalidad del daño provocado por el delito investigado (en el caso se trataba de un arroyo El Durazno, afluente principal del Reconquista, curso de agua que desemboca en el Río Luján y éste a su vez en el Río de La Plata).

c) La Cámara Federal de Apelaciones en lo Criminal y Correccional de la Capital Federal, que en el caso "Transporte Petrolera" declaró la competencia ordinaria para juzgar todos los hechos criminosos previstos por la Ley 24.051.

d) La Cámara Nacional de Casación Penal en el caso "Rodríguez", que declaró la competencia federal para juzgar e investigar los mismos ilícitos, sustentándose en la interpretación literal de la Ley 24.051, que en su Artículo 58 expresamente señala la competencia Federal para el conocimiento de las conductas punibles penalmente previstas en el capítulo IX.

\subsubsection{Referencias sobre el Control Ambiental Industrial}

\subsubsection{Nivel de alcance de las habilitaciones industriales}

La actividad industrial está determinada por numerosas regulaciones con contenidos ambientales que hacen que a la hora de analizar si un establecimiento se encuentra funcionando en regla, nos obliguen a ser sumamente atentos para no soslayar la aplicación de alguna norma. Sin embargo, en primer lugar, hay que referirse a que el cumplimiento de todas las normas regulatorias por parte de un establecimiento industrial no lo exime de la responsabilidad por el daño que eventualmente pudiera producir al ambiente. En efecto, aun cuando una industria obtenga todos los certificados necesarios y cumpla con las exigencias legales establecidas para proteger el ambiente, si de su actividad se genera un daño, ésta no se exime de su obligación de recomponer. Ello así en tanto se trata de una responsabilidad de índole 
objetiva. Al respecto, ya en 1887 la Corte Suprema resolvió en la causa "Los Saladeros Podestá v. Pcia. de Bs. As." que "ninguno puede tener un derecho adquirido en comprometer la salud pública y esparcir en la vecindad la muerte $y$ el duelo por el uso que haga de su propiedad, y especialmente con el ejercicio de una profesión o de una industria", agregando que "la autorización... está siempre fundada en su inocuidad".

Un desarrollo interesante de este tema puede observarse en la sentencia de la Cámara Nacional Civil Sala 1, de junio de 1994 recaída en la causa "Opalinas Hurlingham". Allí dijo el tribunal que "No puede aceptarse que como consecuencia de una actividad o de una omisión de las autoridades a cargo del ejercicio del poder de policía, deba tolerarse la violación del deber de no dañar por parte del contaminante. Toda vez que el poder administrativo, al tiempo de conceder al establecimiento industrial una autorización para funcionar, no ha contado con todos los elementos de juicio necesarios para saber hasta dónde podría llegar el perjuicio a las propiedades vecinas, tal autorización se otorga bajo condición implícita de responder por los daños y perjuicios que puedan causarse a los vecinos"

\subsubsection{Situación del Régimen de Industrias en la Provincia de Buenos Aires}

Según lo explicado anteriormente, las industrias se encuentran sujetas a un complejo régimen normativo. En principio y conforme surge de la distribución de competencias establecida en la Constitución Nacional, la potestad de establecer normas regulatorias sobre la actividad industrial pertenece a las Provincias donde se encuentren establecidas. No obstante, resulta necesario recordar que esta normativa debe respetar los "presupuestos mínimos de protección ambiental" dictados por el Congreso Nacional que les sean aplicables. En particular, en la Provincia de Buenos Aires el establecimiento y funcionamiento de las Industrias en jurisdicción provincial se rige por la Ley 11.459, su Decreto Reglamentario 1.741/96 y normas complementarias. Dicha reglamentación, establece un procedimiento para la obtención del licenciamiento de la actividad y su renovación. Asimismo, esta Ley presupone el cumplimiento de otras específicas, como ser la Ley 19.587 y 
los Decretos 351/79 y 1338/96 que regulan el régimen de seguridad e higiene, el régimen de residuos sólidos domiciliarios (Ley 25.916 de Presupuestos Mínimos), Leyes 13.592 (Régimen de Gestión Integral de Residuos Sólidos Urbanos) y 13.657 (para el conurbano u ordenanzas municipales), Ley de Residuos Especiales 11.720 y decreto 806/97, Efluentes Líquidos Ley 5.965, Decretos 2009/60, 3970/90, Ley 12.257, Emisiones Gaseosas Ley 5.965 у decreto $3.395 / 96$.

\subsection{Normativas complementarias}

\subsubsection{Reportes de sustentabilidad}

En la actualidad existen distintas organizaciones que prestan un servicio basado en la implementación y certificación de índices o reportes de sustentabilidad. En este marco, uno de los más difundidos es la Iniciativa del Reporte Global (Global Reporting Initiative -GRI). Se trata de una organización creada en 1997 por la convocatoria de la Coalición de Economías Responsables del Medio Ambiente (CERES) y el Programa de Medio Ambiente de las Naciones Unidas (PNUMA). EI GRI ha desarrollado la "Guía para la elaboración de un informe de sustentabilidad", cuya primera versión surgió en el 2000, la segunda en el 2002, la tercera en el 2006 y la cuarta en 2013. Actualmente presentó recientemente su nueva versión G4 de la "Guía para la elaboración de los Reportes de Sostenibilidad", ya que se está lanzando una nueva guía integrada, adoptada como estándar único a partir de 2015. Su fuerte son los contenidos ambientales y posee como ventaja una descripción detallada de los posibles indicadores para medir la Responsabilidad Social Empresaria (RSE) en la organización. Los informes elaborados en base al GRI sostienen 4 principios para determinar los asuntos e indicadores sobre los que la organización debería informar. A saber:

a. Materialidad: La información contenida en la memoria deberá cubrir aquellos aspectos e Indicadores que reflejen los impactos significativos, sociales, ambientales y económicos de la 
organización o aquéllos que podrían ejercer una influencia sustancial en las evaluaciones y decisiones de los grupos de interés.

b. Participación de los grupos de interés: La organización debe identificar a sus grupos de interés y describir en la memoria cómo ha dado respuesta a sus expectativas e intereses razonables.

c. Contexto de sostenibilidad: Se consulta sobre la forma en la que contribuye la organización, o pretende contribuir en el futuro, a la mejora $o$ al deterioro de las tendencias, avances y condiciones económicas, ambientales y sociales a nivel local, regional o global. La mera información sobre las tendencias del desempeño individual (o sobre la eficiencia de la organización) no dará respuesta a esta pregunta.

d. Exhaustividad: La cobertura de los Indicadores y la definición de la cobertura de la memoria deben ser suficientes para reflejar los impactos sociales, económicos y ambientales significativos y para permitir que los grupos de interés puedan evaluar el desempeño de la organización informante durante el periodo que cubre la memoria.

Además, propone 6 principios para garantizar la calidad y la presentación adecuada de la información divulgada:

a. Equilibrio: La memoria deberá reflejar los aspectos positivos y negativos del desempeño de la organización para permitir una valoración razonable del desempeño general.

b. Comparabilidad: Se deben seleccionar, recopilar divulgar los aspectos y la información de forma consistente. La información divulgada se debe presentar de modo que permita que los grupos de interés analicen los cambios experimentados por la organización con el paso del tiempo, así como con respecto a otras organizaciones.

c. Precisión: La información debe ser precisa y suficientemente detallada como para que los diferentes grupos de interés de la 
organización puedan valorar el desempeño de la organización informante

d. Periodicidad: La información se presentará a tiempo y siguiendo un calendario periódico de forma que los grupos de interés puedan tomar decisiones con la información adecuada

e. Claridad: La información debe exponerse de una manera comprensible y accesible para los grupos de interés que vayan a hacer uso de la memoria.

f. Fiabilidad: La información y los procedimientos seguidos en la preparación de una memoria deberán ser recopilados, registrados, compilados, analizados y presentados de forma que puedan ser sujetos a examen y que establezcan la calidad y la materialidad de la información.

Y consta de 3 partes:

1. Perfil: Información que define el contexto general de la empresa y permite comprender el desempeño de la organización, entre otros a través de su estrategia, su perfil y sus prácticas de gobierno corporativo. Se incluye la Visión y estrategia de sostenibilidad: Debe estar firmado por el Presidente de la empresa.

2. Enfoque de la dirección: información sobre el estilo de gestión a través del cual una organización aborda aspectos específicos y describe el contexto que permite comprender su comportamiento en un área concreta. Como se maneja la empresa en términos de estructura de decisiones y los sistemas de gestión para controlar tales decisiones. Además se presenta el compromiso con los stakeholders, las políticas sociales y ambientales.

3. Indicadores de desempeño: económico, ambiental y social. Están clasificados en Indicadores principales y optativos. Indicadores que permiten disponer de información comparable respecto al desempeño económico, ambiental y social de la 
organización. En la G3 hay 47 indicadores principales y 32 adicionales.

Para producir un informe exigido por GRI, una empresa debe informar sobre todos los indicadores principales o dar razones de por qué no lo hace.

\subsubsection{Las normas ISO en materia ambiental. Normas superadoras de las exigencias legales}

La International Organization for Standardization (ISO) es una federación mundial que agrupa a representantes de cada uno de los organismos nacionales de estandarización (como lo es el Instituto Argentino de Normalización y Certificación - IRAM - en la Argentina), y que tiene como objeto desarrollar estándares internacionales. Cuando las empresas pueden de forma objetiva evaluar procesos, sistemas, calidad, etc. de un proveedor y/o cliente, el riesgo de entablar negocios con algún tipo de riesgo se reduce significativamente. Si los estándares son los mismos para toda la cadena de comercialización, la misma puede potenciarse en forma significativa. En las áreas de la Gestión Ambiental de las empresas, ISO establece normas internacionales sobre temas tales como la gestión ambiental (ISO 14001/4), el etiquetado ambiental (ISO 14020/21/24/25), la evaluación del ciclo de vida (ISO 14040/44), la medición, verificación y validación de gases de efecto invernadero (ISO 14064/65), y el agua potable y aguas residuales (ISO 24510/11/12). Ha establecido también un amplio esfuerzo de participación de los interesados para desarrollar la nueva norma ISO 26000 sobre responsabilidad social. Este proyecto de alto perfil, (según los informes presentados por ISO) involucró a más de 400 expertos mundiales, procedentes de 91 países y 42 organizaciones internacionales gubernamentales y no gubernamentales, también demuestra cómo el proceso de elaboración de normas ISO puede abordar cuestiones sociales y de sustentabilidad complejas. Otros ejemplos en fase de desarrollo en ISO incluyen la huella de carbono de los productos y servicios; los criterios de sostenibilidad para los biocombustibles; sostenibilidad en la gestión de riesgos, y la huella hídrica de las organizaciones. 
Una buena parte de las Empresas de la Provincia de Buenos Aires son pequeñas y medianas (PyMES). Estas son, en promedio, las empresas que están generando crecimiento más rápido y más innovador junto con la creación de empleo. Además, son menos complejas (estructuralmente) y más eficientes y flexibles que las grandes empresas. La aplicabilidad de las Normas Internacionales, así como los beneficios que puedan llegar a proporcionar, es independiente del tamaño de la empresa. Su uso estratégico depende casi exclusivamente de la decisión de las autoridades de la empresa para la implementación de las mismas.

\section{Metodología y técnicas aplicadas a la investigación}

\subsection{Población y muestra}

La población en estudio está compuesta por empresas que deben cumplir con los siguientes requisitos:

- Estar dentro de la Provincia de Buenos Aires.

- Ser consideradas Industria según la definición del Artículo $2^{13}$ de la Ley 11.459 de Radicación Industrial de la Provincia de Buenos Aires.

- Ser consideradas como $\mathrm{PyME}^{14}$ por la Secretaría de la Pequeña y Mediana Empresa y de Desarrollo Regional, del Ministerio de Industria de la Nación.

13 "A los fines de la presente ley se entenderá por establecimiento industrial a todo aquel donde se desarrolla un proceso tendiente a la conservación, reparación o transformación en su forma, esencia, calidad o cantidad de una materia prima o material para la obtención de un producto final mediante la utilización de métodos industriales".

14 A los efectos de lo dispuesto por el Artículo $1^{\circ}$ del Título I de la Ley $\mathrm{N}^{\circ} 25.300$, serán consideradas Micro, Pequeñas y Medianas empresas aquellas cuyas ventas totales anuales expresadas en Pesos (\$) no superen los valores establecidos en el siguiente detalle: AGROPECUARIO: \$54.000.000; 
- $\quad$ No se encuentren alcanzadas dentro de la Ley 26.168

- Estar a una distancia menor de $350 \mathrm{Km}$ de la Ciudad de La Plata.

En la actualidad, no existen datos reales que reflejen la cantidad de industrias que se encuadren dentro de estas características enunciadas. Por lo tanto, se determinó realizar un muestreo de 50 industrias, procediendo a encuestar a responsables de áreas ambientales. Posteriormente se seleccionaron 6 de las industrias encuestadas, para profundizar el análisis por medio de la realización de entrevistas y visitas a cada una de los establecimientos industriales.

\subsection{Tipo de investigación}

La investigación se llevó acabo de carácter descriptivo, puntualizando precisamente la situación de las empresas objeto de estudio en lo atinente a las exigencias ambientales y la influencia resultante en los procesos de gestión.

\subsection{Técnicas de relevamiento de datos}

Los datos fueron recolectados por medio de:

- Lectura y análisis de:

- Documentos específicos generados por las Industrias en estudio (Estudios de Impacto Ambiental, Declaraciones Juradas presentadas ante OPDS y ADA, estudios técnicos específicos, etc.).

INDUSTRIA Y MINERÍA: \$ 183.000.000; COMERCIO: \$250.000.000; SERVICIOS: \$63.000.000; CONSTRUCCIÓN: \$84.000.000.

15 Crea la Autoridad de Cuenca Matanza Riachuelo como ente de derecho público interjurisdiccional con competencias en el área de la Cuenca Matanza Riachuelo en el ámbito de la Ciudad Autónoma de Buenos Aires y los partidos de Lanús, Avellaneda, Lomas de Zamora, Esteban Echeverría, La Matanza, Ezeiza, Cañuelas, Almirante Brown, Morón, Merlo, Marcos Paz, Presidente Perón, San Vicente y General Las Heras, de la Provincia de Buenos Aires. 
- Marco normativo especifico de las autoridades de aplicación (Organismo Provincial para el Desarrollo Sostenible, Autoridad del Agua, Secretaría de Ambiente y Desarrollo Sustentable de la Nación).

- Normas de certificaciones nacionales e internacionales (Guía para la elaboración de los Reportes de Sostenibilidad del Global Reporting Initiative -GRI-, series 14000, 24000 y 2600 de la International Organization for Standardization -ISO-).

- Observación directa de los procesos y modelos de gestión ambiental que llevan adelante los 6 establecimientos seleccionados.

- Entrevistas y encuestas a los responsables de las industrias. Fueron diseñadas en base a cumplimiento con la gestión ambiental obligatoria, compromiso de las autoridades empresariales, gasto anual asociado, conflictos ambientales, implementación de medidas superadoras y demás variables que permitieron abarcar las posibles respuestas a los objetivos planteados.

- Las entrevistas, fueron no estructuradas o informales y realizadas de manera personal a las máximas autoridades de los establecimientos industriales seleccionados (una industria de Primera Categoría, dos de Segunda y tres de Tercera). Al momento de realizarlas, se contaba con el cuestionario de las encuestas (Anexo I) llevado en una Tablet para poder copiar textualmente las respuestas. Se comenzó en cada caso, con un recorrido de las instalaciones, donde se sacaron fotos y se describieron los procesos en la relación de cada sector con la gestión ambiental. Posteriormente, ya en las oficinas de los entrevistados, se continuó el cuestionario haciendo hincapié en la relación entre las gestiones ambiental y empresarial general y buscando que se explayen lo más posible. De todo esto se tomó nota y quedó registrado.

- Las encuestas (un total de 50, ver diseño en el Anexo I) estuvieron orientadas a los responsables del área ambiental de distintos establecimientos industriales. Fueron diseñadas a 
efectos de poder caracterizar los establecimientos, las acciones de la gestión ambiental y el comportamiento empresarial en relación a la misma. Se utilizó la herramienta de Formularios de Google, que permitía poder realizar los envíos por correo electrónico, compartirlo por redes sociales y completarse de manera online. Esta herramienta recolectaba los datos en un formulario específico, lo que permitía realizar un relevamiento instantáneo. Los encuestados, fueron profesionales extraídos de bases de datos personales y obtenidos de colegas, así como contactos de la red social Linkedln.

\subsection{Técnicas de análisis}

Primeramente, se realizó un registro y clasificación de la normativa de aplicación para la gestión ambiental de las industrias en estudio. Esto permitió armar un listado de requisitos de las autoridades de aplicación, análisis de estudios complementarios y a partir de los mismos, el diseño de las entrevistas y encuestas.

Las encuestas, fueron analizadas por medio de técnicas estadísticas que permitieron obtener datos adicionales a las simples cantidades de respuestas obtenidas. Las mismas se basaron en variables univariadas y fueron utilizados el promedio, el desvío estándar y la varianza. Respecto de las entrevistas, se realizó un análisis lógico de las respuestas que se pudieron recolectar. 


\section{Resultados de la investigación}

\subsection{Relevamiento de datos de fuentes secundarias}

De la lectura y el análisis de documentación existente, tanto de la normativa de referencia como de las industrias, podemos describir que la Gestión Ambiental debe cumplir con requisitos obligatorios que regulan principalmente, tanto el Organismo Provincial para el Desarrollo Sostenible (OPDS) como la Autoridad del Agua (ADA), y con otra serie de trámites no obligatorios que daremos por llamar "trámites complementarios a la gestión ambiental".

\subsubsection{Organismo Provincial para el Desarrollo Sostenible}

\subsubsection{Factibilidad de Radicación de Industrias}

- Marco Normativo: Se rige por los Artículos 62 al 64 del Decreto $\mathbf{N}^{\circ}$ 1741/96, reglamentario de la Ley 11459.

- Descripción: Es una consulta que podrá realizar cualquier interesado que desee radicar una industria en el territorio de la Provincia de Buenos Aires. Tiene por objeto determinar la factibilidad de radicación de un nuevo proyecto industrial, considerando de manera conjunta la aptitud de la zona donde pretende instalarse y el nivel de complejidad ambiental del emprendimiento. Es opcional, es decir que sólo se realiza a solicitud del interesado y como consulta previa a la categorización industrial. El dictamen tiene una validez de 180 días contados desde la fecha en la que el interesado se notifica del acto administrativo emitido por el OPDS. El mismo se instrumenta a través de una Disposición emitida por el Director Provincial de Evaluación de Impacto Ambiental. 


\subsubsection{Categorización Industrial}

- Marco Normativo: Se rige por los Artículos $8^{\circ}$ al $12^{\circ}$ del Decreto $\mathbf{N}^{\circ}$ 1741/96 (modificado por el Decreto 353/11), reglamentario de la Ley $N^{\circ} 11459$.

- Descripción: Es el inicio del trámite en el marco de la Ley $\mathbf{N}^{\circ} 11459$ de Radicación Industrial en el territorio de la provincia de Buenos Aires. Consiste en clasificar las industrias en una de las tres categorías establecidas por ley sobre la base del cálculo del Nivel de Complejidad Ambiental (NCA), que queda definido por:

- La clasificación de la actividad por rubro $(R u)$, que incluye la índole de las materias primas, de los materiales que manipulen, elaboren o almacenen, y el proceso que desarrollen.

- La calidad de los efluentes y residuos que genere (ER).

- Los riesgos potenciales de la actividad, a saber: incendio, explosión, químico, acústico y por aparatos a presión que puedan afectar a la población o al medio ambiente circundante (Ri).

- La dimensión del emprendimiento, considerando la dotación de personal, la potencia instalada y la superficie (Di).

- La localización de la empresa, teniendo en cuenta la zonificación municipal y la infraestructura de servicios que posee (Lo).

El Nivel de Complejidad Ambiental se expresa por medio de una ecuación polinómica de cinco términos:

$$
N C A=R u+E R+R i+D i+L o
$$

De acuerdo a los valores del NCA las industrias se clasificarán en:

- PRIMERA CATEGORÍA: hasta 15 puntos

- SEGUNDA CATEGORÍA: más de 15 y hasta 25 puntos

- TERCERA CATEGORÍA: mayor de 25 puntos

En función de la categoría obtenida (primera, segunda o tercera) y la zona de emplazamiento se determina la viabilidad de instalación de un proyecto industrial. Es obligatorio para la totalidad de los establecimientos industriales instalados y a instalarse, siendo realizado a 
solicitud del interesado. El dictamen se instrumenta a través de una Disposición emitida por el Director Provincial de Evaluación de Impacto Ambiental.

\subsubsection{Solicitud de Recategorización Industrial}

- Marco Normativo: Se rige por el Artículo 57 del Decreto $\mathbf{N}^{\circ}$ 1741/96, reglamentario de la Ley $\mathrm{N}^{\circ} 11.459$.

- Descripción: Es una solicitud que se deberá gestionar con el fin de obtener un nuevo Certificado de Aptitud Ambiental, en forma previa a la realización de ampliaciones, modificaciones o cambios en sus procesos, edificios, ambientes 0 instalaciones, que encuadren en alguno de los siguientes supuestos:

- Incremento en más de un $20 \%$ de potencia instalada.

- Incremento en más de un $20 \%$ de la superficie productiva.

- Cambios en las condiciones de ambiente de trabajo.

- Incremento significativo de los niveles de emisión de efluentes gaseosos, generación de residuos sólidos y/o semisólidos, o variación significativa de la tipificación de los mismos.

- Cambio y/o ampliación del rubro general.

Es obligatorio para la totalidad de los establecimientos industriales instalados que deseen realizar modificaciones y/o ampliaciones, siempre y cuando cuenten con el Certificado de Aptitud Ambiental.

\subsubsection{Obtención del Certificado de Aptitud Ambiental (Industrias)}

- Marco Normativo: Ley

$\mathbf{N}^{\circ}$

11.459 y Decreto Reglamentario $\mathrm{N}^{\circ}$ 1741/96.

- Descripción: Para este trámite, no debe generarse un nuevo expediente sólo para la Evaluación de Impacto Ambiental, dado que el trámite de obtención de Certificado de Aptitud Ambiental es consecuente al de la Categorización. Es indispensable contar con 
la categorización previa otorgada por el OPDS. El expediente que ha sido clasificado de $2^{\circ}$ categoría y haya sido girado al Municipio / Autoridad Portuaria, deberá permanecer en esa órbita hasta que el interesado en obtener el Certificado de Aptitud Ambiental presente la documentación requerida. Una vez incorporada en el expediente la documentación requerida, la Municipalidad / Autoridad Portuaria deberá remitirlo al OPDS (siempre y cuando no medie "Convenio de Delegación de Facultades para establecimientos de $2^{\circ}$ Categoría") con los correspondientes sellos de foliatura y de juntura. Para establecimientos de $3^{\circ}$ Categoría, la presentación debe efectuarse ante el OPDS.

- REQUISITOS:

- Nota de solicitud del Certificado de Aptitud Ambiental, acreditando nombre del titular, razón social y domicilio del establecimiento industrial.

- Evaluación de Impacto Ambiental (EIA) del proyecto o establecimiento, en relación a la Categorización obtenida.

- El EIA deberá estar confeccionado y firmado por profesionales con incumbencia en las áreas específicas e inscripción actualizada en el Registro de Profesionales de OPDS (Ley $\mathbf{N}^{\circ}$ 11.459, Decreto Reglamentario $\mathbf{N}^{\circ}$ 1741/96. Título IV Cap. IX Art. 71 y 72 y Resoluciones No 195/96 y 592/98).

- Formulario $A$ : por triplicado, firmados en todas sus hojas por el titular, responsable o apoderado.

- Formulario C: por triplicado, firmados en todas sus hojas por el titular, responsable o apoderado y por el Profesional responsable interviniente.

- Constancia de pago de las tasas y sellados correspondientes.

- Titularidad (si no se hubiere presentado en una instancia anterior): La documentación que acredite la 
titularidad del emprendimiento, dependerá de los casos que a continuación se detallan:

- Persona Física: Fotocopia de la primera y segunda hoja del DNI en copia fiel del original suscripto por personal autorizado del municipio.

- Sociedad de Hecho: Fotocopia de la primera y segunda hoja del DNI de cada uno de los integrantes en copia fiel del original suscripto por personal autorizado del municipio.

- Persona Jurídica: Estatuto Social debidamente certificado (si el escribano es de otra jurisdicción distinta de la Provincia de Buenos Aires, deberá tener su firma legalizada por el Colegio de Escribanos Provincial).

- Se deberá adjuntar Copia del Acta de Directorio o Acta Poder (certificado ante escribano público), de la persona que firme la documentación en representación del titular del emprendimiento.

\subsubsection{Solicitud de Cambio de Titularidad}

- Marco Normativo: Se rige por el Artículo $\mathrm{N}^{\circ} 12$ de la Ley $\mathbf{N}^{\circ}$ 11459 y los Artículos 55 y 56 del Decreto Reglamentario $N^{\circ}$ $1741 / 96$.

- Descripción: Corresponde que los cambios de titularidad de un establecimiento industrial sean notificados a la Autoridad de Aplicación, dentro de los 90 (noventa) días siguientes a la suscripción del instrumento. Es de carácter obligatorio para las empresas que realicen cambios en la denominación social (titularidad), constituyendo nuevas sociedades, ventas, fusiones, cesiones, etc.

- Documentación Requerida: 
- Las empresas deben realizar la solicitud de usuario de empresas desde el sitio web del organismo.

- Deberán completar los formularios que se encuentran en la página web de este Organismo Provincial.

- Nota de Solicitud: Se deberá presentar una nota dirigida al OPDS solicitando el trámite correspondiente. La misma deberá estar firmada por el titular o responsable.

- Formulario A: por triplicado, firmados en todas sus hojas por el titular, responsable o apoderado.

- Constancia de pago de las tasas y sellados correspondientes.

- Titularidad: La documentación que acredite la nueva titularidad del emprendimiento, dependerá de los casos que a continuación se detallan:

- Persona Física: Fotocopia de la primera y segunda hoja del DNI en copia fiel del original suscripto por personal autorizado del municipio

- Sociedad de Hecho: Fotocopia de la primera y segunda hoja del DNI de cada uno de los integrantes en copia fiel del original suscripto por personal autorizado del municipio

- Persona Jurídica: deberá presentar la documentación que a continuación se detalla (ambos documentos deben estar certificados por Notario. Si el Escribano es de una jurisdicción distinta de la provincia de Buenos Aires, deberá tener su firma legalizada por el Colegio de Escribanos de la jurisdicción que se trate):

- Nueva Conformación Societaria: es la escritura de constitución de la sociedad del nuevo titular

- Designación de Autoridades y Representación Legal: deberá presentar el acta de asamblea 
actualizada donde se indiquen las autoridades y representantes legales designados

- Se deberá adjuntar Copia del Acta de Directorio o Acta Poder (certificado ante escribano público), de la persona que firme la documentación en representación del titular del emprendimiento.

- Acto Jurídico: es el documento que expresa el Cambio de Titularidad. Puede tratarse de una Venta de fondo de comercio, Cesión de derechos, Compra, Venta, Fusión, etc.

- Constancia de CUIT (Clave Única de Identificación Tributaria) de la firma continuadora.

\subsubsection{Obtención Primigenia del Permiso de Descarga de Efluentes Gaseosos a la Atmósfera - Establecimientos Industriales}

- Marco Normativo: Decreto No 3395/96 Resolución N N04/01 Decreto-Ley Nº 7647/70 Resolución 242/97

- Descripción: Es un trámite que debe iniciar toda Industria (existente o a instalarse) que genere emisiones gaseosas a la atmósfera ya sea de manera puntual o difusa.

- Documentación Requerida:

- Los profesionales con incumbencia en las áreas específicas e inscripción actualizada en el Registro de Profesionales de OPDS (Ley No 11.459, Decreto Reglamentario N$^{\circ}$ 1741/96. Título IV Cap. IX Art. 71 y 72 y Resoluciones $N^{\circ} \mathbf{1 9 5 / 9 6}$ y 592/98) deberán presentarse en el Departamento de Evaluación de Impacto Ambiental, dependiente de este Organismo Provincial, a efectos de obtener un nombre de usuario y una contraseña. Posteriormente, deberán completar los formularios que se encuentran en la página web de este Organismo Provincial según el trámite a realizar.

- Nota de presentación indicando razón social, domicilio, CUIT y trámite a realizar. 
- Formulario A: por triplicado, firmados en todas sus hojas por el titular, responsable o apoderado.

- Formulario D: por triplicado, firmados en todas sus hojas por el titular, responsable o apoderado y por el Profesional responsable interviniente.

- Plano con ubicación de fuentes de emisión.

- Protocolos de laboratorio autorizado por el OPDS (Resolución N 504/01).

- Timbrado provincial de $\$ 22,00$.

- Constancia de pago de las tasas y sellados correspondientes.

- Fotocopias de contratación de tareas profesionales.

- Libro de actas de 200 folios (art. $15^{\circ}$ Decreto $N^{\circ}$ 3395/96).

- Breve memoria descriptiva de las actividades productivas.

- Propuesta de plan de monitoreo de fuentes y calidad de aire.

- Predicción del impacto sobre calidad de aire según etapas

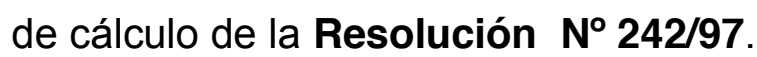

- Plan de adecuaciones en caso de corresponder.

- Informe de cumplimiento del art. $14^{\circ}$ del Decreto $\mathbf{N}^{\circ}$ $3395 / 96$.

- Evaluación de alcances y detalle de procedimientos y registros de capacitaciones y simulacros ante eventos con implicancia sobre la calidad de aire.

- Titularidad: La documentación que acredite la titularidad del emprendimiento, dependerá de los casos que a continuación se detallan:

- Persona Física: Fotocopia de la primera y segunda hoja del DNI en copia fiel del original suscripto por personal autorizado del municipio.

- Sociedad de Hecho: Fotocopia de la primera y segunda hoja del DNI de cada uno de los 
integrantes en copia fiel del original suscripto por personal autorizado del municipio.

- Persona Jurídica: Estatuto Social debidamente certificado (si el escribano es de otra jurisdicción distinta de la Provincia de Buenos Aires, deberá tener su firma legalizada por el Colegio de Escribanos Provincial).

- Se deberá adjuntar Copia del Acta de Directorio o Acta Poder (certificado ante escribano público), de la persona que firme la documentación en representación del titular del emprendimiento.

\subsubsection{Obtención de la Renovación del Permiso de Descarga de Efluentes Gaseosos a la Atmósfera - Establecimientos Industriales}

- Marco Normativo: Decreto No 3395/96 Resolución N N 504/01 Decreto-Ley No 7647/70 Resolución 242/97

- Descripción: La validez de los Permisos de Descarga de Efluentes Gaseosos a la Atmósfera es de dos años, la misma de los Certificados de Aptitud Ambiental de la Ley $N^{0} 11.459$, y la renovación se debe tramitar de manera conjunta. En el caso de los establecimientos ya hubieren obtenido el certificado antes referenciado, la validez del permiso será por el tiempo que falte para que el certificado deba ser renovado $u$ obtenido primigeniamente.

- Documentación Requerida:

- Los profesionales con incumbencia en las áreas específicas e inscripción actualizada en el Registro de Profesionales de OPDS (Ley No 11.459, Decreto Reglamentario $\mathbf{N}^{\circ} \mathbf{1 7 4 1 / 9 6}$. Título IV Cap. IX Art. 71 y 72 y Resoluciones $N^{\circ} \mathbf{1 9 5 / 9 6}$ y 592/98) deberán presentarse en el Departamento de Evaluación de Impacto Ambiental, dependiente de este Organismo Provincial, a efectos de obtener un nombre de usuario y una contraseña. 
Posteriormente, deberán completar los formularios que se encuentran en la página web de este Organismo Provincial según el trámite a realizar.

- Nota de presentación indicando razón social, domicilio, CUIT y trámite a realizar.

- Formulario A: por triplicado, firmados en todas sus hojas por el titular, responsable o apoderado.

- Formulario D: por triplicado, firmados en todas sus hojas por el titular, responsable o apoderado y por el Profesional responsable interviniente.

- Ante casos de actualización de datos:

- Plano con ubicación de fuentes de emisión.

- Breve memoria descriptiva de las actividades.

- Protocolos de laboratorio autorizado por la secretaria (Resolución N 504/01).

- Timbrado provincial de $\$ 22$.

- Constancia de pago de las tasas y sellados correspondientes.

- Fotocopias de contratación de tareas profesionales.

- Resultados de las campañas de monitoreos llevados por la firma, ante lo requerido por Art. $2^{\circ}$ de la Resolución de obtención del Permiso de Descarga de Efluentes Gaseosos o anterior renovación. Análisis de las tendencias de los valores obtenidos.

- Predicción del impacto sobre la calidad de aire según las etapas de cálculos establecidos por la Resolución 242/97, sobre las últimas determinaciones llevadas a cabo.

- Informe sobre cumplimiento del Art.14 del Decreto No 3395/96.

- Plan de adecuaciones en caso de corresponder.

- Informe sobre eventos con implicancia en la calidad de aire ocurridos y medidas correctivas implementadas (Art. $15^{\circ}$ ). 
- La empresa deberá cumplir con el requisito previsto en el artículo 24 de la Decreto-Ley No 7647/70, debiendo constituir el domicilio, para las presentes actuaciones, en el radio de la ciudad de La Plata.

- Se deberá adjuntar Copia del Acta de Directorio o Acta Poder (certificado ante escribano público), de la persona que firme la documentación en representación del titular del emprendimiento (en caso de que la persona sea distinta a la que intervino en el trámite primigenio).

\subsubsection{Inscripción en el Registro Provincial de Generadores de Residuos Especiales}

- Marco Normativo: Se rige por los Artículos 24, 27 y 38 y concordantes de la Ley $\mathrm{N}^{\circ} \mathbf{1 1 . 7 2 0}$ y su Decreto reglamentario $\mathrm{N}^{\circ} \mathbf{8 0 6 / 9 7}$

- Descripción: Es el inicio del trámite en el marco de la Ley $\mathbf{N}^{\circ}$ 11.720 de Residuos Especiales para su inscripción en el Registro Provincial de Generadores de Residuos Especiales y el otorgamiento del Certificado de Habilitación Especial (CHE). Es obligatorio para todas las personas físicas o jurídicas responsables de la generación de residuos especiales, según la definición de la Ley 11.720 .

- Documentación Requerida:

- Los profesionales con incumbencia en las áreas específicas e inscripción actualizada en el Registro de Profesionales de OPDS (Ley $\mathbf{N}^{\circ}$ 11.459, Decreto

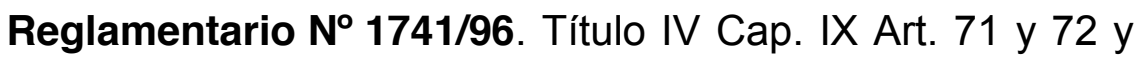
Resoluciones $N^{\circ} \mathbf{1 9 5 / 9 6}$ y 592/98) deberán presentarse en el Departamento de Evaluación de Impacto Ambiental, dependiente de este Organismo Provincial, a efectos de obtener un nombre de usuario y una contraseña. Posteriormente, deberán completar los formularios que se 
encuentran en la página web de este Organismo Provincial según el trámite a realizar.

- Nota de Solicitud Se deberá presentar una nota solicitando el trámite correspondiente. La misma deberá estar firmada por el titular o responsable.

- Formulario A: por triplicado, firmados en todas sus hojas por el titular, responsable o apoderado.

- Formulario E: por triplicado, firmados en todas sus hojas por el titular, responsable o apoderado y por el Profesional responsable interviniente.

○ Timbrado provincial de $\$ 22,00$.

- Constancia de pago de las tasas y sellados correspondientes.

- Titularidad: La documentación que acredite la titularidad del emprendimiento, dependerá de los casos que a continuación se detallan:

- Persona Física: Fotocopia de la primera y segunda hoja del DNI en copia fiel del original suscripto por personal autorizado del municipio.

- Sociedad de Hecho: Fotocopia de la primera y segunda hoja del DNI de cada uno de los integrantes en copia fiel del original suscripto por personal autorizado del municipio.

- Persona Jurídica: Estatuto Social debidamente certificado (si el escribano es de otra jurisdicción distinta de la Provincia de Buenos Aires, deberá tener su firma legalizada por el Colegio de Escribanos Provincial).

- Se deberá adjuntar Copia del Acta de Directorio o Acta Poder (certificado ante escribano público), de la persona que firme la documentación en representación del titular del emprendimiento. 
- Constancia de CUIT (Clave Única de Identificación Tributaria) de la firma continuadora.

\subsubsection{Habilitación de Aparatos Sometidos a Presión según Resoluciones $N^{\circ} 231 / 96,1126 / 07$ Y 124/10}

- Marco Normativo: Resoluciones $N^{\circ} 231 / 96$, 1126/07 y 124/10

- Descripción: Todos los aparatos y recipientes que se instalen en la Provincia de Buenos Aires, que contengan fluidos a presión y sean alcanzados por la normativa de referencia, deberán ser habilitados ante el OPDS y llevar leyendas o placa de identificación grabada en forma indeleble. Se consideran aparatos a presión todos aquellos recipientes que se encuentren sometidos a presión interna y reúnan cualquiera de las siguientes características:

- Con fuego: Volumen mínimo 200 litros y/o presión de trabajo manométrica mínima $0,5 \mathrm{~kg} / \mathrm{cm}^{2}$.

- Sin fuego: Volumen mínimo 80 litros y/o presión de trabajo manométrica mínima $3,00 \mathrm{~kg} / \mathrm{cm}^{2}$.

- En los equipos sometidos a esfuerzos combinados (dinámicos, flexotorsión, etc.) los límites serán: el volumen mínimo 80 litros y/o presión de trabajo manométrica $1,00 \mathrm{~kg}$ $/ \mathrm{cm} 2$.

- Documentación Requerida:

- Los profesionales con incumbencia en las áreas específicas e inscripción actualizada en el Registro de Profesionales de del OPDS deberán presentarse en el Departamento de Aparatos Sometidos a Presión, a efectos de obtener un nombre de usuario y una contraseña. Posteriormente, deberán completar los formularios que se encuentran en la página web de este Organismo Provincial según el trámite a realizar.

- Nota de Solicitud de Habilitación y/o extensión de vida útil

- Solicitud de aviso de fecha de inspección, con al menos 30 días de anticipación. 
- Formulario A: por triplicado, firmados en todas sus hojas por el titular, responsable o apoderado.

- Formulario F: por triplicado, firmados en todas sus hojas por el titular, responsable o apoderado y por el Profesional responsable interviniente.

○ Timbrado provincial de $\$ 22,00$.

- Constancia de pago de las tasas y sellados correspondientes.

- Contrato Profesional

- Acta de verificación original

- Memoria de cálculo original

- Plano en tela o film poliester con detalles de cada equipo

- Certificado de validación de los equipos a utilizar por el profesional

- Registros de Aparatos Sometidos a Presión

- Disposición de Habilitación de los Registros de ASP

\subsubsection{Renovación de Aparatos Sometidos a Presión}

- Marco Normativo: Resoluciones $N^{\circ} 231 / 96$, 1126/07 y 124/10

- Descripción: En función de las habilitaciones realizadas de los aparatos sometidos a presión según las resoluciones de referencia, anualmente se deberán solicitar las renovaciones correspondientes. Se debe tener en cuenta, que para los aparatos sometidos a presión con fuego, todos los años deben realizarse las pruebas hidráulicas correspondientes, mientras que esto se debe realizar cada 5 años recipientes sin fuego.

- Documentación Requerida:

- Los profesionales con incumbencia en las áreas específicas e inscripción actualizada en el Registro de Profesionales de del OPDS deberán presentarse en el Departamento de Aparatos Sometidos a Presión, a efectos de obtener un nombre de usuario y una contraseña. 
Posteriormente, deberán completar los formularios que se encuentran en la página web de este Organismo Provincial según el trámite a realizar.

- Nota de Solicitud haciendo referencia al expediente de Habilitación original.

- Solicitud de aviso de fecha de inspección, con al menos 30 días de anticipación.

- Formulario A: por triplicado, firmados en todas sus hojas por el titular, responsable o apoderado.

- Formulario F: por triplicado, firmados en todas sus hojas por el titular, responsable o apoderado y por el Profesional responsable interviniente.

- Timbrado provincial de $\$ 22,00$.

- Constancia de pago de las tasas y sellados correspondientes.

- Contrato Profesional

- Acta de verificación original

- Memoria de cálculo original

- Plano en tela o film poliester con detalles de cada equipo

- Certificado de validación de los equipos a utilizar por el profesional

- Registros de Aparatos Sometidos a Presión

- Disposición de Habilitación de los Registros de ASP

\subsubsection{Plan de Gestión de Residuos Sólidos Asimilables a Urbanos para Industrias}

- Marco Normativo: Resolución OPDS 139/13

- Descripción: los establecimientos industriales considerados grandes generadores conforme los términos del artículo $3^{\circ}$ de la Ley $\mathrm{N}^{\circ}$ 14.273; instalados en el ámbito del Área Metropolitana de Buenos Aires deberán presentar al momento de solicitar la renovación del Certificado de Aptitud Ambiental, un plan de gestión de residuos sólidos urbanos o asimilables a ellos. La vigencia del 
trámite es de un año, para lo que se deberá solicitar la renovación correspondiente.

\section{- Documentación Requerida:}

- Nota de Solicitud: Se deberá presentar una nota solicitando el trámite correspondiente. La misma deberá estar firmada por el titular o responsable.

- Plan de Gestión de Residuos Sólidos Asimilables a Urbanos de la Planta Industrial. Deben figurar indicadores de generación y de materiales recuperados.

- Designación de un Referente Ambiental, quien será el encargado de implementar las prácticas de gestión de los residuos sólidos urbanos y monitorear su cumplimiento.

- Acreditación de la contratación de un servicio de recolección de los residuos generados y/o del envío a un destino sustentable.

- Llevar un libro de operaciones en el que se vuelquen, como mínimo, mensualmente las acciones realizadas en el marco de la gestión integral de sus residuos.

- Titularidad: La documentación que acredite la titularidad del emprendimiento, dependerá de los casos que a continuación se detallan:

- Persona Física: Fotocopia de la primera y segunda hoja del DNI en copia fiel del original suscripto por personal autorizado del municipio.

- Sociedad de Hecho: Fotocopia de la primera y segunda hoja del DNI de cada uno de los integrantes en copia fiel del original suscripto por personal autorizado del municipio.

- Persona Jurídica: Estatuto Social debidamente certificado (si el escribano es de otra jurisdicción distinta de la Provincia de Buenos 
Aires, deberá tener su firma legalizada por el Colegio de Escribanos Provincial).

- Se deberá adjuntar Copia del Acta de Directorio o Acta Poder (certificado ante escribano público), de la persona que firme la documentación en representación del titular del emprendimiento.

- Constancia de CUIT (Clave Única de Identificación Tributaria) de la firma continuadora.

\subsubsection{Autoridad del Agua}

\section{TRÁMITES}

- Inscripción en el BUDURH

- Solicitud de Permiso de explotación del recurso hídrico subterráneo

- Factibilidad hidráulica del predio

- Solicitud de Permiso de vuelco de efluentes líquidos previamente tratados

Teniendo en cuenta que la Autoridad del Agua (ADA) tenía la necesidad de establecer procedimientos claros para la obtención de Permisos de los proyectos a desarrollar, así como la regularización de los establecimientos en funcionamiento, emitió la Resolución ADA N 734/14 por la cual se aprobó una serie de trámites obligatorios. Para los mismos, existe un detalle de cómo deben ser los procedimientos para la gestión de Permisos general, para nuevos proyectos y para establecimientos en Funcionamiento. Asimismo, se detallan un listado de productos / documentos que emite ADA.

\subsubsection{Procedimiento para la Gestión de Permisos}

El procedimiento de regulación comienza con la inscripción del proyecto o establecimiento en actividad en el Banco Único de Usuarios de los Recursos Hídricos ante el Departamento de Permisos y Concesiones según el ordenamiento establecido en la Resolución ADA 465/13. El trámite de 
inscripción concluye con la caratulación de la Declaración Jurada de inicio luego de la presentación de la documentación respaldatoria correspondiente. A partir de ese momento y cada un año según la fecha de presentación, se debe renovar el mismo informando de ser necesario las modificaciones realizadas.

Se destaca que todas las gestiones deberán ser realizadas solo por el propietario de las tierras donde se desarrollará el proyecto. De considerarlo conveniente, el propietario podrá designar un único apoderado que quedará debidamente acreditado en las actuaciones (Expediente principal). Este llevará a cabo toda la gestión íntegramente.

En el Anexo II de la citada Resolución, se detallan las documentaciones que deberá presentar según sea un proyecto a desarrollar (Anexo II a) o la regulación de los establecimientos en funcionamiento (Anexo II b). Los señaladores alfabéticos indican el orden de presentación que deberá observar el trámite.

En el Anexo III se listan los documentos que emitirá la ADA según corresponda en orden a:

- El camino crítico establecido

- La aprobación de la documentación detallada en los señaladores alfabéticos correspondientes.

El punto de partida del proceso de regulación consiste en la apertura del expediente, con el correspondiente cronograma de presentaciones y acreditación del apoderado.

El Departamento Permisos y Concesiones reportará a las Direcciones de Usos y Aprovechamiento y de Planificación y Control para que se conforme la Comisión Técnica con intervención de los Departamentos de Planes Hidrológicos, Preservación y Mejoramiento de los Recursos y Evaluación de Proyectos, quienes participarán de la Primera Audiencia Técnica donde el desarrollador realizará una presentación basada en las características del emprendimiento y los parámetros e indicadores que utilizará para las distintas fases del proyecto. Los integrantes de la Comisión Técnica serán los responsables de analizar la documentación en cada una de las etapas donde, 
por las incumbencias de los Departamentos respectivos, les corresponde intervenir.

Una vez formalizado el cronograma, el Departamento realiza la convocatoria a la Primer Audiencia Técnica. En el Acta de la Audiencia se formaliza los criterios a utilizar y las directrices que deberá respetar el proyecto. Para el desarrollo de la Audiencia será requisito ineludible la participación del propietario o apoderado y los profesionales intervinientes en cada uno de los desarrollos específicos (pluviales, agua, cloacas, gestión del agua, etc.).

A continuación, cada uno de los documentos es agrupado según su especificidad como Alcances del Expediente Principal y son tratados como se indicó más arriba.

Finalmente, se realiza una Segunda (y última) Audiencia Técnica, donde se presentará el proyecto consolidado del desarrollo que deberá haber incluido las consideraciones y observaciones realizadas por las áreas competentes. Para esta instancia, a la Comisión Técnica se le acoplará representantes del Departamento Inspección y Control. El Acta de la Segunda Audiencia dará por finalizada la etapa de consultas y aprobará el proyecto consolidado.

A partir de allí se realizarán las presentaciones definitivas de los proyectos específicos procediéndose a completar el procedimiento de aprobación de proyectos.

El plazo entre una y otra Audiencia Técnica no debe exceder los 90 días.

La resolución aprobatoria de proyectos tendrá una vigencia de 1 año. Si vencido el plazo, las obras no hubiesen comenzado, se debe solicitar una prórroga que puede ser emitida por otro año. Si al cabo del segundo año, las obras no se hubiesen iniciado, la aprobación automáticamente caducará y el proyecto nuevamente será sometido a revisión a solicitud del propietario interesado o apoderado.

Para el inicio de las obras, el propietario debe anunciar ante la ADA la fecha de inicio, el cronograma de obras, las empresas contratistas involucradas y la contratación de un Auditor Externo quién certificará el avance de las obras según proyecto, monitoreará el período de ajuste hasta la puesta en marcha. El 
Plan de Auditorías será presentado simultáneamente al anuncio de inicio, debidamente rubricado por el Auditor Externo Contratado. Durante el período de ajuste, el propietario o apoderado solicitará la inspección de ADA para verificar las obras y su ajuste a proyecto que dará lugar a la emisión del final de obra correspondiente. El otorgamiento del final de obra no autoriza al emprendimiento a la explotación de los recursos hídricos ni al vuelco de sus aguas residuales, cualquiera sea el cuerpo receptor.

Finalizado el período de ajuste de los sistemas de abastecimiento y aguas residuales, el propietario o apoderado solicitará el Permiso Precario adjuntando el informe final del Auditor. El Departamento Presentación y Mejoramiento diseña los controles y autocontroles pertinentes y eleva al Departamento Inspección y Control a esos efectos. Por último, el Departamento Permisos y Concesiones completan las proformas que dan a lugar a la confección del acto administrativo correspondiente.

ADA emitirá un solo Permiso Conjunto adaptándose a la integralidad del ciclo del agua. En el documento de otorgamiento del Permiso se establece además las consignas de operación que deben respetarse y los rangos de variabilidad admitidos. La superación de esos límites hace pasible al establecimiento de recibir sanciones que pueden derivar en la suspensión o anulación del permiso o concesión otorgada. Conjuntamente, se entrega un Diploma que deberá ser exhibido en la Administración del Establecimiento.

En conjunto, la tramitación de los permisos no debe superar los 6 meses, sin contar el tiempo que demande la ejecución de las obras.

Para las actuaciones iniciadas en trámite, se procede a glosar los expedientes abiertos en uno único, sistematizando la información en alcances tal como lo establece el Anexo II b.

\section{Gestión de Permisos para nuevos proyectos}

\section{Ordenamiento administrativo - Expediente único}

- Alcance 0: 
- A: Solicitud de apertura del Expediente

- Acreditación del Apoderado

- Certificación del ingreso al BUDURH

- Cronograma de presentaciones

○ B: Bases de Anteproyecto

- Master Plan

- Indicadores urbanísticos y de uso de suelo. Restricciones

- Estudio de Impacto Ambiental

- Declaración de Impacto Ambiental o Certificado de Aptitud Ambiental más Anexos Expedido por OPDS

- Solicitud de prestación de servicios de provisión de agua y cloacas

- C: Solicitud de marcación de Línea de Ribera y restricciones al dominio (si correspondiera)

- Plano de mensura

- Informe hidrológico / geomorfológico (en caso de no contar con antecedentes hidrológicos)

○ G:Proyecto consolidado

- Descripción del Proyecto Integral

- Zonificación y unidades a construirse

- Indicadores

- Cálculo de Huella Hídrica del Establecimiento

- Alcance 1:

- D: Solicitud de Prefactibilidad Hidráulica

- H: Presentación del Proyecto de Manejo y Evaluación de Excedentes Pluviales

- Memoria descriptiva

- Documentación referente a la Resolución ADA 234/10

- Memoria técnica

- Planos y perfiles

- Cómputo y presupuesto

- Aprobación DIPSOH Resolución MIN 589/10 
- Comprobante de pago de tasa

○ N:

- Anuncio de inicio de obra

- Contratistas, cronograma e inicio de obras.

- Designación de Auditor Externo y Plan de Auditorías.

- Solicitud de final de obra

- Memoria técnica

- Planos según obra

- Manual con las consignas de manejo

- Comprobante de pago de tasas.

- Alcance 2:

- E: Solicitud de Prefactibilidad de Abastecimiento de Agua

- Estudio de Demandas de agua discriminado por uso

○ l: Presentación del Proyecto de Explotación

- Estudios de base

- Proyecto de Explotación

- Cómputo y presupuesto

- Comprobante pago de tasas

- J: Presentación del Proyecto de Explotación (Agua subterránea y superficial)

- Caracterización de la/las fuente/s y modelación del flujo bajo las condiciones de operación

- Memoria descriptiva

- Memoria técnica

- Planos y perfiles

- Cómputo y presupuesto

- L: Presentación del Proyecto del sistema de tratamiento, distribución y almacenamiento de agua

- Memoria descriptiva

- Memoria técnica

- Planos y perfiles 
- Cómputo y presupuesto

- Comprobante pago de tasas

$\circ \tilde{\mathrm{N}}$ :

- Anuncio de inicio de obra

- Contratistas, cronograma e inicio de obras.

- Designación de Auditor Externo y Plan de Auditorías.

- Solicitud de final de obra

- Memoria técnica

- Planos según obra

- Manual con las consignas de manejo

- Comprobante de pago de tasas.

- Alcance 3:

- F: Solicitud de Certificado de Capacidad Hidráulica del cuerpo receptor

- Caracterización de la/las fuente/s generadoras de efluentes

- Diagrama de flujo (todas las líneas húmedas) y carga estimada

- Capacidad de asimilación de carga orgánica por parte del/los cuerpo/s receptor/es

○ K: Presentación del Proyecto del/los sistemas de tratamiento

- Memoria descriptiva

- Memoria técnica

- Eficiencia de las unidades de tratamiento

- Planos y perfiles

- Cómputo y presupuesto

- Comprobante pago de tasas

- LL: Presentación del Proyecto del sistema de colección y disposición final de aguas residuales

- Memoria descriptiva

- Memoria técnica 
- Planos y perfiles

- Cómputo y presupuesto

- Comprobante pago de tasas

○ M: Presentación del Proyecto de reúso

- Memoria descriptiva

- Memoria técnica

- Planos y perfiles

- Cómputo y presupuesto

- Comprobante pago de tasas

○ O:

- Anuncio de inicio de obra

- Contratistas, cronograma e inicio de obras.

- Designación de Auditor Externo y Plan de Auditorías.

- Solicitud de final de obra

- Memoria técnica

- Planos según obra

- Manual con las consignas de manejo

- Comprobante de pago de tasas.

- Alcance 4:

○ P: Solicitud de Permiso

- Conformación de consorcio (si correspondiere) bajo términos de la Ley 12.257

- Informe de Auditoría Externa

- Q: Presentación del Plan Gestión del Ciclo del Agua

- Plan de Gestión del Ciclo del Agua

- Metas de uso y eficiencia

- Manual de operaciones

- Consignas de control

- Plan de contingencias 


\section{Gestión de Permisos para Establecimientos en funcionamiento \\ Ordenamiento administrativo - Convergencia en un Expediente único}

- Alcance 0:

- A: Solicitud de Regularización

- Acreditación del Apoderado

- Certificación del ingreso al BUDURH

- Cronograma de regularización

- B: Caracterización de la actividad

- Memoria general

- Indicadores urbanísticos y de uso de suelo. Restricciones

- Estudio de Impacto Ambiental

- Declaración de Impacto Ambiental o Certificado de Aptitud Ambiental más Anexos Expedido por OPDS

- Solicitud de prestación de servicios de provisión de agua y cloacas

- C: Solicitud de marcación de Línea de Ribera y restricciones al dominio (si correspondiera)

- Plano de mensura

- Informe hidrológico / geomorfológico (en caso de no contar con antecedentes hidrológicos)

○ G:Proyecto consolidado

- Descripción del Proyecto Integral

- Zonificación y unidades a construirse

- Indicadores

- Cálculo de Huella Hídrica del Establecimiento

- Obras e instrumental de control

- Alcance 1:

- D: Relevamiento de obras pluviales

- Memoria y cálculo

- Planimetría y cortes 
- Copia de planos aprobados antecedentes

- Informe de convalidación técnica o proyecto de modificación

- H: Presentación del Proyecto de Manejo y Evaluación de Excedentes Pluviales

- Memoria descriptiva

- Documentación referente a la Resolución ADA 234/10

- Memoria técnica

- Planos y perfiles

- Cómputo y presupuesto

- Aprobación DIPSOH Resolución MIN 589/10

- Comprobante de pago de tasa

- N: Solicitud de final de obra

- Memoria técnica

- Planos según obra

- Manual con las consignas de manejo

- Comprobante de pago de tasas.

- Alcance 2:

- E: Relevamiento del sistema de Abastecimiento de Agua

- Memoria descriptiva

- Memoria técnica

- Caracterización de las fuentes de abastecimiento y modelación del flujo bajo condiciones de operación

- Estudio de Demandas de agua discriminado por uso

- Planimetría y cortes (incluye pozos

- Copia de planos aprobados antecedentes

- Informe de convalidación técnica y propuesta de mejoras

- I: Presentación del Proyecto de estudio hidrogeológico o de obras de control

- Estudios de base

- Proyecto de Explotación

- Cómputo y presupuesto 
- Comprobante pago de tasas

- J: Presentación del Proyecto de Modificación del Sistema de Explotación (Agua subterránea y superficial)

- modelación

- Memoria descriptiva

- Memoria técnica

- Planos y perfiles

- Cómputo y presupuesto

- Comprobante pago de tasas

- L: Presentación del Proyecto de mejora del sistema de tratamiento, distribución y almacenamiento de agua

- Memoria descriptiva

- Memoria técnica

- Planos y perfiles

- Cómputo y presupuesto

- Comprobante pago de tasas

○ $\tilde{\mathrm{N}}$ : Solicitud de final de obra

- Memoria técnica

- Planos según obra

- Manual con las consignas de manejo

- Comprobante de pago de tasas.

- Alcance 3:

- F: relevamiento del sistema de aguas residuales (incluye cloacales)

- Diagrama de flujo (todas las líneas húmedas) y carga estimada

- Capacidad de asimilación de carga orgánica por parte $\mathrm{del} /$ los cuerpo/s receptor/es

- Memoria descriptiva

- Memoria técnica

- Eficiencia de las unidades de tratamiento

- Planimetría y cortes

- Copia de planos aprobados antecedentes 
- Informe de convalidación técnica o propuesta de mejoras

- K: Presentación del Proyecto de mejora del/los sistemas de tratamiento

- Memoria descriptiva

- Memoria técnica

- Eficiencia de las unidades de tratamiento

- Planos y perfiles

- Cómputo y presupuesto

- Comprobante pago de tasas

- LL: Presentación del Proyecto de mejora del sistema de colección y disposición final de aguas residuales

- Caracterización de la/s fuente/s

- Memoria descriptiva

- Memoria técnica

- Planos y perfiles

- Cómputo y presupuesto

- Comprobante pago de tasas

- M: Presentación del Proyecto de mejora de reúso

- Memoria descriptiva

- Memoria técnica

- Planos y perfiles

- Cómputo y presupuesto

- Comprobante pago de tasas

- O: Solicitud de final de obra

- Memoria técnica

- Planos según obra

- Manual con las consignas de manejo

- Comprobante de pago de tasas.

- Alcance 4:

- P: Solicitud de Permiso

- Conformación de consorcio (si correspondiere) bajo términos de la Ley 12.257 
○ Q: Presentación del Plan Gestión del Ciclo del Agua

- Plan de Gestión del Ciclo del Agua

- Metas de uso y eficiencia

- Manual de operaciones

- Consignas de control

- Plan de contingencias

\subsubsection{Fuentes complementarias}

En relación a los trámites complementarios a la gestión ambiental obligatoria, los podemos dividir en 2 conjuntos:

- Informes de Sustentabilidad (GRI) y Planes de Responsabilidad Social Empresaria

- Implementación de Normas ISO (International Organization for Standardization)

\subsubsection{Informes de Sustentabilidad}

La Guía para la elaboración de Informes (también llamados reportes) de Sustentabilidad de GRI (Global Reporting Initiative), es el estándar para la elaboración más utilizado del mundo y facilita a las organizaciones los instrumentos que precisan para satisfacer las actuales demandas relacionadas con el compromiso con el ambiente y la sociedad en general.

Estos Informes facilitan a las organizaciones la elaboración de información fiable, relevante y estandarizada para valorar oportunidades y riesgos y tomar decisiones fundamentadas. De este modo, las empresas aumentan su valor, miden y gestionan el cambio y promueven mejoras e innovación.

La G4 es la cuarta versión de la Guía y en ella se hace referencia a otros marcos reconocidos ampliamente. La Guía busca convertirse en un marco consolidado para la elaboración de memorias conformes con distintos códigos y normas de sustentabilidad. No solo incrementa la relevancia y la calidad de los informes de sustentabilidad independientes, sino que facilita un estándar 
internacional reconocido para la información sobre sustentabilidad que debe incluirse en las memorias integradas.

\subsubsection{Implementación de Normas ISO}

La International Organization for Standardization (ISO) es una federación mundial que agrupa a representantes de cada uno de los organismos nacionales de estandarización (como lo es el Instituto Argentino de Normalización y Certificación - IRAM - en la Argentina), y que tiene como objeto desarrollar estándares internacionales.

Cuando las empresas pueden de forma objetiva evaluar procesos, sistemas, calidad, etc. de un proveedor y/o cliente, el riesgo de entablar negocios con algún tipo de riesgo se reduce significativamente. Si los estándares son los mismos para toda la cadena de comercialización, la misma puede potenciarse en forma significativa.

ISO establece normas internacionales sobre temas tales como:

- ISO 9000 - Gestión de la calidad

- ISO 14000 - Gestión ambiental

- ISO 3166 - Los códigos de país

- ISO 22000 - Gestión de la seguridad alimentaria

- ISO 26000 - Responsabilidad social

- ISO 50001 - Gestión de la energía

- ISO 31000 - Gestión del riesgo

- ISO 4217 - Códigos de las monedas

- ISO 639 - Códigos de idioma

- 20121 ISO - Eventos sostenibles

- ISO 27001 - Seguridad de la información

En base a la Familia de las ISO 14000, encontramos las siguientes normas:

- la gestión ambiental (ISO 14001/4),

- el etiquetado ambiental (ISO 14020/21/24/25), 
- la evaluación del ciclo de vida (ISO 14040/44),

- la medición, verificación y validación de gases de efecto invernadero (ISO 14064/65).

La ISO 14001: 2004 es la certificación de sistemas de gestión ambiental por excelencia. Establece los requisitos para los sistemas de gestión ambiental a nivel mundial para las organizaciones que deseen llevar acabo sus actividades en el ambiente de manera sustentable.

Hasta finales de diciembre de 2013 (en 171 países), se emitieron 301.647 certificados, teniendo un crecimiento del $6 \%$ (16.993) en relación al año anterior.

Los tres países con mayor número total de certificados emitidos fueron China, Italia y Japón, mientras que los tres primeros para el crecimiento en el número de certificados en 2013 fueron China, Italia y la India.

Específicamente, en Argentina durante 2013 se emitieron 1.308 Certificados (ver Gráfico 3).

\section{Evolution of ISO 14001 certificates in Argentina}

Selict a country Argentina

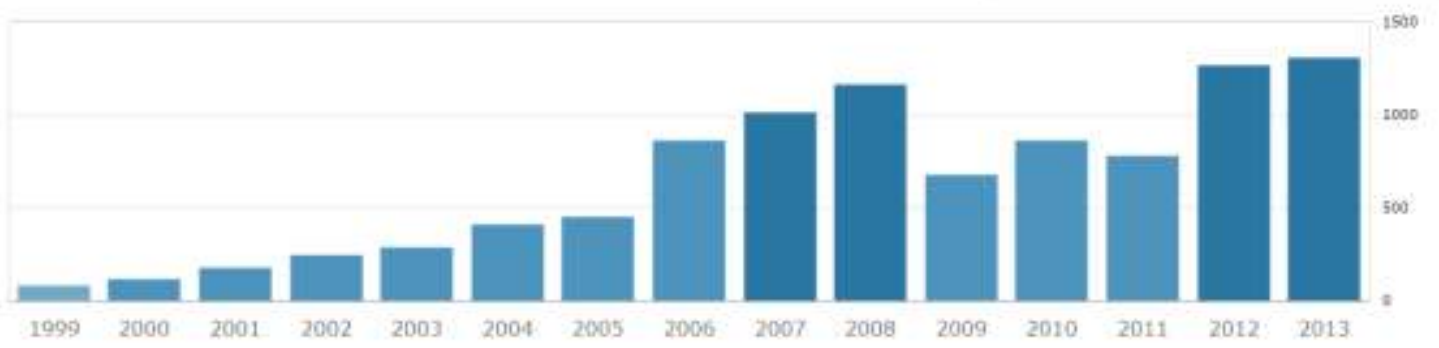

Gráfico 1. Evolución de la norma ISO 14001 en Argentina. Fuente: Encuesta ISO 2013.

Gran parte de las Empresas de la Provincia de Buenos Aires son pequeñas y medianas (PyMES). Estas son, en promedio, las empresas que están generando crecimiento más rápido y más innovador junto con la creación de empleo. Además son menos complejas (estructuralmente) y más eficientes y flexibles que las grandes empresas.

La aplicabilidad de las Normas Internacionales, así como los beneficios que puedan llegar a proporcionar, es independiente del tamaño de la empresa. 
Su uso estratégico depende casi exclusivamente de la decisión de las autoridades de la empresa para la implementación de las mismas.

\section{Normas ISO 14.000}

Son las normas internacionales que tratan sobre Gestión Ambiental. Se debe tener presente que las normas estipuladas por ISO 14.000 no fijan metas ambientales para la prevención de la contaminación, ni tampoco se involucran en el desempeño ambiental a nivel mundial, sino que, establecen herramientas y sistemas enfocadas a los procesos de producción al interior de una empresa u organización, y de los efectos o externalidades que de estos deriven al medio ambiente.

El documento ISO 14.001 Ilamado "Sistema de Administración Ambiental" es el de mayor importancia en la serie ISO 14.000, dado que esta norma establece los elementos del SGA (Sistema de Gestión Ambiental) exigidos para que las organizaciones cumplan con el fin de lograr su registro o certificación bajo esta norma.

Se debe tener en cuenta que el Sistema de Gestión Ambiental (SGA) forma parte de la Administración General de una Empresa, y en este sentido el SGA debe incluir: Planificación, Responsabilidades, Procedimientos, Procesos y Recursos que le permitan desarrollarse, alcanzar, revisar y poner en práctica la Política Ambiental.

En definitiva, esto se refiere a la creación de un área con profesionales específicos. La misma podrá tener colaboración externa, pero se requiere que realicen un sistema de control que le permita su permanencia en el tiempo. Los elementos del Sistema de Control los describe la norma como:

1. Compromiso de la Dirección y la Política Ambiental.

2. Metas y Objetivos Ambientales.

3. Programa de Control Ambiental, integrado por procesos, prácticas, procedimientos y líneas de responsabilidad.

4. Auditoría y Acción correctiva, cuya función radica en la entrega de información periódica que permite la realización de 
revisiones administrativas y asegurar que el SGA funciona correctamente.

5. Revisión Administrativa, que es la función ejecutada por la gerencia con el objeto de determinar la efectividad del SGA.

6. Mejoría Constante, esta etapa permite asegurar que la organización cumple sus obligaciones ambientales y protege el medio ambiente.

Las ISO 14.001 tienen aplicación en cualquier tipo de organización, independiente de su tamaño, rubro y ubicación geográfica.

\subsection{Relevamiento de datos de fuentes primarias}

\subsubsection{Relevamiento en industrias}

\subsubsection{Trámites ante OPDS}

De las 50 encuestas realizadas, podemos primeramente dividir a las industrias relevadas, de acuerdo en su complejidad ambiental, según la categorización de OPDS. De las mismas, según se desprende del Gráfico 4, tenemos que el $10 \%$ (5 industrias) corresponden a la Primera categoría, el 36 \% (18 industrias) a la Segunda categoría y el $54 \%$ (27 industrias) a la Tercera categoría. 


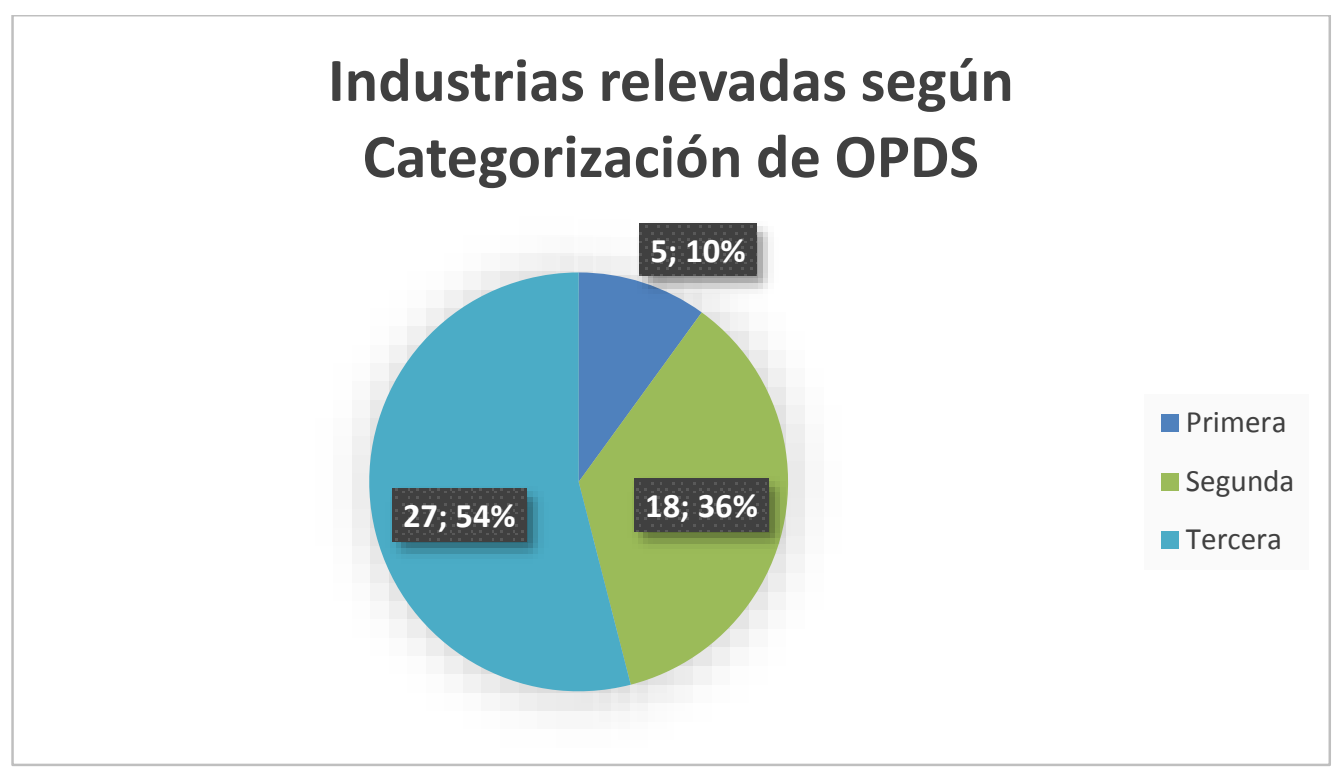

Gráfico 2. Industrias relevadas según Categorización de OPDS.

Para expresar los resultados obtenidos en relación a si han presentado Estudios de Impacto Ambiental (EIA's), si les han otorgado el Certificado de Aptitud Ambiental (CAA), si cuentan con los trámites de presentaciones de Aparatos Sometidos a Presión (ASP), presentaciones de Residuos Especiales (RREE) y si han solicitado el Permiso de Descarga de Efluentes Gaseosos a la Atmósfera, se optó por similares características agrupar a las industrias de primera y segunda categoría y diferenciarlas de las de tercera.

En relación a la presentación de EIA's de industrias de primera y segunda categoría (Gráfico 5), encontramos que el $52 \%$ han realizado la misma y el trámite se encuentra actualizado. El 39 \% expresa que más allá de que se presentó el estudio, no se encuentra actualizado. Esta situación se da principalmente porque se han producido modificaciones en las instalaciones y ellas no han sido rectificadas en la presentación original. El 9 \% nunca realizó la presentación. 


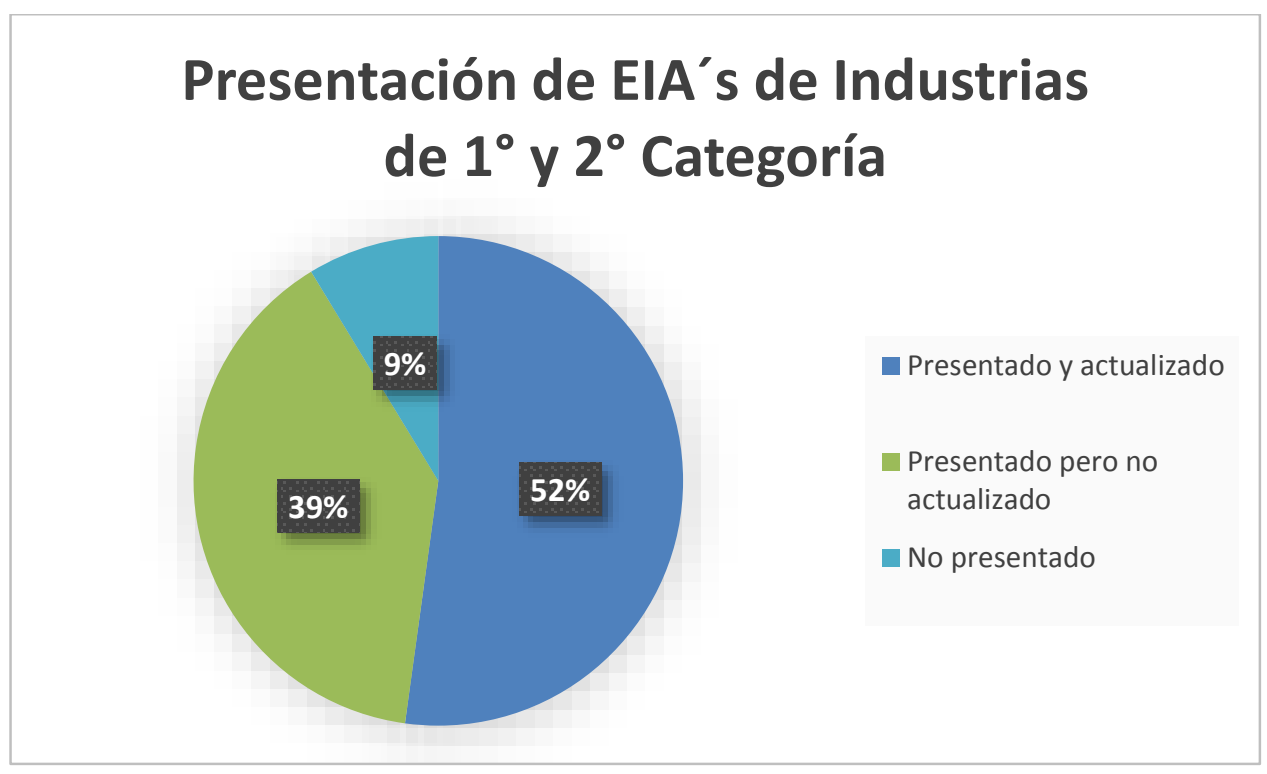

Gráfico 3. Presentación de EIA's de Industrias de $1^{\circ}$ y $2^{\circ}$ Categoría.

En el Gráfico 6 se puede ver que todas las de tercera categoría declararon que han realizado la presentación de EIA's. El $63 \%$ tiene el trámite actualizado mientras que el $37 \%$ no.

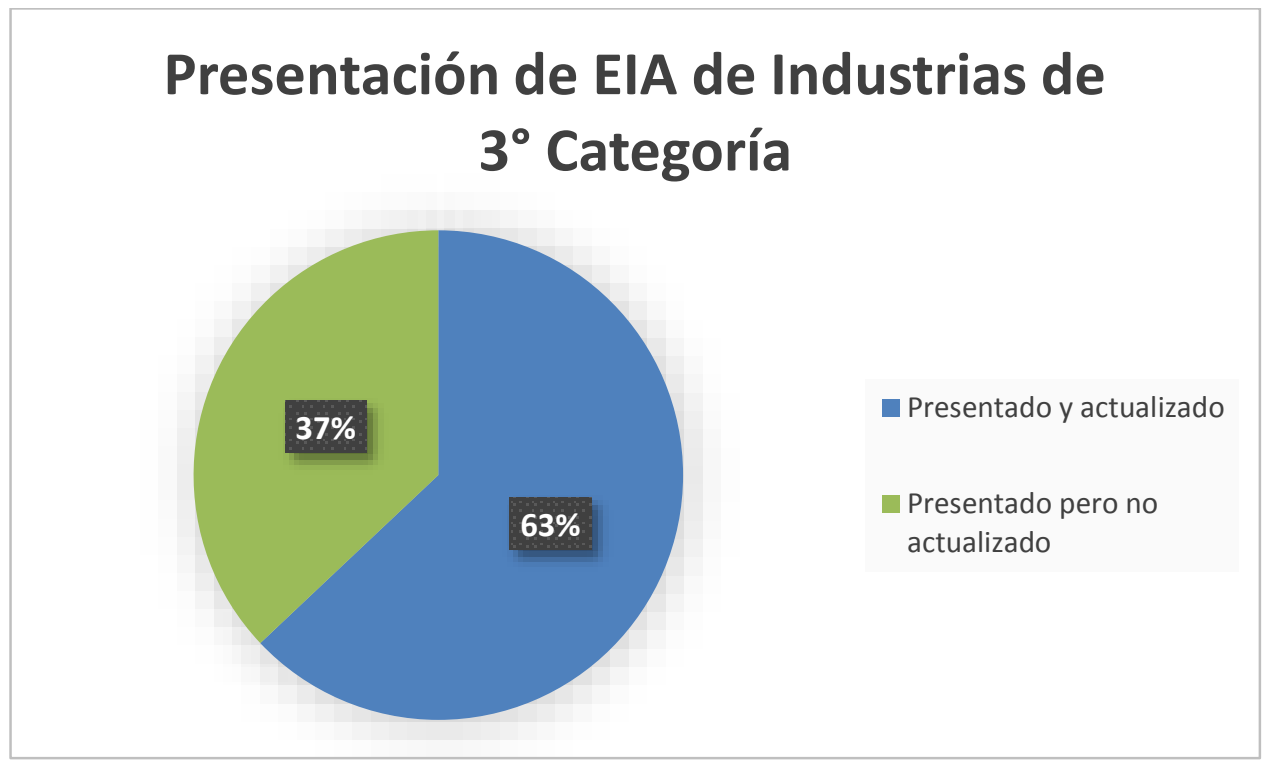

Gráfico 4. Presentación de EIA`s de Industrias de $3^{\circ}$ Categoría.

Comparando las de primera y segunda categoría con las de tercera, encontramos que en estas últimas todas declararon que realizaron la presentación y hay un mayor porcentaje que tiene el trámite actualizado. 
En cuanto al otorgamiento del CAA, en los Gráficos 7 y 8 , encontramos que una mayor proporción de los mismos se han realizado a industrias de tercera categoría (59\% contra el $48 \%$ ).

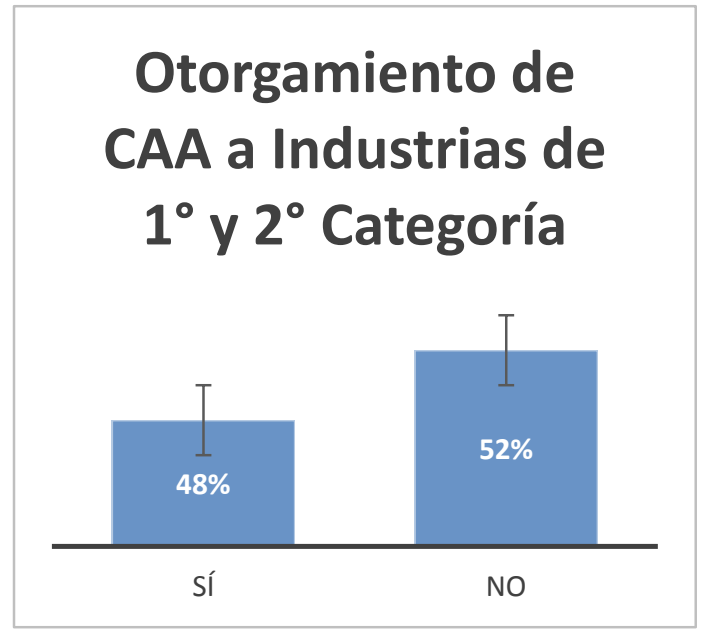

Gráfico 5. Otorgamiento de CAA a Industrias de $1^{\circ}$ y $2^{\circ}$ Categoría.

\section{Otorgamiento de \\ CAA a Industrias de $3^{\circ}$ Categoría}

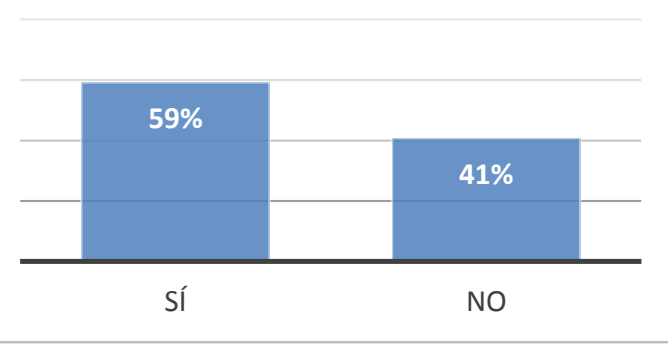

Gráfico 6. Otorgamiento de CAA a Industrias de $3^{\circ}$ Categoría.

En el Gráfico 9, en relación a las presentaciones de ASP, RREE y Efluentes Gaseosos, se desprende que al $44 \%$ de las industrias de primera y segunda categoría no tienen la obligación de la presentación de alguno de estos trámites. Esto se presenta por la complejidad de los establecimientos y su limitación de impactos ambientales que causa. Del resto de las industrias de estas categorías, el 39 \% declara tener las tres presentaciones al día, mientras que el $17 \%$ se encuentra en deuda con OPDS en alguna de las mismas. 


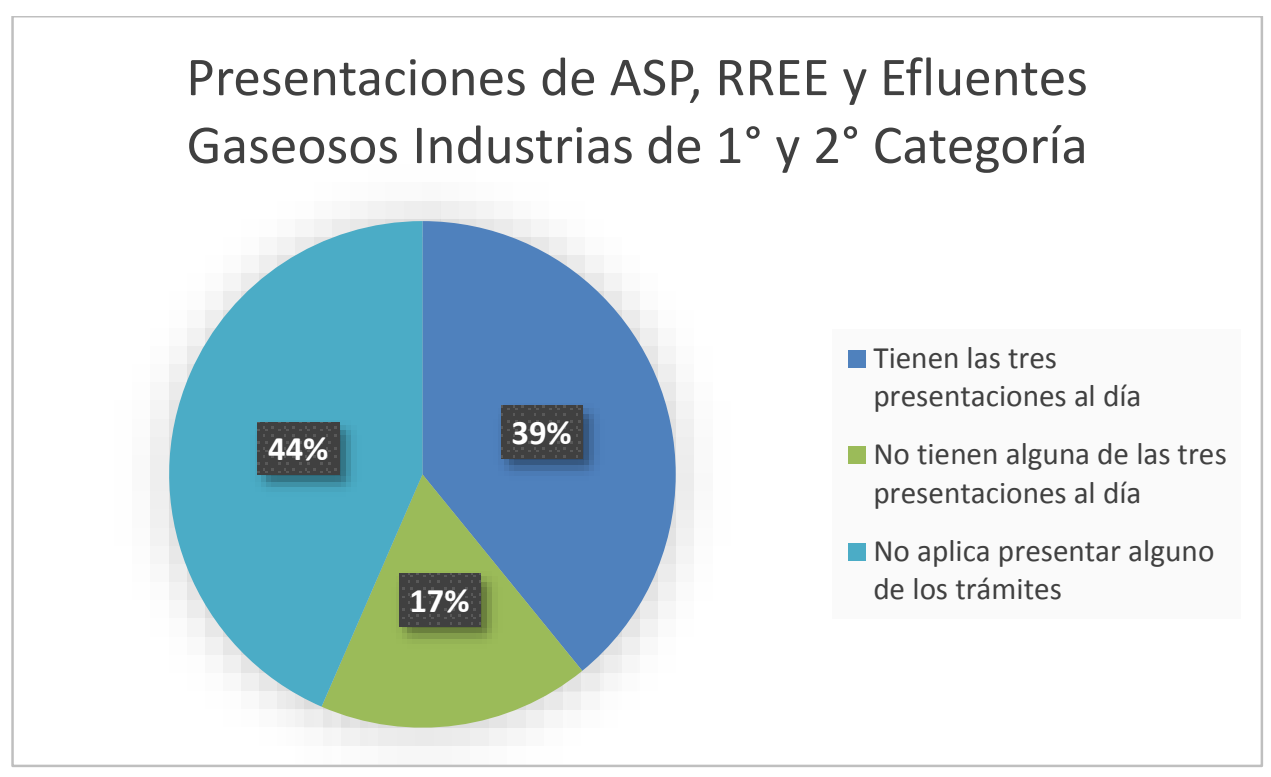

Gráfico 7. Presentación de trámites de Aparatos Sometidos a Presión (ASP), Residuos Especiales (RREE) y Efluentes Gaseosos de Industrias de $1^{\circ}$ y $2^{\circ}$ Categoría.

Todas las industrias de tercera categoría declaran que deben presentar los tres trámites como se puede ver en el Gráfico 10. El $85 \%$ se encuentra con estos trámites al día, mientras que el $15 \%$ adeuda alguno.

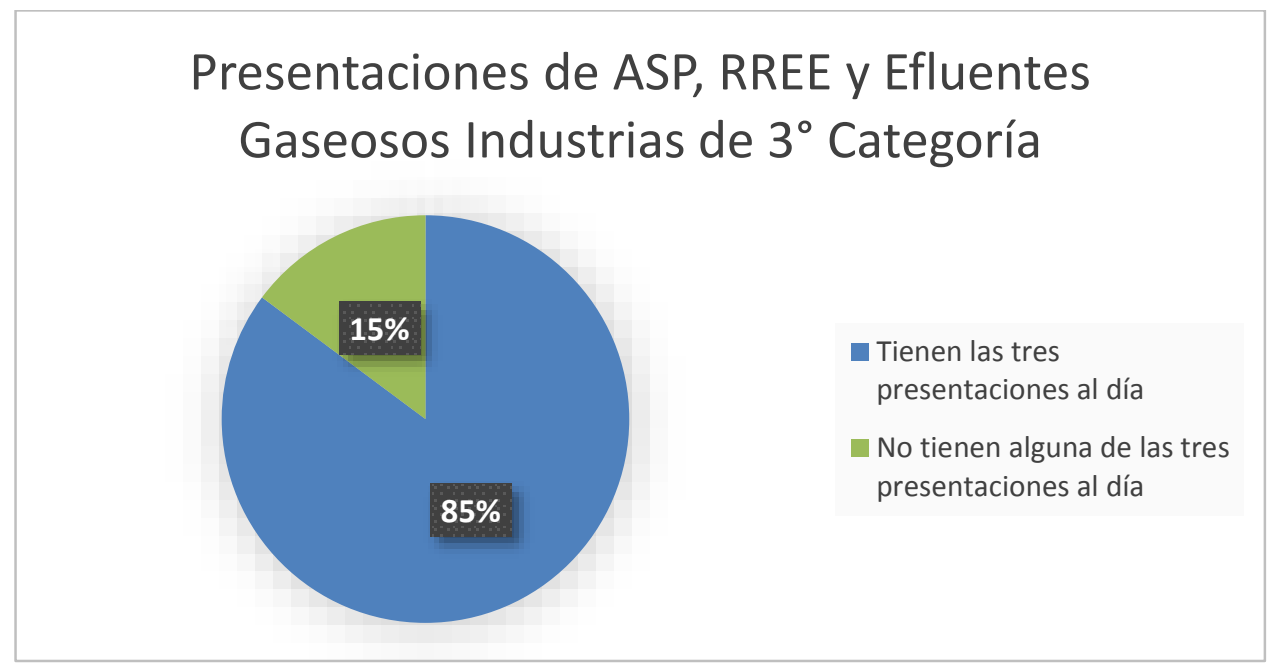

Gráfico 8. Presentación de trámites de Aparatos Sometidos a Presión (ASP), Residuos Especiales (RREE) y Efluentes Gaseosos de Industrias de $3^{\circ}$ Categoría.

Comparando las industrias de primera y segunda categoría, con las de tercera, encontramos en primera instancia que estas últimas deben cumplir obligatoriamente con los tres trámites. Además, se desprende que las de mayor complejidad cumplen en mayor medida con las presentaciones (85 \% contra el $39 \%)$. 
En relación a las industrias que han solicitado el Permiso de Descarga de Efluentes Gaseosos a la Atmósfera, el $62 \%$ declara que cuenta con el Certificado correspondiente como se puede ver en el Gráfico 11.

\section{¿Cuentan con Certificado de Descarga de Efluentes Gaseosos vigente?}

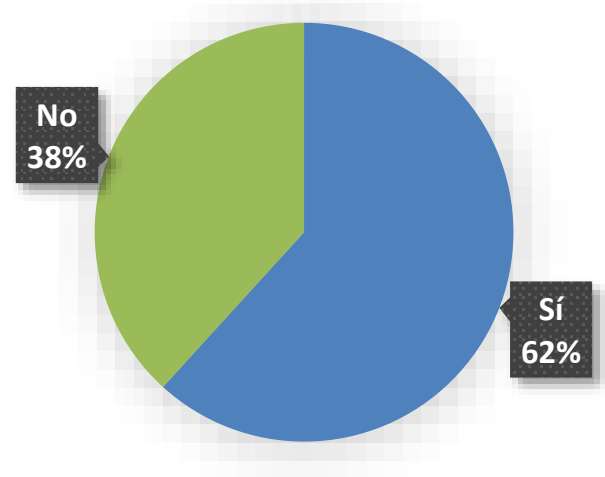

Gráfico 9. Certificado de Descarga de Efluentes Gaseosos a la Atmósfera vigente, de las Industrias que han solicitado el mismo.

Teniendo en cuenta la periodicidad de monitoreos de calidad de aire y efluentes gaseosos en cada planta industrial, en el Gráfico 12 encontramos que la mayoría declara realizar monitoreos anuales (36\%) o semestrales (26\%).

\section{Periodicidad de monitoreos de Efluentes Gaseosos}

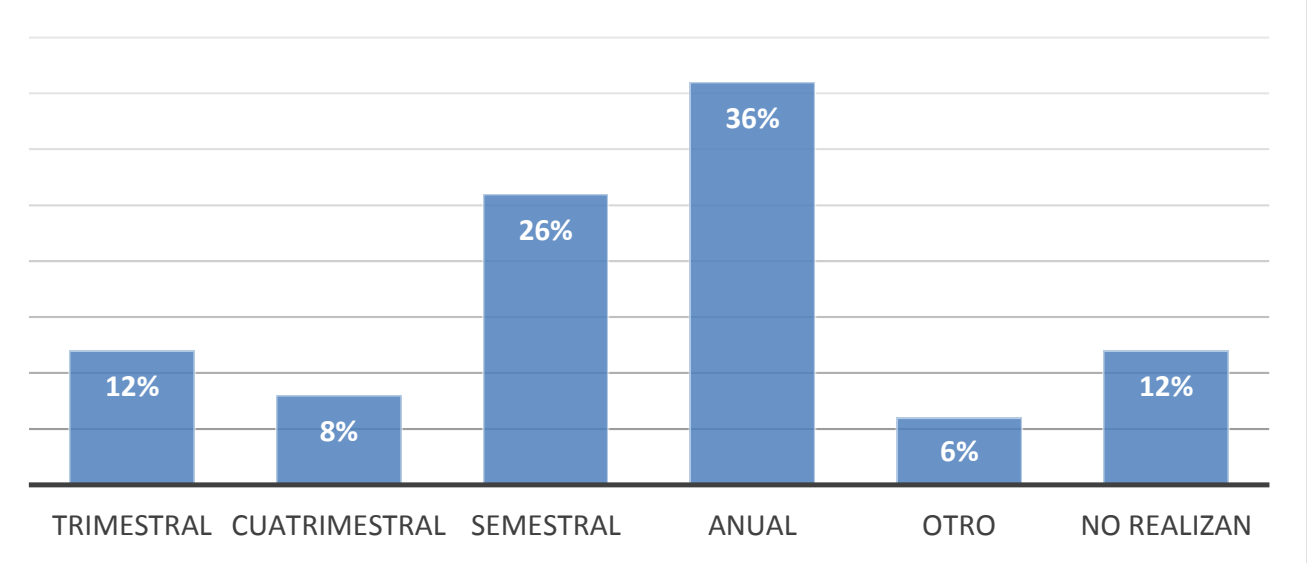

Gráfico 10. Periodicidad de monitoreos de Efluentes Gaseosos. 


\subsubsection{Trámites ante ADA}

El trámite inicial que se debe realizar ante la Autoridad del Agua (ADA), es la inscripción en el Banco Único de Usuarios del Recurso Hídrico (BUDURH). El $82 \%$ de las industrias relevadas, declara estar inscripto en el mismo como se describe en el Gráfico13.

\section{Inscripción en el BUDURH}

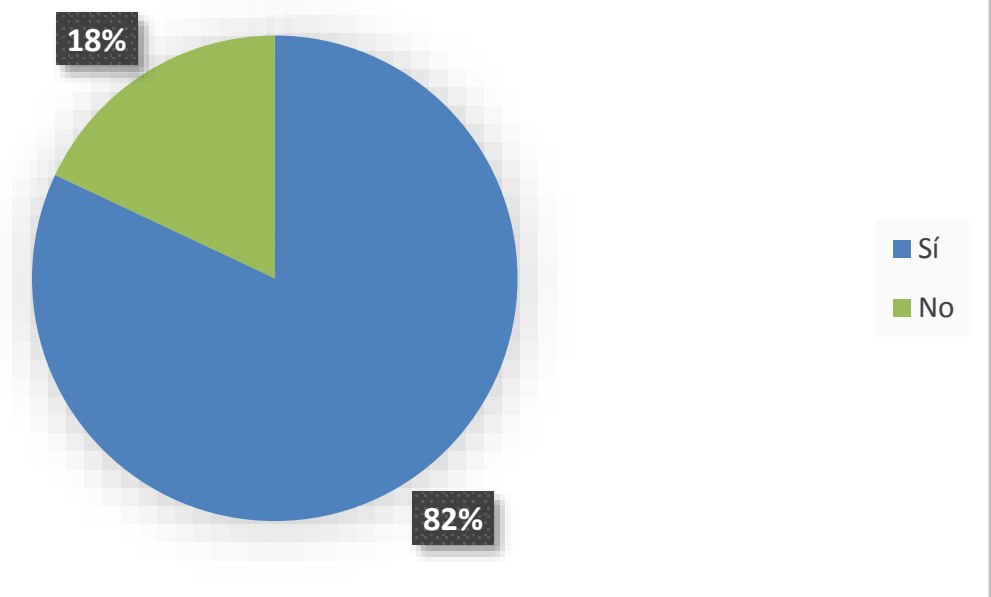

Gráfico 11. Inscripción en el BUDURH.

De las industrias que deben solicitar el Permiso de Explotación del Recurso Hídrico Subterráneo (ERHS), el 85 \% expresa que han iniciado el trámite, pero solo el $34 \%$ cuenta con el Permiso correspondiente vigente (Gráficos 14 y 15). 


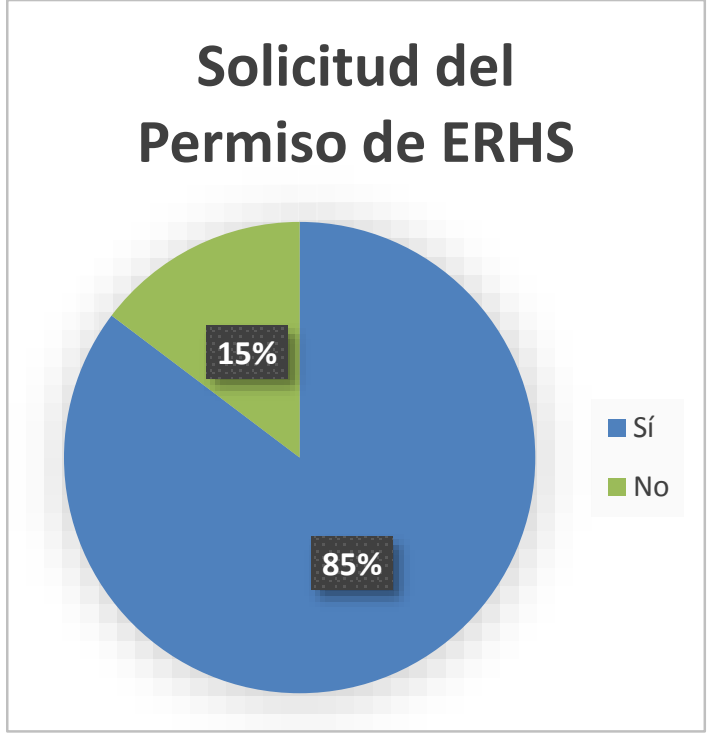

Gráfico 12. Solicitud del Permiso de Explotación del Recurso Hídrico Subterráneo.

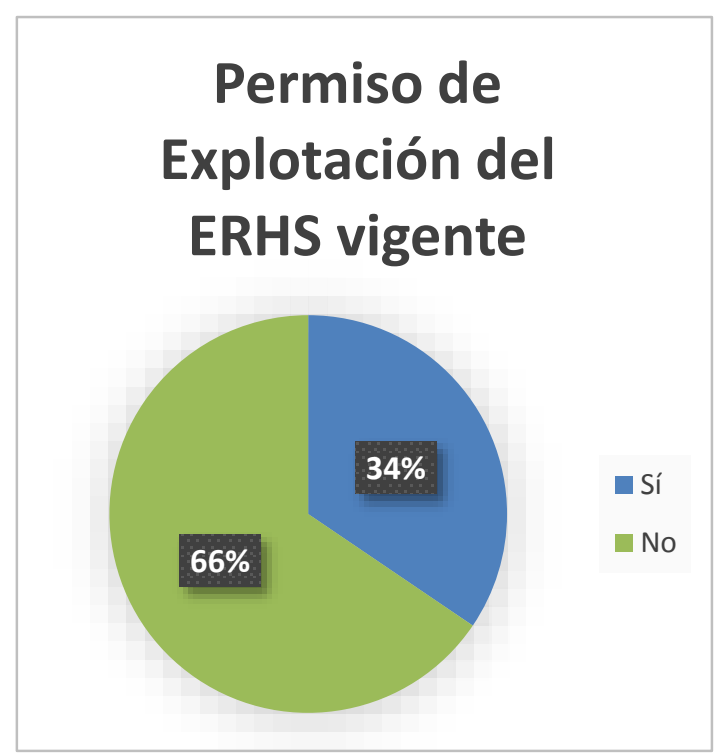

Gráfico 13. Permiso de Explotación del Recurso Hídrico Subterráneo vigente.

El $64 \%$ de las industrias relevadas declara tener una planta de tratamiento de efluentes líquidos como lo demuestra el Gráfico 16.

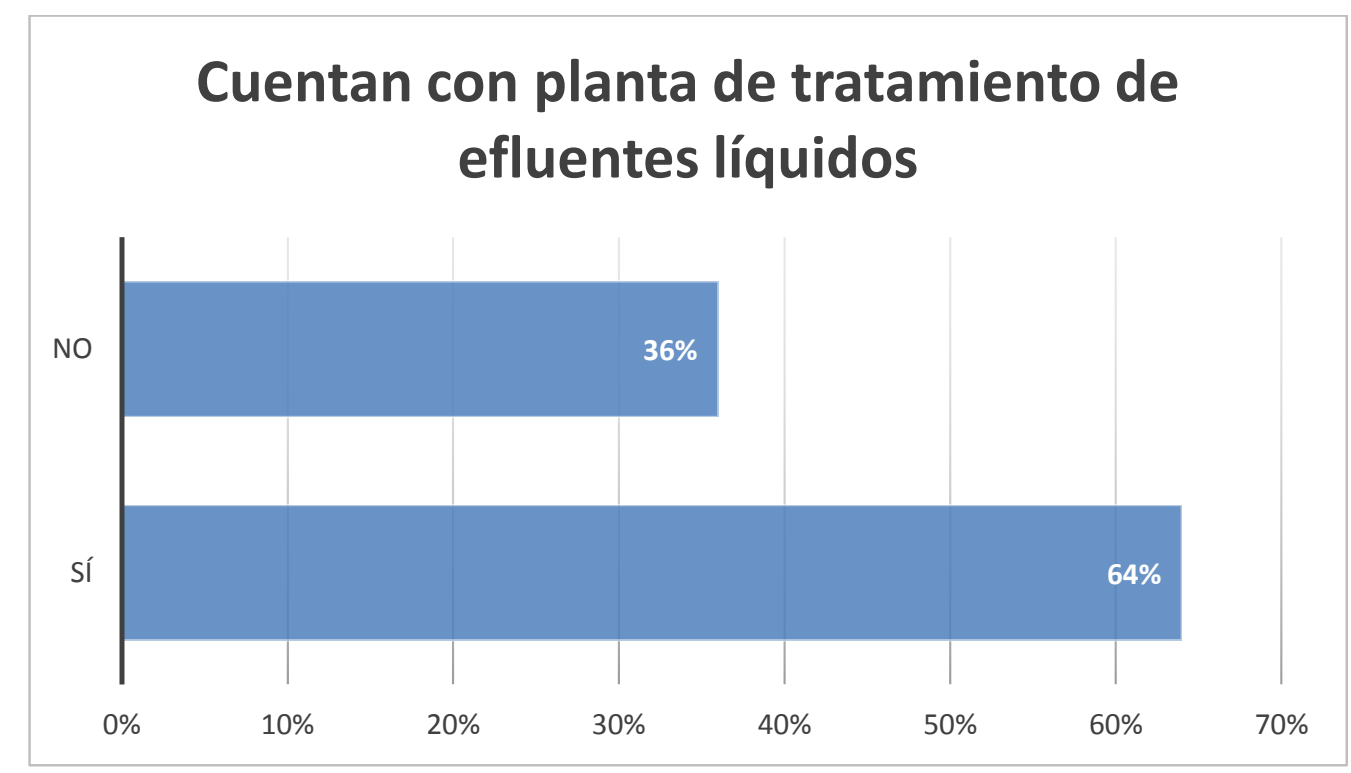

Gráfico 14. Cuentan con planta de tratamiento de efluentes líquidos.

Teniendo en cuenta que las industrias que tienen planta de tratamiento de efluentes líquidos deben realizar la Solicitud del Permiso de Vuelco correspondiente, encontramos que un alto porcentaje de las mismas (el 91 \%) ha iniciado dicho trámite como se ve en el Gráfico 17. Pero de estas industrias, 
se aprecia en el Gráfico 18 que solamente el $38 \%$ cuentan con el Permiso correspondiente emitido por ADA.

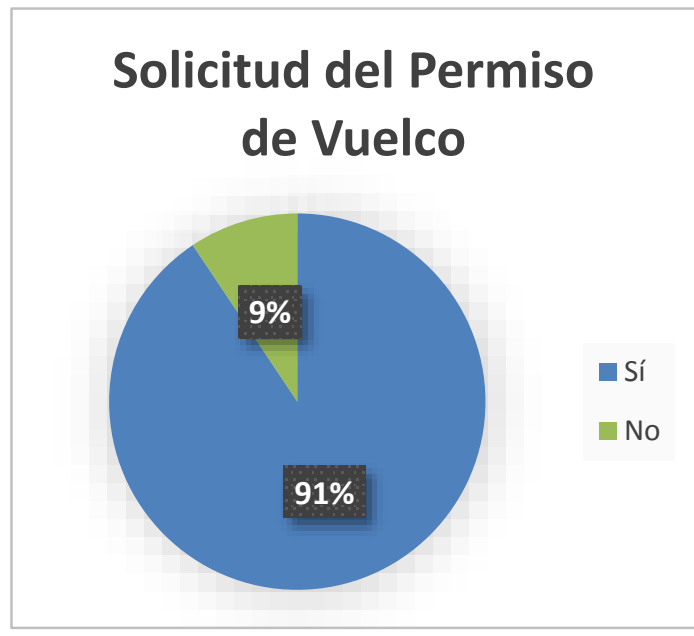

Gráfico 15. Solicitud del Permiso de Vuelco de Efluentes Líquidos previamente tratados.

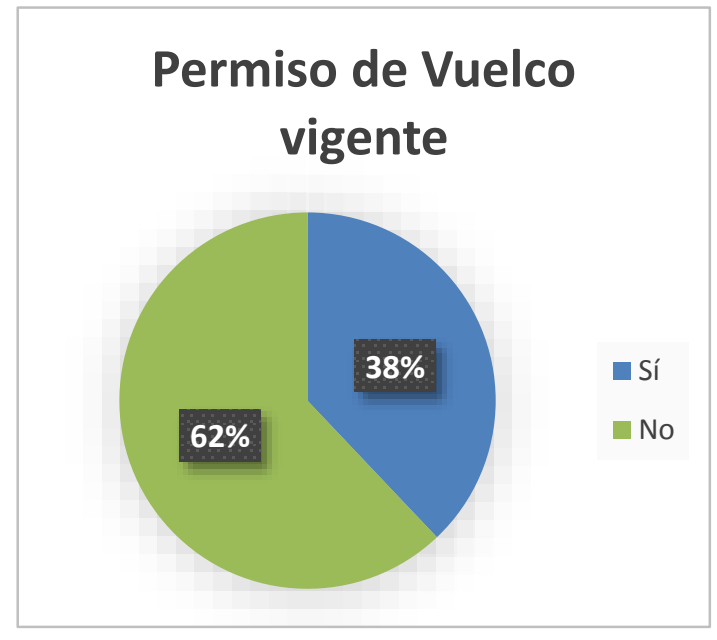

Gráfico 16. Otorgamiento del Permiso de Vuelco de Efluentes Líquidos previamente tratados.

\subsubsection{Sistemas de Gestión ISO y planes de RSE y/o Sustentabilidad}

En relación a la implementación de los sistemas de Gestión ISO, en el Gráfico 19 se desprende que el $48 \%$ expresó contar con alguno de ellos. De estas industrias, el Gráfico 20 muestra que el $92 \%$ declaró contar con la certificación ISO 9001. Además de esta, el $54 \%$ también cuenta con la certificación ISO 14001. 


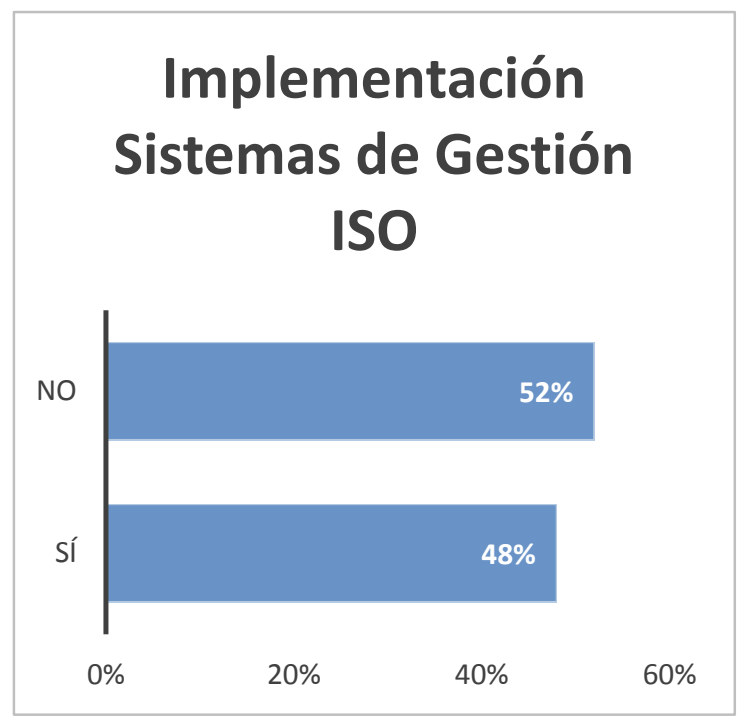

Gráfico 17. Implementación de Sistemas de Gestión ISO.

\section{Sistemas de Gestión ISO Implementados}

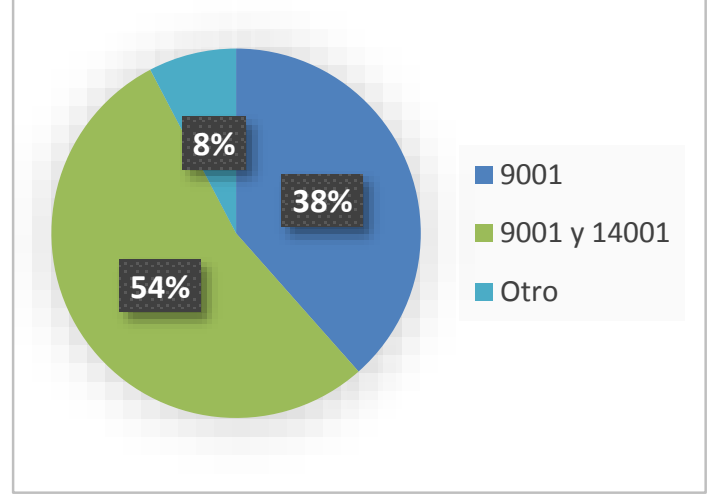

Gráfico 18. Sistemas de Gestión ISO implementados.

Las industrias que declararon contar con algún sistema de Gestión ISO, expresaron que obtienen algún beneficio asociado a la implementación de la misma (Gráfico 21). Al consultar con cuáles actores identificaban estos beneficios, en el Gráfico 22 se observa que el $33 \%$ lo relacionó con los clientes. Con la autoridad de aplicación, empleados y proveedores lo relacionó el $26 \%, 21 \%$ y $14 \%$ respectivamente, mientras que solo el $5 \%$ lo hizo con los competidores. 


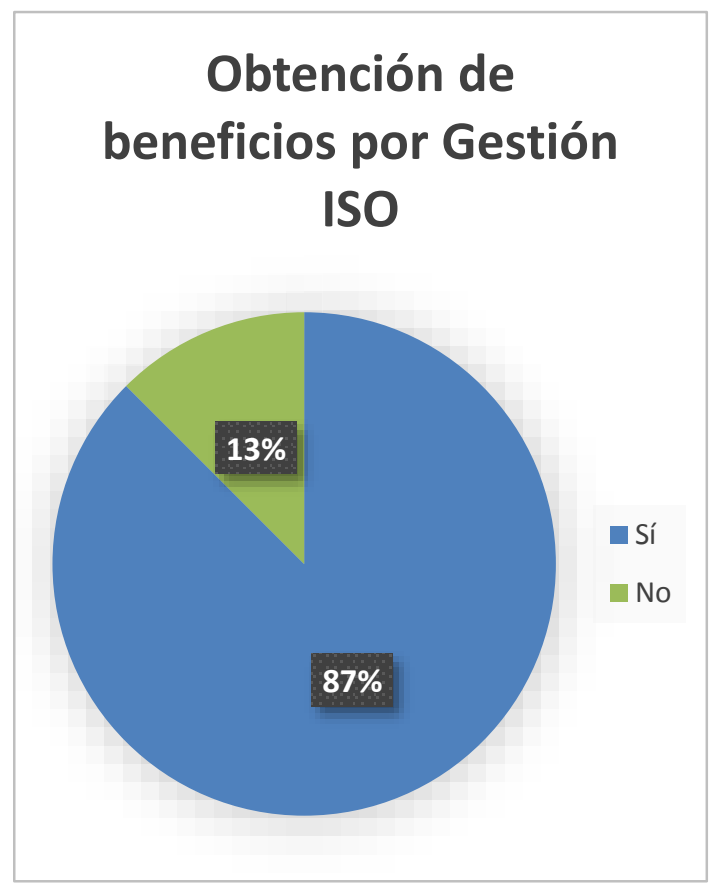

Gráfico 19. Obtención de beneficios en relación a la implementación de Sistemas de Gestión ISO.

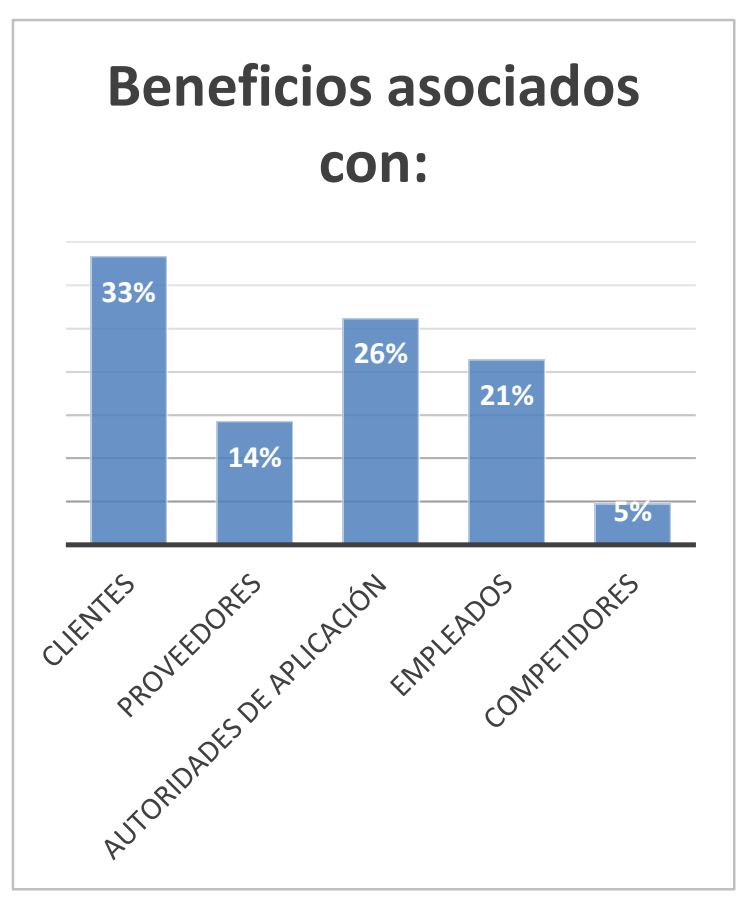

Gráfico 20. Beneficios obtenidos en relación a la implementación de Sistemas de Gestión ISO.

Planes de Responsabilidad Social Empresaria (RSE) y/o de Sustentabilidad, fueron implementados por el $32 \%$ de las industrias reveladas (Gráfico 23). De estas, en el Gráfico 24 se observa que el 69\% expresa que los mismos los realizan dentro de la propia empresa de forma informal, sin contratar servicios externos ni realizar certificaciones específicas (como por ejemplo GRI). 


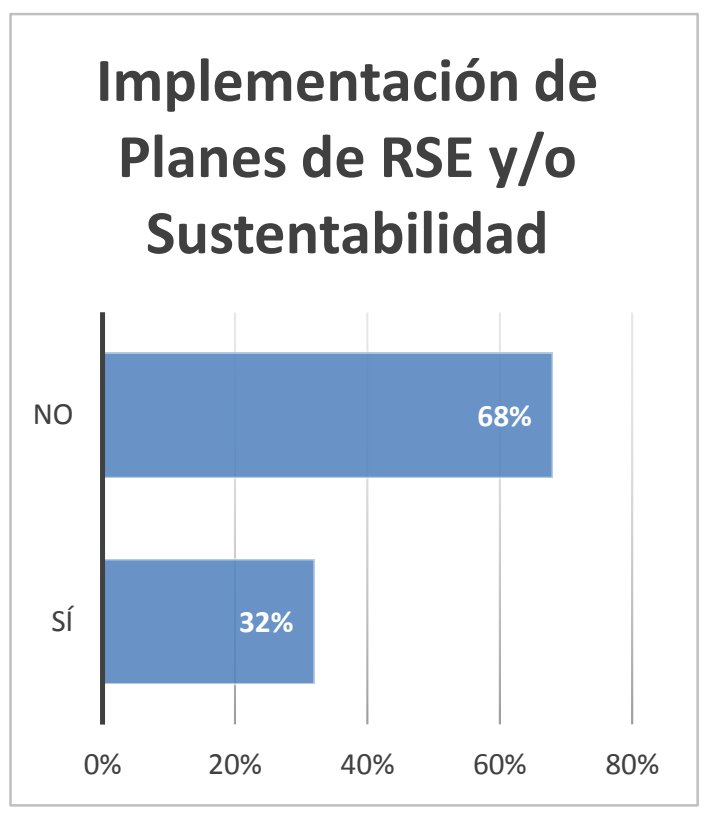

Gráfico 21. Implementación de Planes de RSE y/o Sustentabilidad.

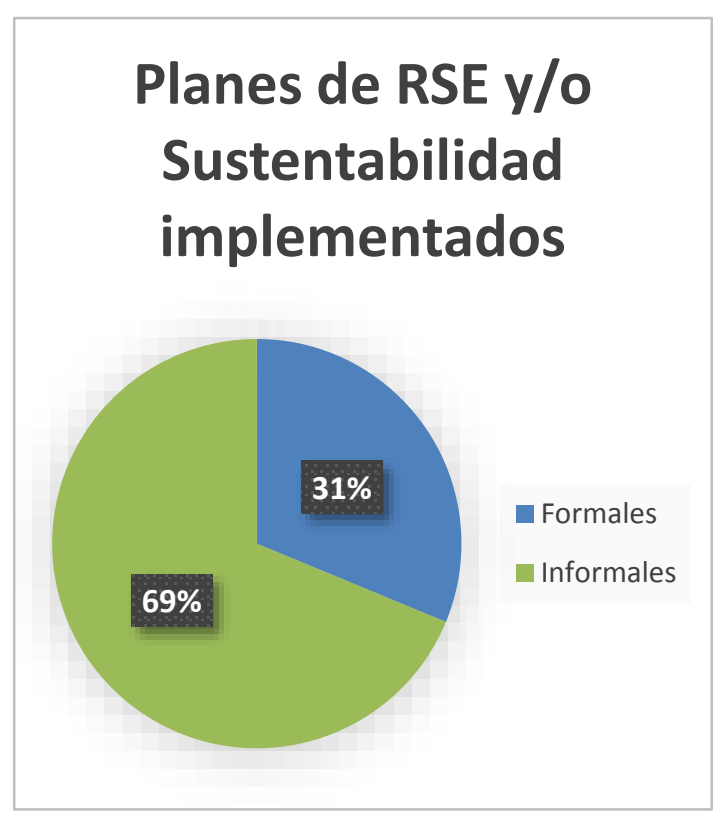

Gráfico 22. Tipos de planes de RES y/o Sustentabilidad implementados.

De los que tienen implementados Planes de RSE y/o Sustentabilidad, el $100 \%$ expuso que obtuvieron algún beneficio asociado. De estos, en sintonía con lo expresado por las empresas que tienen implementados sistemas de Gestión ISO, en el Gráfico 25 se expresa que el mayor beneficio lo identifican con los clientes (39\%) mientras que el menor con los competidores (7\%). Con empleados, proveedores y autoridades de aplicación lo relacionaron el $24 \%$, $21 \%$ y $14 \%$ respectivamente. 


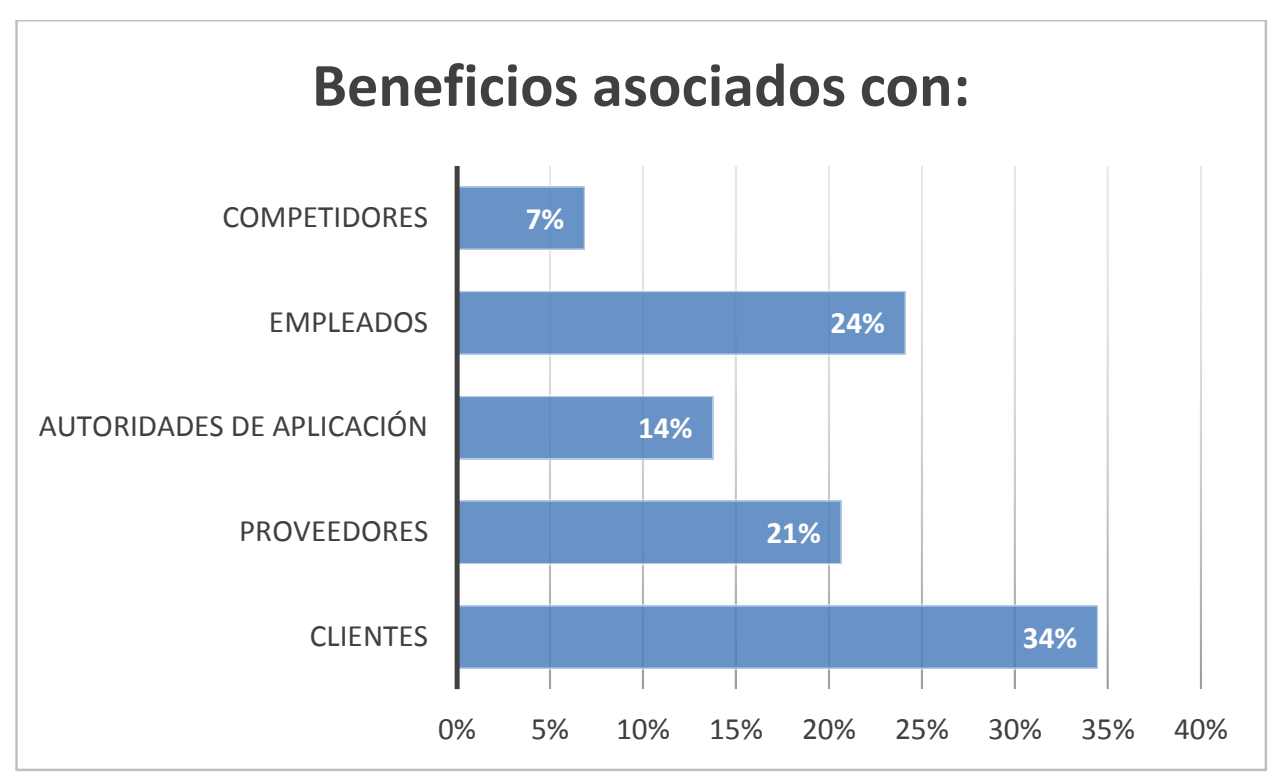

Gráfico 23. Beneficios obtenidos en relación a la implementación de planes de RSE y/o Sustentabilidad.

\subsubsection{Gestión Ambiental General}

En relación a los Recursos Humanos (RRHH) dedicados a la Gestión Ambiental en las industrias de primera categoría, se encuentra que el $60 \%$ no disponen de los mismos en forma exclusiva ni general. El resto de las industrias declaran tener 1 recurso humano de forma exclusiva.

El $39 \%$ de las industrias de segunda categoría expresan que cuentan solamente con una persona dedicada a la Gestión Ambiental pero no de forma exclusiva ya que cumplen otras funciones y solo parte de su tiempo le dedican a la misma. El $22 \%$ no tienen ningún recurso humano interno que se dedique a la gestión ambiental. El $17 \%$ declara tener dos personas, uno de forma exclusiva y uno de forma no exclusiva. Dos personas en forma no exclusiva declaran tener el $11 \%$, mientras que dos personas en forma no exclusiva y dos en forma exclusiva declaran tener el $6 \%$ de las industrias relevadas. Por último, se da el caso de que tienen 10 personas dedicadas de forma no exclusiva y dos de forma exclusiva (Gráfico 26). 


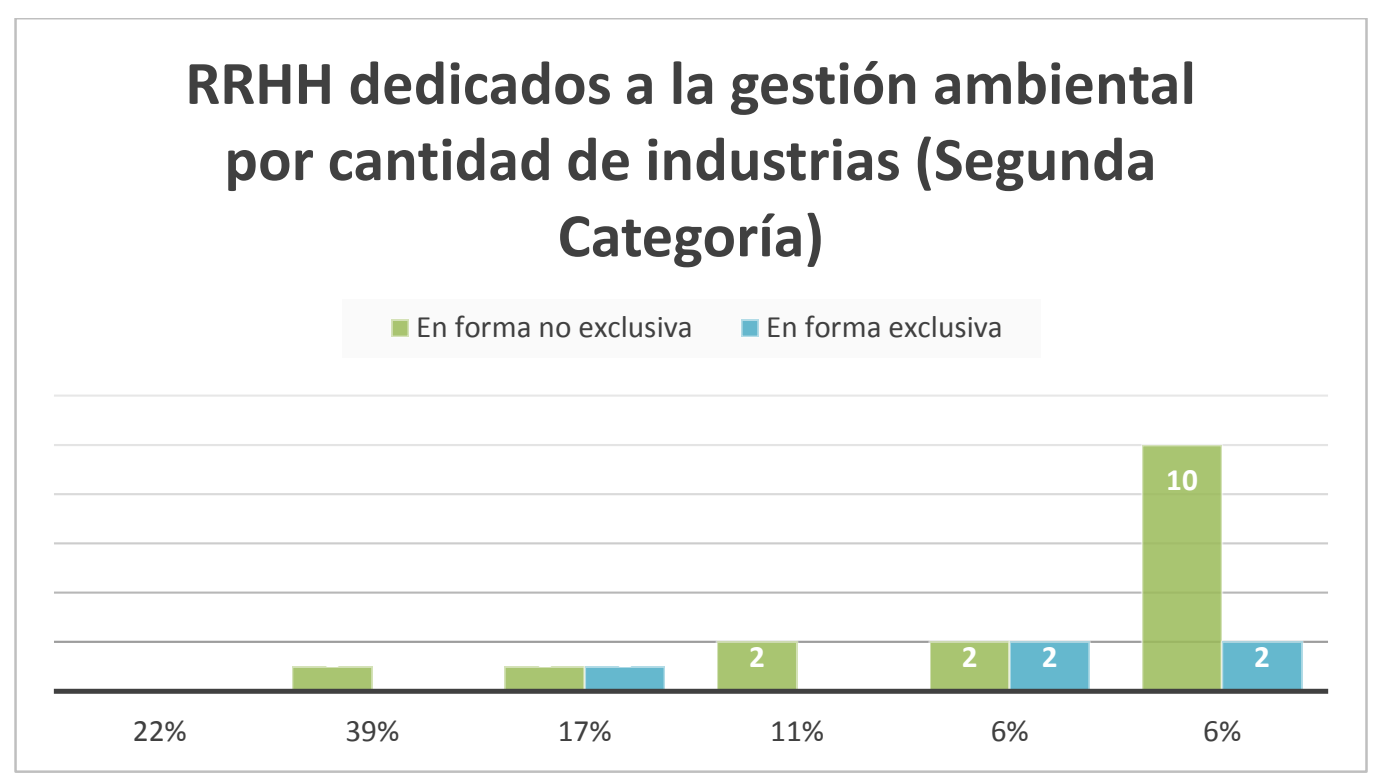
Categoría.

Gráfico 24. RRHH dedicados a la Gestión Ambiental en Industrias de Segunda

El relevamiento mostró que las industrias de tercera categoría difieren más aún en cuanto a la variación de recursos humanos dedicados a la gestión ambiental. Más allá de esto, en el Gráfico 27 se observa que la mayoría de las industrias (22\%) declararon que no cuentan con personas internas dedicadas a la misma. El $15 \%$ cuentan con una persona en forma no exclusiva y uno en forma exclusiva. El resto de las variaciones de personal ocupado para estas tareas, lo podemos encontrar detallado en el siguiente gráfico.

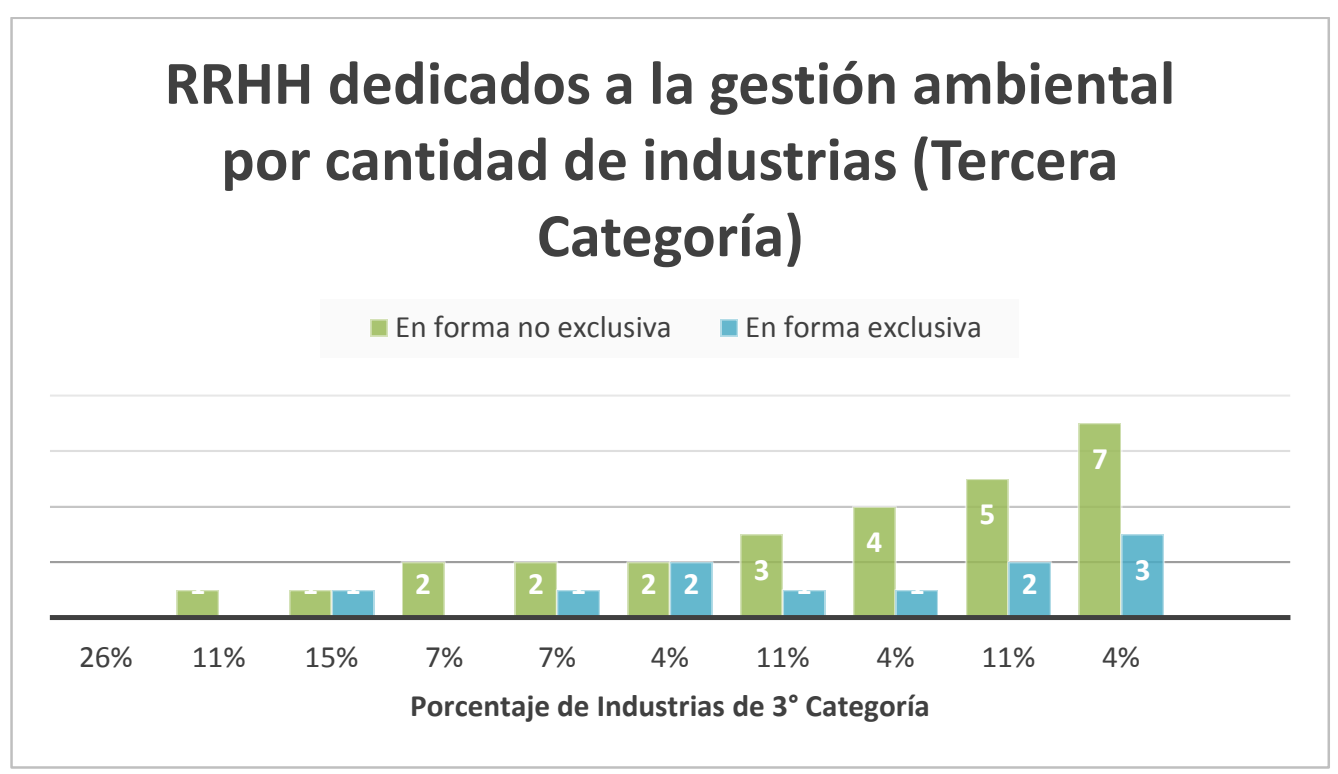

Gráfico 25. RRHH dedicados a la Gestión Ambiental en Industrias de Tercera Categoría. 
Comparando los resultados obtenidos entre las industrias de segunda y tercera categoría, más allá de encontrar mayor variedad en estas últimas (motivo que puede deberse en relación a que fueron más cantidad las relevadas), encontramos una diferencia en relación a la mayor dedicación de RRHH en las de mayor complejidad. Solo el $12 \%$ de las industrias de segunda categoría declara tener tres o más personas, mientras que la misma cantidad la declara el $41 \%$ de las industrias de tercera categoría.

Las industrias deben contratar distintos servicios para cumplir con el mantenimiento de una Gestión Ambiental eficiente ya que por más que cuenten con recursos humanos internos que se dediquen a la misma, no es posible que puedan cumplir de manera autónoma con todas las acciones necesarias.

Al consultar cuáles servicios contratan (Gráfico 28), y teniendo en cuenta que cada industria podía contestar más de una opción y por lo tanto los porcentajes están expresados según la totalidad de las mismas y no solo de la sumatoria de opciones, encontramos que el $86 \%$ contratan algún servicio de consultoría y asesoramiento externo (el $44 \%$ un servicio integral mientras que el $42 \%$ para cada tema puntual). Además, el $80 \%$ contrata servicios de laboratorio de análisis ambientales para cumplir con sus monitoreos periódicos. Los menores porcentajes obtenidos se relacionan a la contratación de implementación y mantenimiento de sistemas de gestión ISO y de planes de Responsabilidad Social Empresaria (RSE) y/o Sustentabilidad (un 8 \% para cada uno de estos servicios). Un solo caso expresó que no contratan ningún servicio externo. 


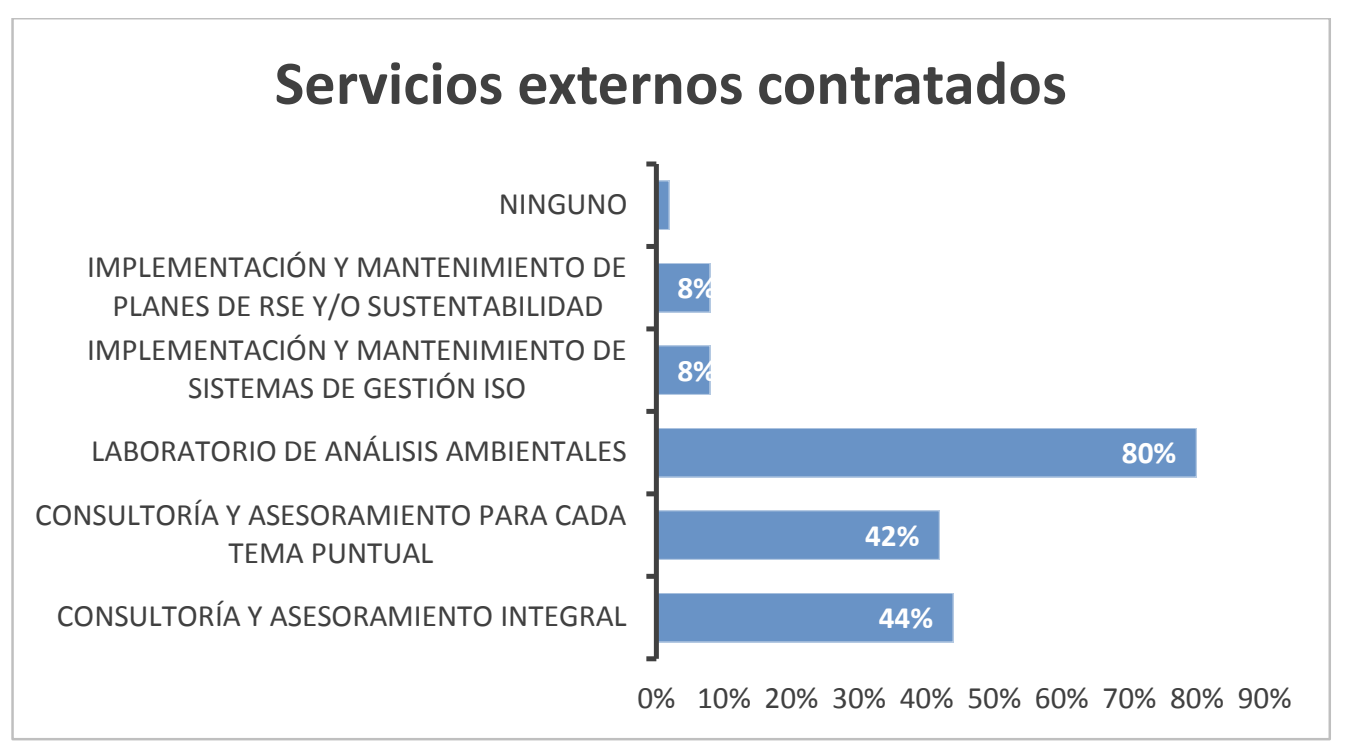

Gráfico 26. Servicios contratados para el mantenimiento de la Gestión Ambiental.

El $68 \%$ de las industrias relevadas, recibieron inspecciones de alguna de las autoridades de aplicación en el último año (Gráfico 29). De estas, el 50 \% declaró que las mismas fueron de rutina por parte de las áreas de fiscalización, mientras que el $41 \%$ para corroborar datos presentados previamente. En menor proporción, se debieron a denuncias y a otros motivos (Gráfico 30). 


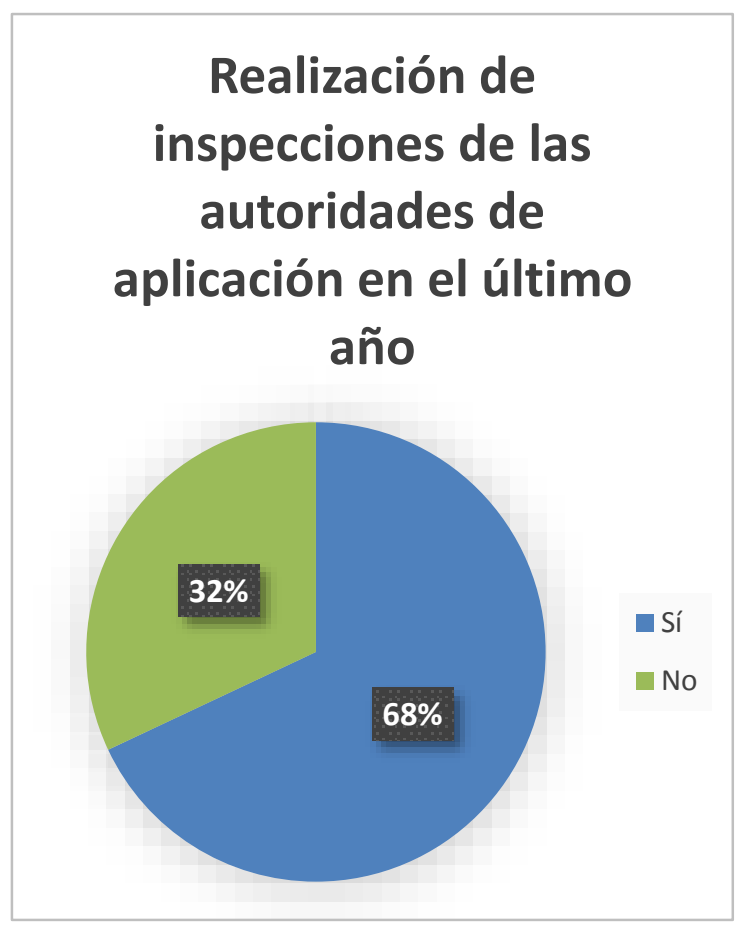

Gráfico 27. Realización de inspecciones de las autoridades de aplicación ambiental en el último año.

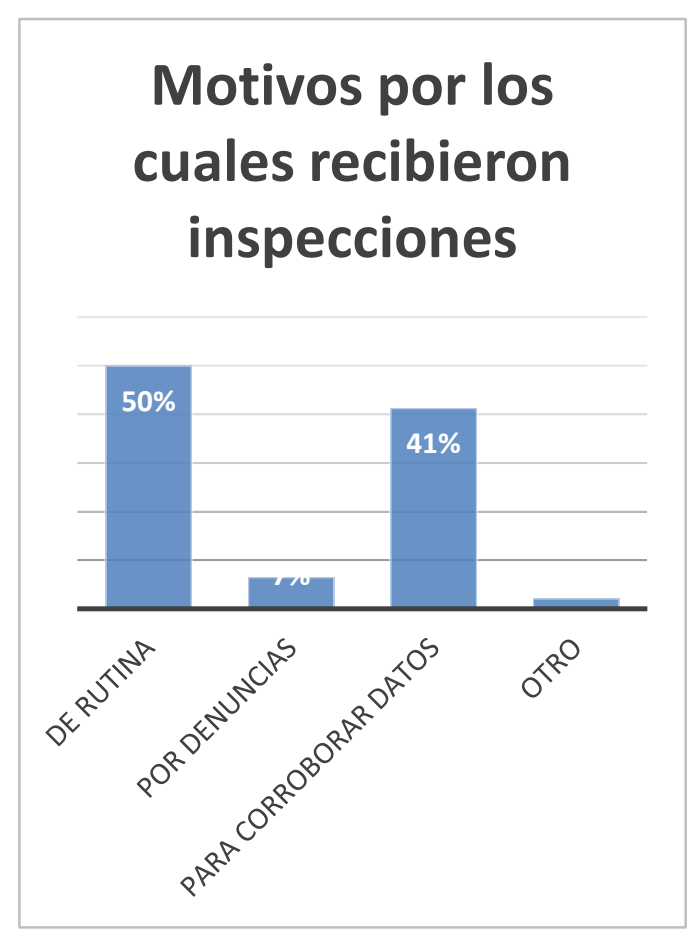

Gráfico 28. Motivos por los cuales recibieron inspecciones.

Para profundizar el análisis en relación a las industrias que recibieron inspecciones en el último año, se procedió a dividir las mismas según la categorización de OPDS. En este sentido, en el Gráfico 31 vemos grandes diferencias en relación a que el $85 \%$ de tercera categoría recibieron inspecciones, mientras que solo el $50 \%$ y $40 \%$ de las de segunda y primera respectivamente lo hicieron. 


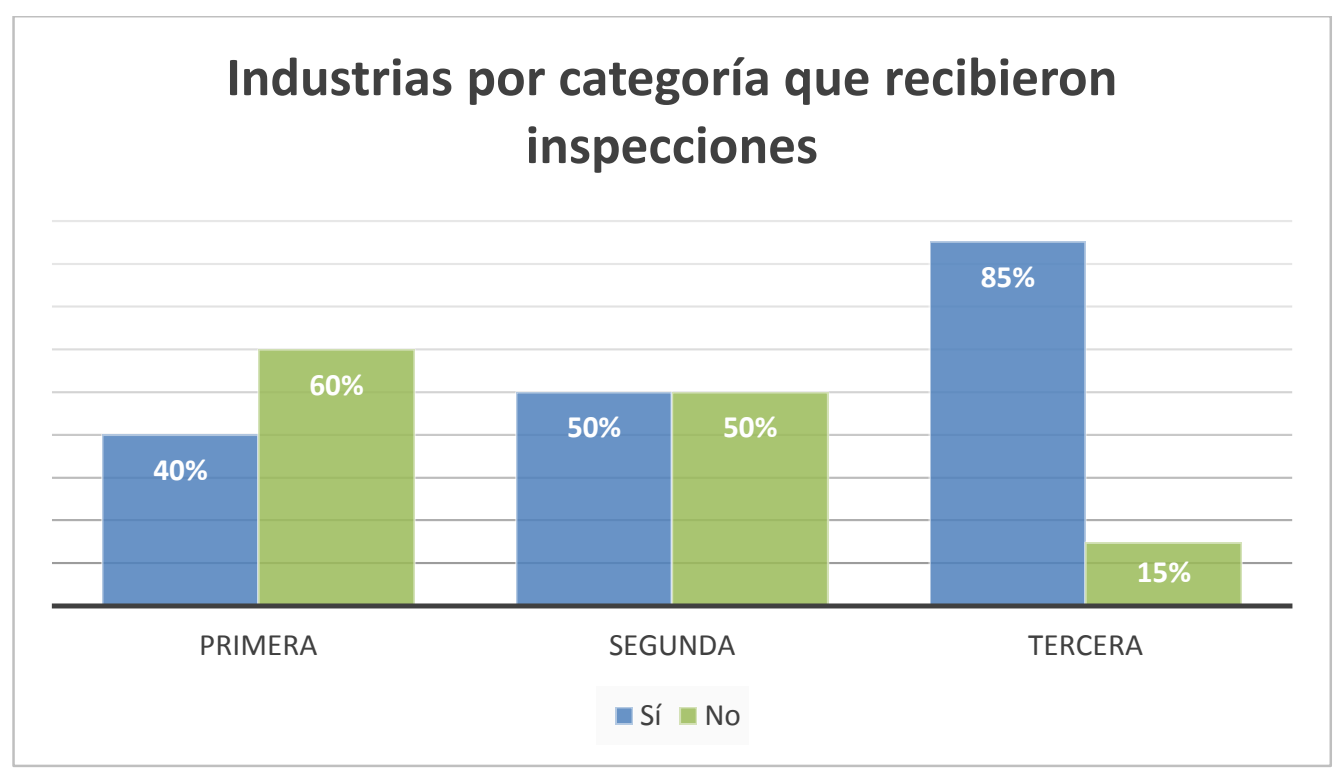

Gráfico 29. Porcentaje de inspecciones por Categoría, que recibieron inspecciones.

Al consultar los motivos por los cuales la empresa toma decisiones en relación a la Gestión Ambiental (Gráfico 32), el 62 \% expresa que se debe al cumplimiento de la normativa obligatoria y con el sentido de evitar sanciones (multas, clausuras, etc.).

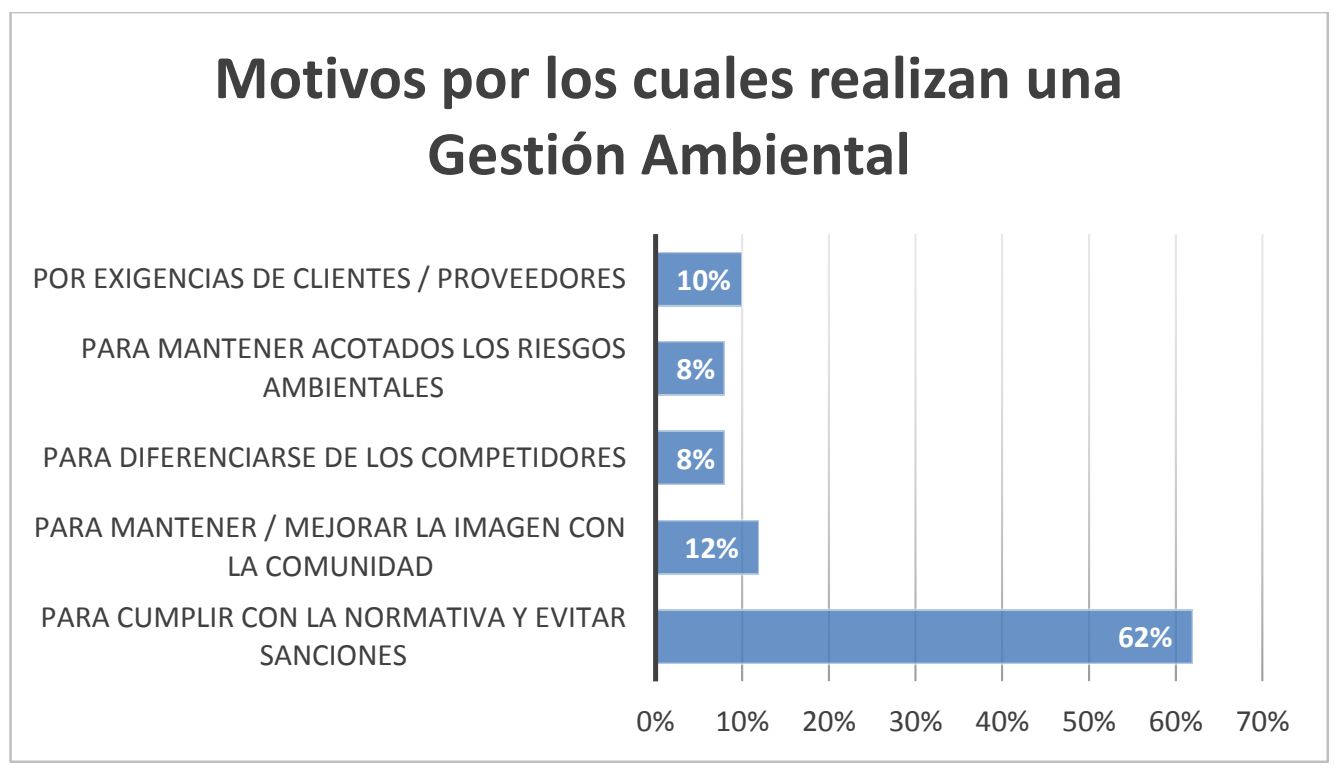

Gráfico 30. Motivos por los cuales realizan una Gestión Ambiental.

En este sentido, en el Gráfico 33 vemos coincidencias en cuanto al compromiso de las mayores autoridades de la empresa en relación a la Gestión Ambiental con los motivos por los cuales realizan la misma, ya que el $72 \%$ expresa que dichas autoridades se involucran en estos temas solo en el caso 
de recibir inspecciones y/o sanciones. El $22 \%$ expresa que se solicitan informes periódicos para realizar un seguimiento más cercano, mientras que el $6 \%$ afirma que en ningún caso las mayores autoridades se ven comprometidas con la Gestión Ambiental.

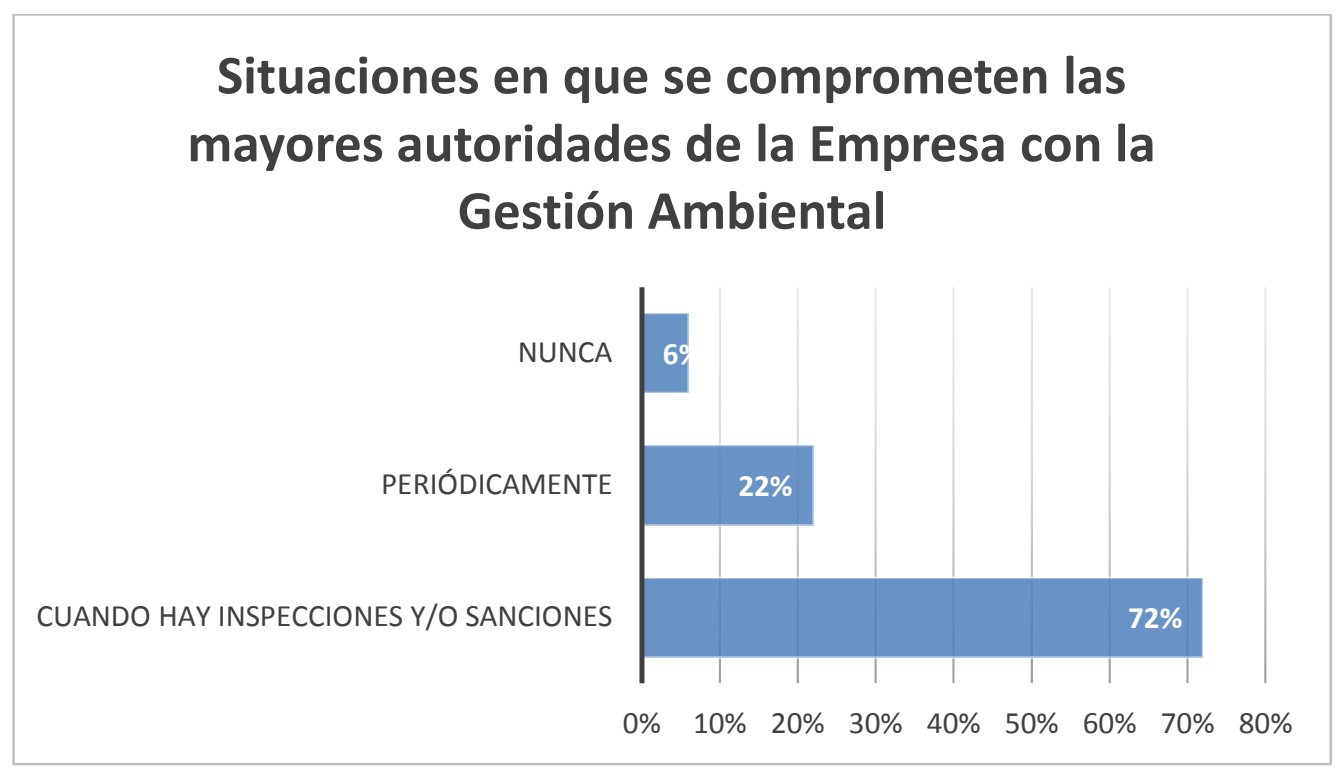

Gráfico 31. Situaciones en las que se comprometen las mayores autoridades de la Empresa con la Gestión Ambiental.

En cuanto al cumplimiento de la normativa en base a las presentaciones ante OPDS y ADA, en los Gráficos 34 y 35 se identifican diferencias significativas en relación a si son industrias de primera y segunda categoría o de tercera. El $70 \%$ de tercera categoría expresa que se encuentra con los trámites al día, mientras que solo el $43 \%$ de las de primera y segunda categoría afirma lo mismo. Otra diferencia sustancial, es que todas las industrias de las más complejas expresan que han realizado presentaciones en relación a estos temas. 


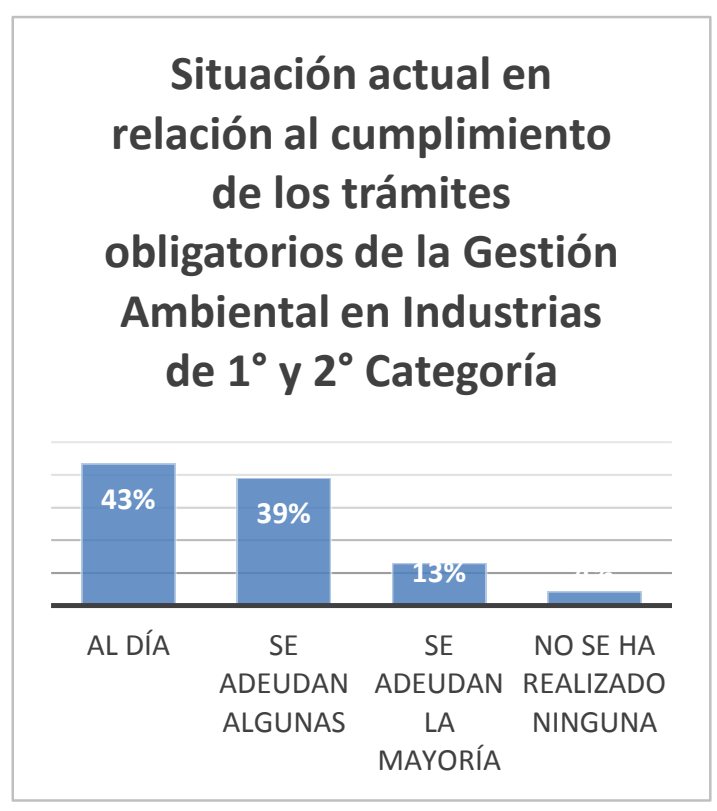

Gráfico 32. Situación actual en relación al cumplimiento de los trámites obligatorios de la Gestión Ambiental en Industrias de $1^{\circ}$ y $2^{\circ}$ Categoría.

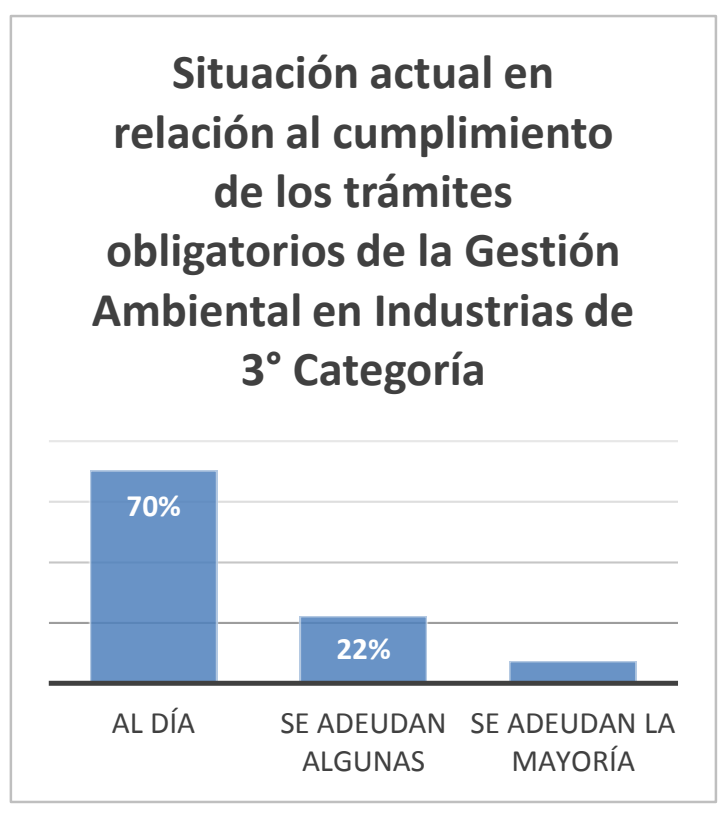

Gráfico 33. Situación actual en relación al cumplimiento de los trámites obligatorios de la Gestión Ambiental en Industrias de $3^{\circ}$ Categoría.

Comparando el estado de presentación de los distintos trámites con la facturación anual de las empresas, en el Gráfico 36 encontramos que respecto a las que facturan más de 50 millones de pesos al año, el $78 \%$ se encuentran al día, adeudan algunos trámites el $19 \%$ y la mayoría de los mismos el $4 \%$. Respecto a las que facturan menos de 50 millones de pesos al año, solo el 35 $\%$ se encuentran al día, mientras que la mayor cantidad de industrias expresa que adeudan al menos alguno de los trámites; la mayoría lo adeuda el $17 \%$, mientras que el $4 \%$ no ha realizado ninguno. 


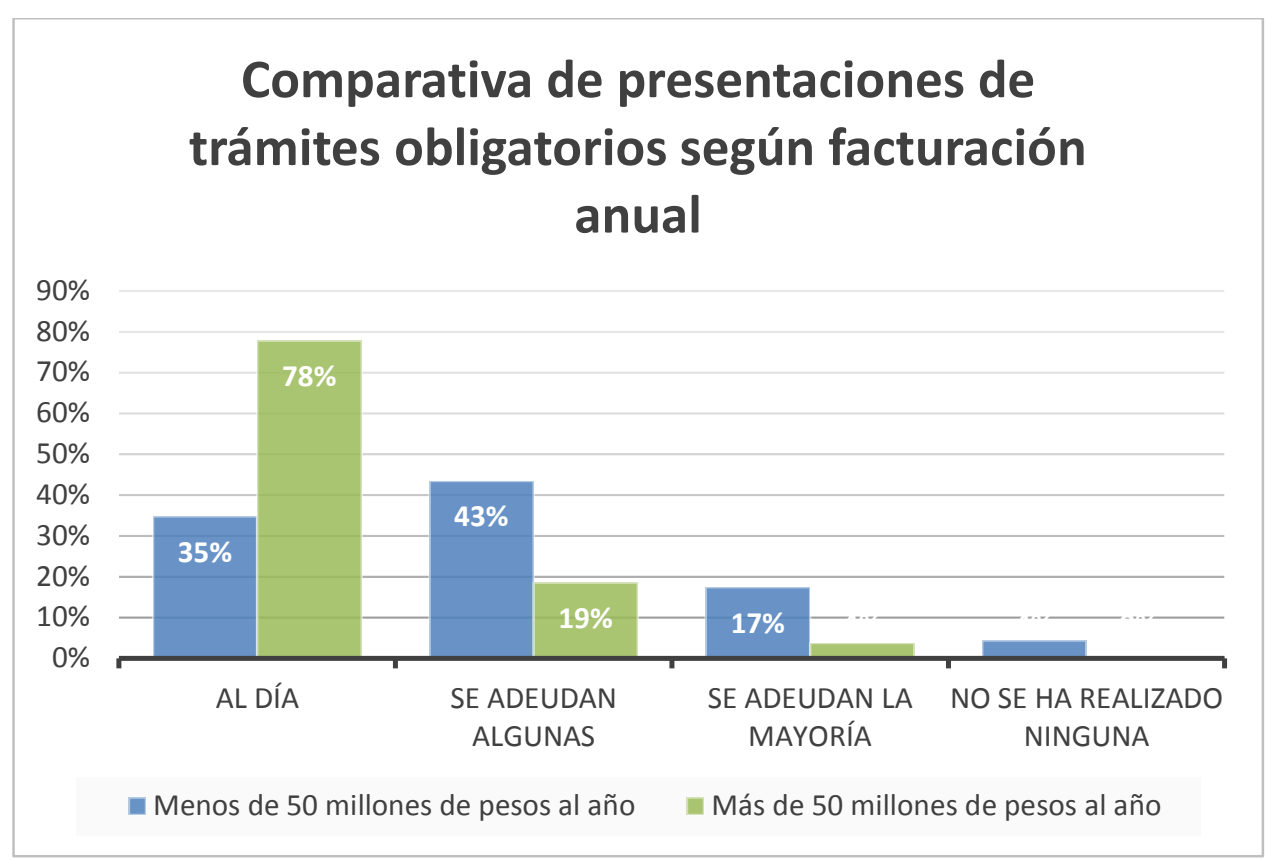
anual.

Gráfico 34. Comparativa de presentaciones de trámites obligatorios según facturación

Relacionando los gastos de la Gestión Ambiental con la facturación (ambas variables anualizadas), se encuentra en el Gráfico 37 que el $96 \%$ de las empresas que facturan menos de 50 millones de pesos tienen un gasto menor a 200 mil pesos. En relación a las empresas que facturan más de 50 millones de pesos, el gasto se encuentra más equilibrado entre las industrias que invierten más o menos de 200 mil pesos.

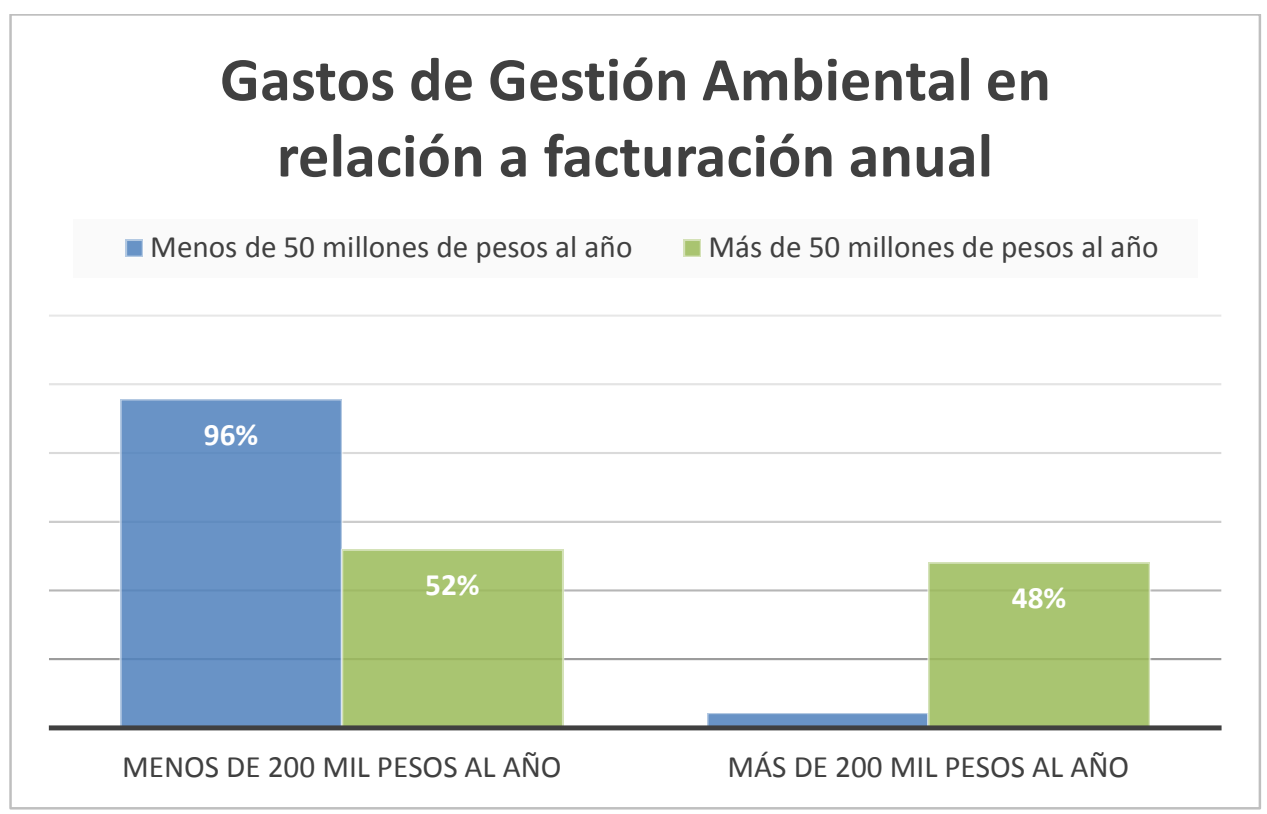

Gráfico 35. Gastos de Gestión Ambiental en relación a facturación anual. 
Entre las limitaciones que pueden presentarse para no llevar una Gestión Ambiental eficiente (Gráfico 38), el 48 \% declaró que se debe a falta de recursos económicos destinados al área específica y el $38 \%$ que se trata de decisiones empresariales. El $12 \%$ expresó que se debe a la falta de RRHH capacitados mientras que el $2 \%$ expuso otras explicaciones. Vale aclarar que ninguna industria expresó que estas limitaciones se debían a la falta de asesoramiento.

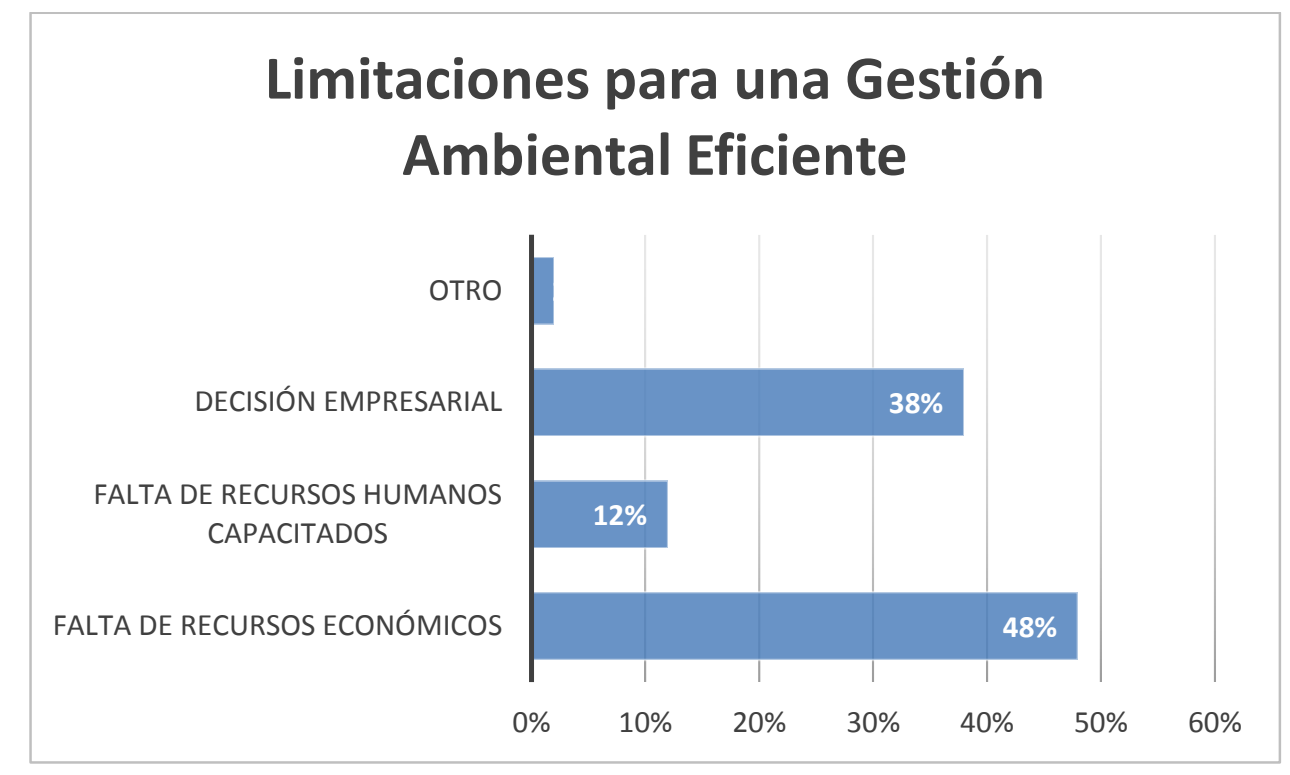

Gráfico 36. Limitaciones para una Gestión Ambiental eficiente.

Teniendo en cuenta la relación entre la empresa con clientes y proveedores, se consultó si reciben auditorías por parte de estos en las que realicen controles sobre la Gestión Ambiental, así como si vieron afectada de manera negativa la relación por ineficiencias con la misma. Según se observa en los Gráficos 39 y 40, el 42 \% expresó que sí les realizan auditorías periódicas, y de estos el 19 \% declaró que se vio afectada de manera negativa su relación. De los que no recibieron auditorías, ninguno declaró haber tenido problemas como consecuencia de la Gestión Ambiental. 


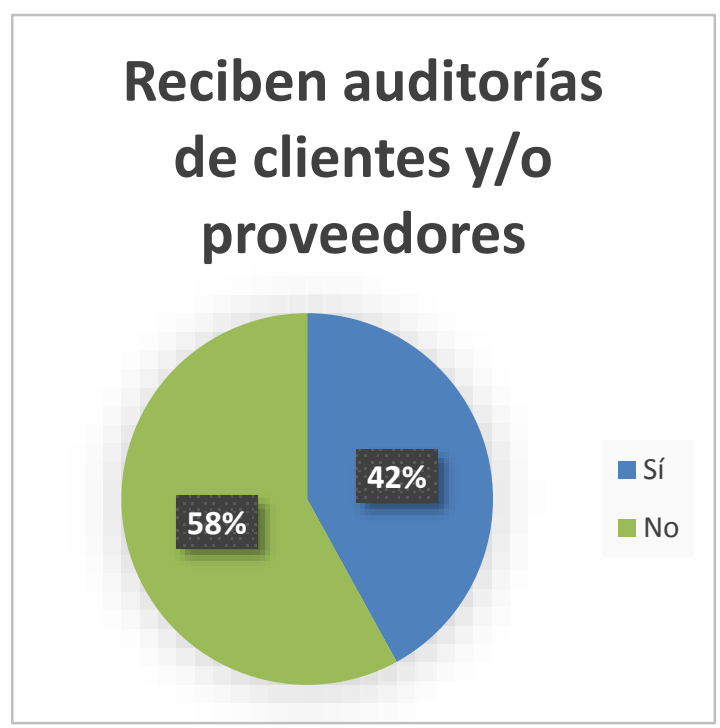

Gráfico 37. Reciben auditorías de clientes y/o proveedores.

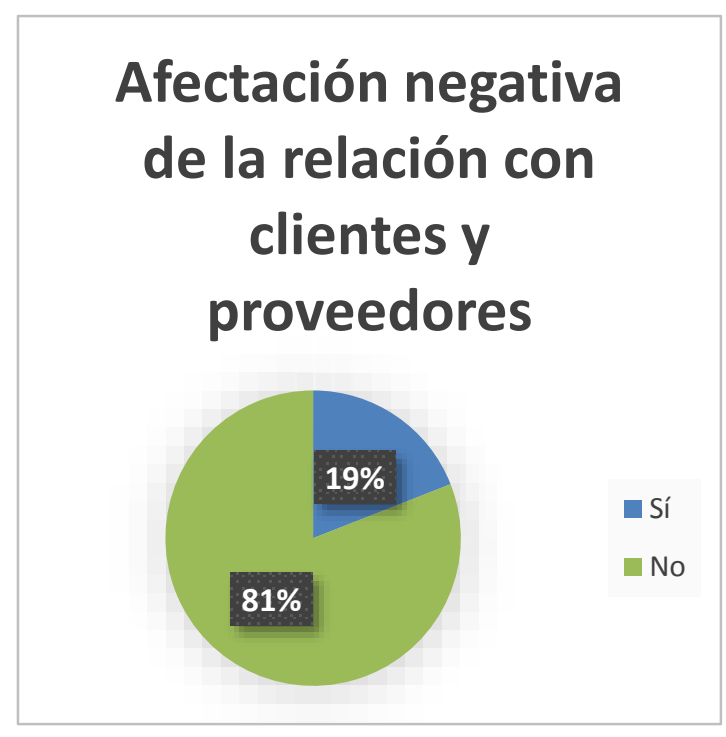

Gráfico 38. Afectación negativa de la relación con clientes y/o proveedores como consecuencia de una Gestión Ambiental ineficiente.

Al consultar si tuvieron conflictos con la comunidad como consecuencia de una Gestión Ambiental ineficiente, el $16 \%$ declaró que sí los han tenido y que los mismos han generado gastos económicos adicionales para poder mitigarlos (Gráfico 41).

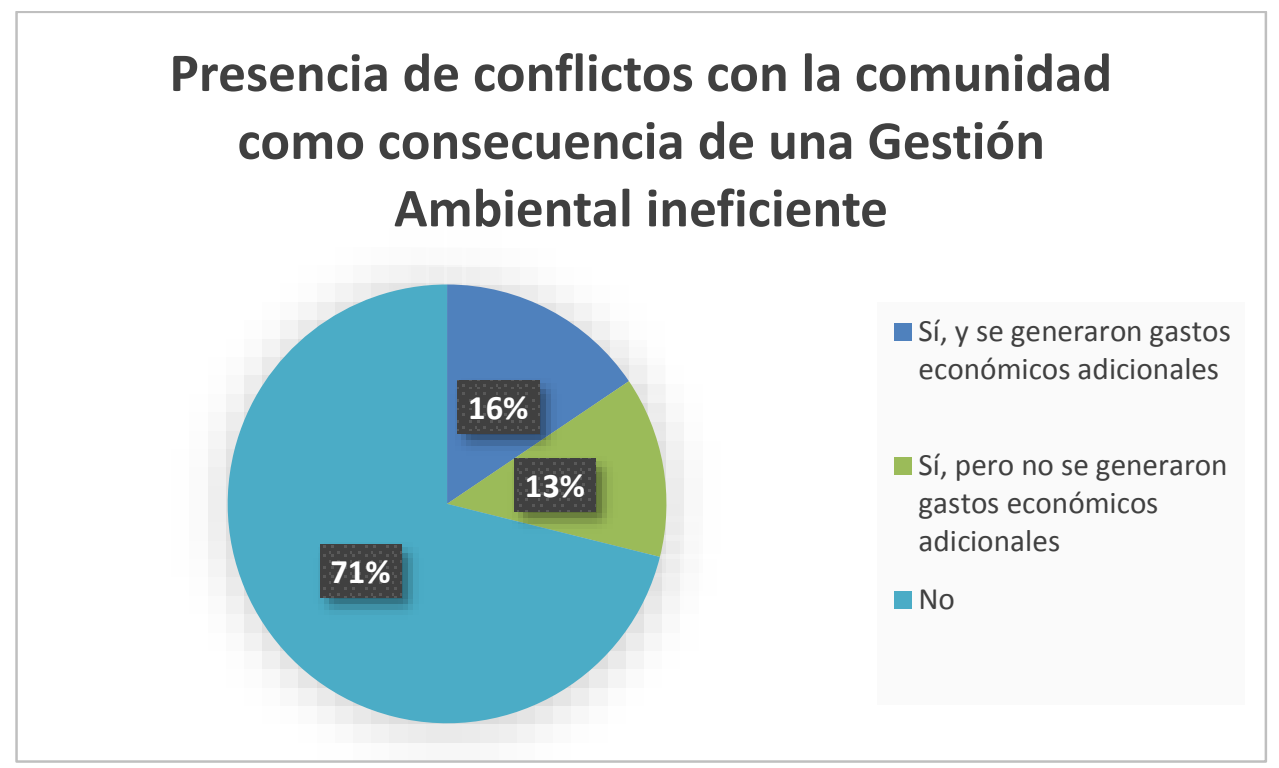

Gráfico 39. Presencia de conflictos con la comunidad como consecuencia de una Gestión Ambiental ineficiente. 
Respecto a si conocen cuales son las responsabilidades civiles y/o penales de las personas que ocupan puestos claves de la Gestión Ambiental, en el Gráfico 42 se observa que el 50 \% declaró conocerlos parcialmente (40 $\%)$ o directamente no conocerlos (10\%).

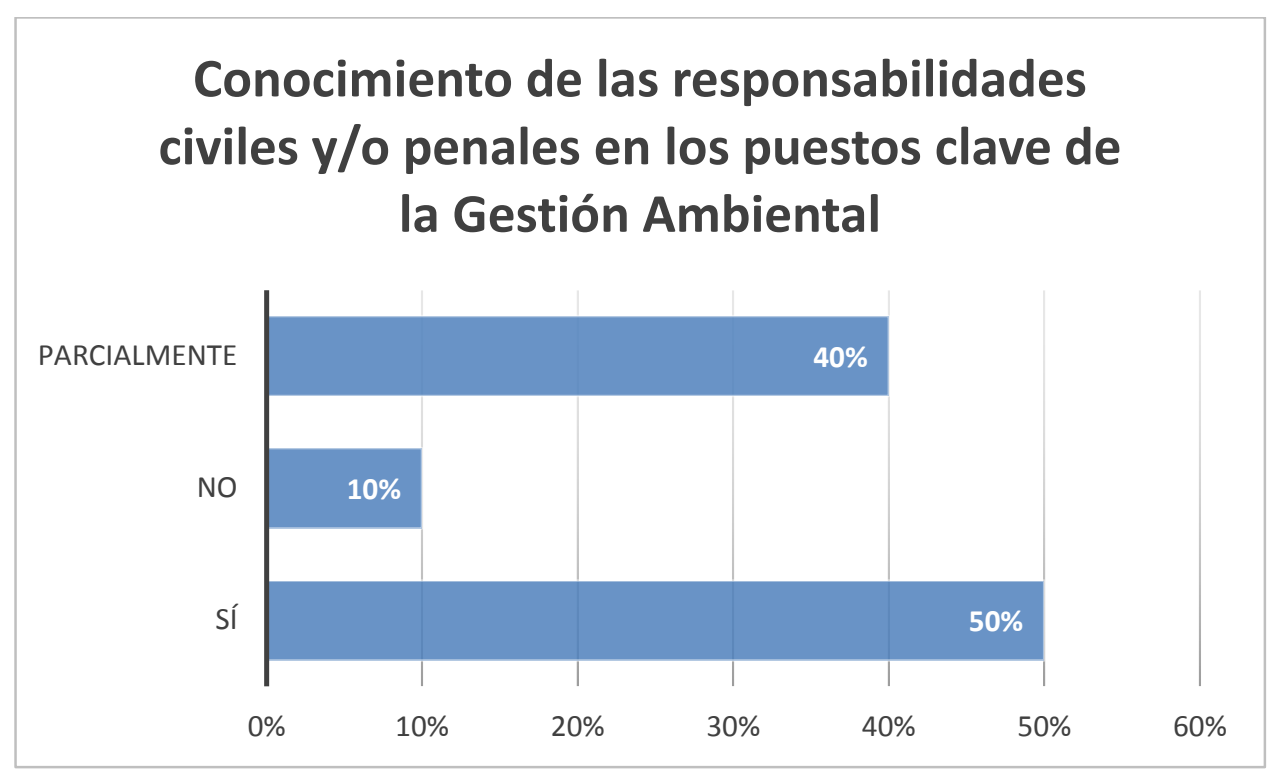

Gráfico 40. Conocimiento de responsabilidades civiles y/o penales en los puestos clave de la Gestión Ambiental.

\subsubsection{Grados de compromiso de la gestión empresarial general con la gestión ambiental}

Para determinar el compromiso de la gestión empresarial general con la Gestión Ambiental, se creó un índice denominado "Grado de Compromiso" expresado en la Tabla 1. Para obtener el mismo, se procedió a comparar cada una de las 50 industrias que respondieron la encuesta, con valores obtenidos de las siguientes 5 variables (cuyos valores individuales se expresaran en los apartados anteriores):

1. inversión realizada en gestión ambiental teniendo en cuenta la facturación anual,

2. situación actual de los trámites obligatorios,

3. realización de acciones complementarias,

4. participación de los responsables máximos de la empresa,

5. principales limitaciones que no permiten cumplir con una gestión ambiental eficiente. 
Cada una de estas variables, se tabuló con valores entre 1 (compromiso mínimo) y 5 (compromiso máximo) en función de la siguiente descripción:

Tabla 1. Detalle de posibles valores para tabular variables en la determinación del Grado de Compromiso por Industria.

\begin{tabular}{|c|c|c|c|}
\hline Variable & Características & $\begin{array}{l}\text { Posibles } \\
\text { valores }\end{array}$ & Detalle \\
\hline \multirow{8}{*}{$\begin{array}{c}\text { Inversión } \\
\text { realizada en } \\
\text { gestión ambiental } \\
\text { teniendo en } \\
\text { cuenta la } \\
\text { facturación anual. } \\
\text { Variable } A \text {. }\end{array}$} & \multirow{3}{*}{$\begin{array}{c}\text { Industrias que } \\
\text { facturan menos de } \\
50 \text { millones de } \\
\text { pesos al año }\end{array}$} & 1 & $\begin{array}{l}\text { Inversión menor a } 100 \text { mil } \\
\text { pesos al año }\end{array}$ \\
\hline & & 3 & $\begin{array}{l}\text { Inversión entre } 100 \text { y } 200 \\
\text { mil pesos al año }\end{array}$ \\
\hline & & 5 & $\begin{array}{c}\text { Inversión mayor a } 200 \text { mil } \\
\text { pesos al año }\end{array}$ \\
\hline & \multirow{5}{*}{$\begin{array}{l}\text { Industrias que } \\
\text { facturan más de } \\
50 \text { millones de } \\
\text { pesos al año }\end{array}$} & 1 & $\begin{array}{l}\text { Inversión menor a } 100 \text { mil } \\
\text { pesos al año }\end{array}$ \\
\hline & & 2 & $\begin{array}{l}\text { Inversión entre } 100 \text { y } 200 \\
\text { mil pesos al año }\end{array}$ \\
\hline & & 3 & $\begin{array}{l}\text { Inversión entre } 200 \text { y } 300 \\
\text { mil pesos al año }\end{array}$ \\
\hline & & 4 & $\begin{array}{l}\text { Inversión entre } 300 \text { y } 500 \\
\text { mil pesos al año }\end{array}$ \\
\hline & & 5 & $\begin{array}{l}\text { Inversión mayor a } 500 \text { mil } \\
\text { pesos al año }\end{array}$ \\
\hline \multirow{4}{*}{$\begin{array}{c}\text { Situación actual } \\
\text { de los trámites } \\
\text { obligatorios. } \\
\text { Variable } B .\end{array}$} & \multirow{4}{*}{$\begin{array}{l}\text { En relación a la } \\
\text { presentación de } \\
\text { los trámites } \\
\text { obligatorios ante } \\
\text { OPDS y ADA }\end{array}$} & 1 & No se ha realizado ninguna \\
\hline & & 2 & Se adeudan la mayoría \\
\hline & & 3 & Se adeudan algunas \\
\hline & & 5 & Al día \\
\hline \multirow{5}{*}{$\begin{array}{c}\text { Realización de } \\
\text { acciones } \\
\text { complementarias. } \\
\text { Variable C. }\end{array}$} & \multirow{5}{*}{$\begin{array}{l}\text { Implementación } \\
\text { de Sistemas de } \\
\text { Gestión ISO y/o } \\
\text { Planes de RSE o } \\
\text { Sustentabilidad }\end{array}$} & 1 & $\begin{array}{l}\text { No cuentan con ningún de } \\
\text { los dos }\end{array}$ \\
\hline & & 2 & $\begin{array}{c}\text { Cuentan con alguno de los } \\
\text { dos }\end{array}$ \\
\hline & & 3 & $\begin{array}{c}\text { Cuentan con } \\
\text { implementación de una } \\
\text { norma ISO y planes de } \\
\text { RSE o Sustentabilidad } \\
\text { informal }\end{array}$ \\
\hline & & 4 & $\begin{array}{c}\text { Cuentan con } \\
\text { implementación de una } \\
\text { norma ISO y planes de } \\
\text { RSE o Sustentabilidad } \\
\text { formales }\end{array}$ \\
\hline & & 5 & $\begin{array}{c}\text { Cuentan con } \\
\text { implementación de al } \\
\text { menos dos normas ISO y } \\
\text { planes de RSE o } \\
\text { Sustentabilidad formales }\end{array}$ \\
\hline $\begin{array}{l}\text { Participación de } \\
\text { los responsables }\end{array}$ & $\begin{array}{l}\text { Situaciones en las } \\
\text { que se comprometen } \\
\text { la/s mayor/es }\end{array}$ & 1 & Nunca \\
\hline
\end{tabular}




\begin{tabular}{|c|c|c|c|}
\hline \multirow{4}{*}{$\begin{array}{c}\text { máximos de la } \\
\text { empresa. } \\
\text { Variable } D .\end{array}$} & \multirow{4}{*}{$\begin{array}{l}\text { autoridad/es de la } \\
\text { Empresa con la } \\
\text { Gestión Ambiental. }\end{array}$} & 2 & $\begin{array}{l}\text { Cuando hay sanciones } \\
\text { (multas / clausuras) }\end{array}$ \\
\hline & & 3 & $\begin{array}{c}\text { Cuando hay inspecciones / } \\
\text { intimaciones }\end{array}$ \\
\hline & & 4 & $\begin{array}{c}\text { Solicitan informes } \\
\text { periódicos }\end{array}$ \\
\hline & & 5 & La conocen al detalle \\
\hline \multirow{3}{*}{$\begin{array}{c}\text { Principales } \\
\text { limitaciones que } \\
\text { no permiten } \\
\text { cumplir con una } \\
\text { gestión ambiental } \\
\text { eficiente. } \\
\text { Variable } E .\end{array}$} & \multirow{3}{*}{$\begin{array}{l}\text { Principales causas } \\
\text { por las cuales se } \\
\text { presentan limitaciones } \\
\text { que lleven una } \\
\text { Gestión Ambiental } \\
\text { ineficiente. }\end{array}$} & 1 & Decisión empresarial \\
\hline & & 2 & $\begin{array}{l}\text { Falta de recursos } \\
\text { económicos }\end{array}$ \\
\hline & & 5 & $\begin{array}{c}\text { Falta de recursos humanos } \\
\text { capacitados }\end{array}$ \\
\hline
\end{tabular}

En la Tabla 2, se encuentran los resultados obtenidos al expresar los valores anteriormente mencionados para cada variable $(A, B, C, D$ y $E)$ en relación a las respuestas de cada industria. Asimismo, se aplicó un factor de ponderación para cada variable, en relación a la consideración de cómo se adaptaba la misma al concepto de "Compromiso de la Gestión Empresarial con la Gestión Ambiental". De este modo, luego de realizar la sumatoria de los valores ponderados, se obtuvo el índice denominado "Grado de compromiso" por Industria. Este índice, puede tomar valores de 1 a 5, en relación a un menor o mayor compromiso respectivamente.

Las industrias 1 a 5 , corresponden a establecimientos de primera categoría, mientras que de la 6 a 23 de segunda y de la 24 a 50 de tercera. 
Tabla 2. Determinación del Grado de Compromiso por Industria.

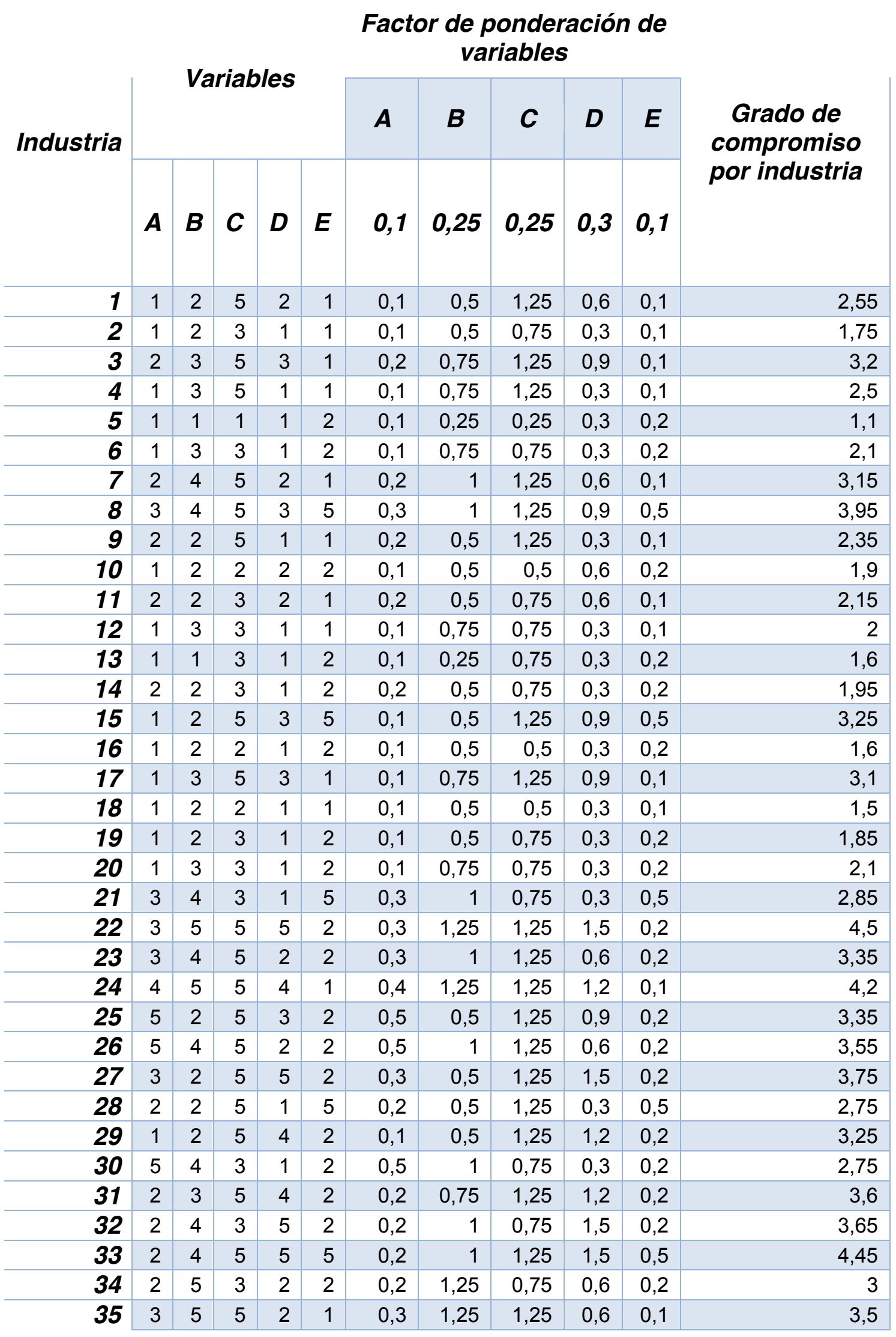




\begin{tabular}{r|r|r|r|r|r|r|r|r|r|r|r|}
\hline $\mathbf{3 6}$ & 1 & 2 & 5 & 1 & 2 & 0,1 & 0,5 & 1,25 & 0,3 & 0,2 & 2,35 \\
\hline $\mathbf{3 7}$ & 1 & 3 & 5 & 1 & 2 & 0,1 & 0,75 & 1,25 & 0,3 & 0,2 & 2,6 \\
\hline $\mathbf{3 8}$ & 1 & 3 & 5 & 1 & 1 & 0,1 & 0,75 & 1,25 & 0,3 & 0,1 & 2,5 \\
\hline $\mathbf{3 9}$ & 1 & 3 & 5 & 1 & 2 & 0,1 & 0,75 & 1,25 & 0,3 & 0,2 & 2,6 \\
\hline $\mathbf{4 0}$ & 1 & 3 & 5 & 1 & 2 & 0,1 & 0,75 & 1,25 & 0,3 & 0,2 & 2,6 \\
\hline $\mathbf{4 1}$ & 4 & 1 & 2 & 2 & 5 & 0,4 & 0,25 & 0,5 & 0,6 & 0,5 & 2,25 \\
\hline $\mathbf{4 2}$ & 1 & 4 & 3 & 3 & 2 & 0,1 & 1 & 0,75 & 0,9 & 0,2 & 2,95 \\
\hline $\mathbf{4 3}$ & 4 & 4 & 5 & 3 & 5 & 0,4 & 1 & 1,25 & 0,9 & 0,5 & 4,05 \\
\hline $\mathbf{4 4}$ & 2 & 4 & 5 & 1 & 1 & 0,2 & 1 & 1,25 & 0,3 & 0,1 & 2,85 \\
\hline $\mathbf{4 5}$ & 4 & 4 & 5 & 1 & 1 & 0,4 & 1 & 1,25 & 0,3 & 0,1 & 3,05 \\
\hline $\mathbf{4 6}$ & 1 & 3 & 2 & 1 & 2 & 0,1 & 0,75 & 0,5 & 0,3 & 0,2 & 1,85 \\
\hline $\mathbf{4 7}$ & 1 & 3 & 3 & 3 & 1 & 0,1 & 0,75 & 0,75 & 0,9 & 0,1 & 2,6 \\
\hline $\mathbf{4 8}$ & 1 & 2 & 3 & 3 & 1 & 0,1 & 0,5 & 0,75 & 0,9 & 0,1 & 2,35 \\
\hline $\mathbf{4 9}$ & 1 & 3 & 5 & 4 & 1 & 0,1 & 0,75 & 1,25 & 1,2 & 0,1 & 3,4 \\
\hline $\mathbf{5 0}$ & 2 & 3 & 5 & 3 & 1 & 0,2 & 0,75 & 1,25 & 0,9 & 0,1 & 3,2 \\
\hline
\end{tabular}

En el Gráfico 43, se puede ver la dispersión de los valores obtenidos de los Grados de Compromiso por Industrias.

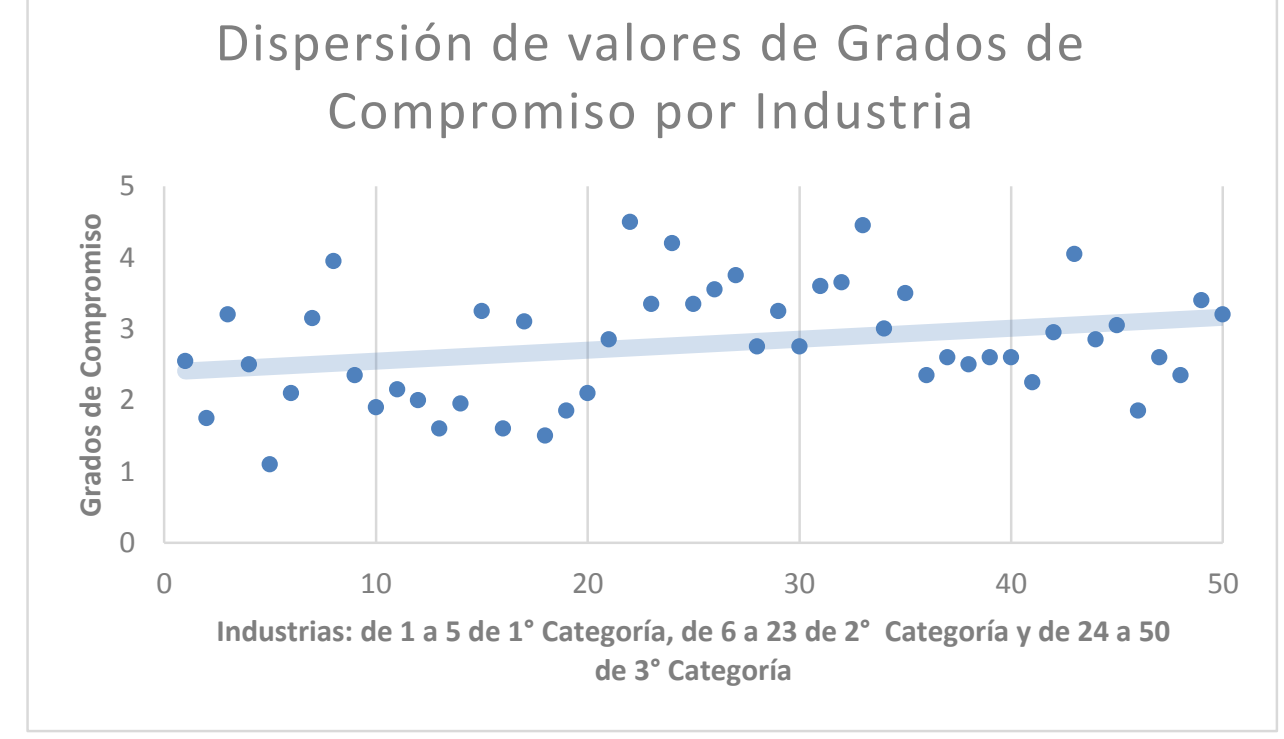

Gráfico 41. Dispersión de valores de Grados de Compromiso por Industrias.

Luego del análisis de la Tabla 2 de Determinación del Grado de Compromiso por Industrias, se obtienen valores representativos de promedio, desvío estándar y varianza. Estos resultados, expresan un aumento en los valores del índice, en relación al aumento de la categorización de la industria (Tabla 3). Las de tercera categoría, presentan el mayor valor de Grado de 
Compromiso (3.07), y los menores valores de desvío estándar (0.64) y varianza (0.41).

Tabla 3. Promedio, desvío estándar y varianza de valores de grados de compromiso por tipo de industrias.

\begin{tabular}{|r|r|r|r|}
\hline Industrias & Promedio & Desvio Estándar & \multicolumn{1}{c|}{ Varianza } \\
\hline $\begin{array}{r}\text { Primera } \\
\text { Categoría }\end{array}$ & 2.22 & 0.81 & 0.66 \\
\hline $\begin{array}{r}\text { Segunda } \\
\text { Categoría }\end{array}$ & 2.51 & 0.86 & 0.75 \\
\hline $\begin{array}{r}\text { Tercera } \\
\text { Categoría }\end{array}$ & 3.07 & 0.64 & 0.41 \\
\hline $\begin{array}{r}\text { Industrias en } \\
\text { General }\end{array}$ & 2.79 & 0.8 & 0.63 \\
\hline
\end{tabular}

\subsubsection{Opinión de expertos}

Se seleccionaron 6 Industrias de distintas características en las que se hicieron recorridos específicos y entrevistas con las máximas autoridades de la Gestión Ambiental. La entrevista se basó en la realización de la encuesta diseñada (Anexo I), teniendo la posibilidad de explayarse en cada respuesta. De surgir otras consultas además de las realizadas en la encuesta, se procedió a anotar todo y dejar constancia de cada respuesta. La selección se realizó teniendo en cuenta la categorización ante OPDS, las características generales y la predisposición de las máximas autoridades para poder colaborar con el presente trabajo (Tabla 4). 
Tabla 4. Resumen de características de industrias seleccionadas para la realización de entrevistas.

\section{Industria Categorización de OPDS \\ Características generales Partido}

\begin{tabular}{|c|c|c|c|}
\hline$A$ & Primera & $\begin{array}{l}\text { Realiza actividades de logística } \\
\text { y cuenta con } 15 \text { empleados. }\end{array}$ & Quilmes \\
\hline$B$ & Segunda & $\begin{array}{c}\text { Realiza autopartes (procesos de } \\
\text { inyección y soplado), siendo sus } \\
\text { principales clientes grandes } \\
\text { automotrices. }\end{array}$ & Berazategui \\
\hline C & Segunda & $\begin{array}{c}\text { Realiza autopartes (proceso de } \\
\text { inyección), siendo una planta } \\
\text { industrial que abastece } \\
\text { solamente a otra planta de } \\
\text { fabricación de baterías de } \\
\text { automotor de la misma } \\
\text { empresa. }\end{array}$ & Ayacucho \\
\hline$D$ & Tercera & $\begin{array}{l}\text { Realiza procesos de destilación } \\
\text { de petróleo crudo. Sus clientes } \\
\text { son principalmente grandes } \\
\text { industrias. }\end{array}$ & Pilar \\
\hline$E$ & Tercera & $\begin{array}{l}\text { Realiza procesos de } \\
\text { fraccionamiento de Gas Licuado } \\
\text { a Presión (GLP), para obtener } \\
\text { distintos tipos de garrafas. Sus } \\
\text { clientes son distribuidores en } \\
\text { general y particulares. }\end{array}$ & Chivilcoy \\
\hline$F$ & Tercera & Realiza procesos de fabricación & Ayacucho \\
\hline
\end{tabular}




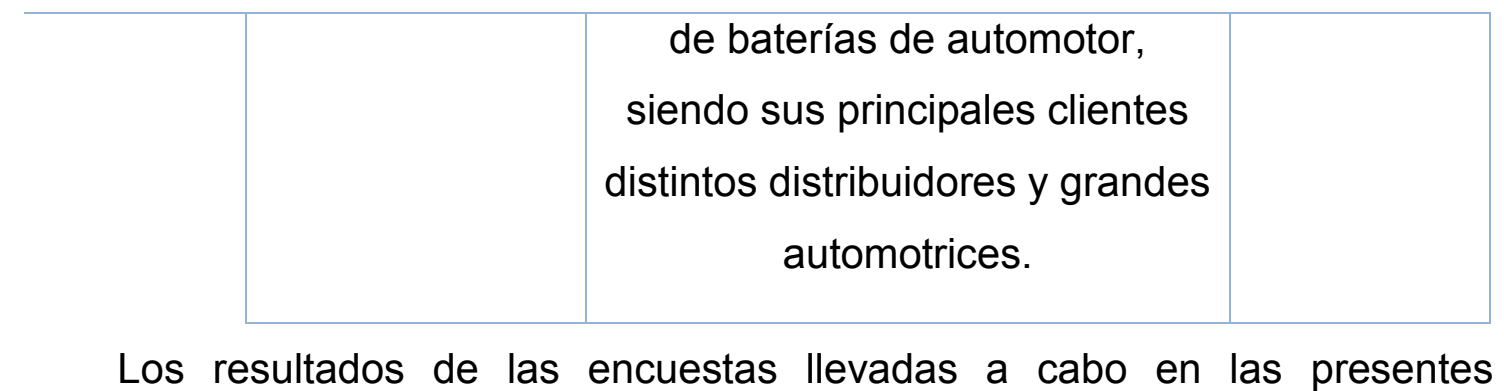
industrias, se verán reflejados en el apartado específico a "Encuestas" (punto 7.2.1.). Solo se expresan en este apartado las respuestas en las cuales había consideraciones extras, y que pudieron desprenderse de la entrevista. Se aclara, que las entrevistas aportaron detalles significativos para poder interpretar las encuestas generales, así como entender el funcionamiento de cada Industria visitada.

A continuación se exponen los resultados de las entrevistas realizadas:

\subsubsection{Industria A:}

Se realizó la entrevista al Presidente de la empresa.

- Rubro general de la industria: Logística

- Cuidad: Quilmes

- Cantidad de Operarios: 15

- Cantidad de Recursos Humanos Internos dedicados a la Gestión Ambiental: Ninguno

- Cantidad de Recursos Humanos internos dedicados a la Gestión Ambiental en forma exclusiva: Ninguno

- ¿Cuál es su categorización de Industria?: primera

- ¿Tienen Estudio de Impacto Ambiental presentado?: sí. Al ser una empresa de primera categoría, no está obligado a presentarse ante OPDS. Pero sí existe normativa municipal que solicita la realización de un Estudio de Impacto Ambiental. El mismo se presentó ante la autoridad del municipio en mayo del 2012, y no ha habido respuesta en relación a la aprobación. Se espera que se apruebe para poder obtener la habilitación municipal definitiva.

- ¿Cuentan con Certificado de Aptitud Ambiental (CAA) vigente?: No 
- $\quad$ Sus Aparatos Sometidos a Presión (ASP), ¿están habilitados y cuentan con las renovaciones periódicas?: cuentan con un compresor, habilitado y con la renovación al día en OPDS. Los renuevan todos los agostos de cada año.

- ¿Cuentan con las renovaciones de Residuos Especiales correspondientes?: tienen todas las renovaciones de Residuos Especiales al día. Realizan envíos de residuos especiales aproximadamente cada 4 meses, y en muy poca cantidad. No tienen un sector de almacenamiento de Residuos Especiales según marca la normativa. Saben que están en falta con eso, pero por ahora no van a adecuar un sector para estar en regla.

- ¿Han solicitado el Permiso de Descarga de Efluentes Gaseosos a la Atmósfera?: No corresponde. No presentar emisiones a la atmósfera, por lo que no aplica el pedido de este permiso.

- ¿Cuentan con el Permiso de Descarga de Efluentes Gaseosos a la Atmósfera?: No.

- ¿Cuál es la periodicidad de los monitoreos de aire y/o conductos?: no corresponde.

- ¿Están inscriptos en el Banco Único de Datos de Usuarios de los Recursos Hídricos (BUDURH)?: No. Más allá de que saben que deben realizar la inscripción, no han tomado la decisión de realizar la inscripción. Esperan alguna notificación formal de la Autoridad del Agua (ADA) o el momento en que algún inspector se lo pida.

- ¿Tienen presentaciones solicitando el Permiso de Explotación del Recurso Hídrico Subterráneo de los pozos de extracción de agua?: Sí. Tienen un pozo y han realizado la solicitud en mayo de 2012. Nunca han recibido respuesta por parte de ADA.

- ¿ ¿Cuentan con el Permiso de Explotación del Recurso Hídrico Subterráneo vigente?: No.

- ¿Tienen presentaciones solicitando la Factibilidad Hidráulica?: No corresponde. Los efluentes pluviales son evacuados del predio hacia colectores municipales.

- ¿Cuentan con la Factibilidad Hidráulica vigente?: No corresponde.

- ¿Tienen planta de tratamiento de efluentes líquidos?: No generan efluentes líquidos, por lo que no necesitan planta de tratamiento para los 
efluentes líquidos. Los efluentes cloacales, se vuelcan directamente por cloacas.

- ¿Han solicitado el Permiso de Vuelco al Recurso Hídrico?: No corresponde ya que no realizan vuelco de efluentes líquidos.

- ¿Cuentan con el Permiso de Vuelco al Recurso Hídrico vigente?: No corresponde.

- ¿Qué servicios externos contratan para mantener la Gestión Ambiental?: Contrata un servicio de consultoría externo, en el cuál una vez al mes reciben visitas del mismo. Ese servicio se brinda de forma simultánea con el de Seguridad e Higiene. Ese servicio se encarga de realizar las presentaciones necesarias así como la contratación de un laboratorio para los análisis correspondientes.

- ¿ ¿Tienen implementados Sistemas de Gestión ISO?: No.

- ¿ ¿Tienen implementados Planes de Responsabilidad Social Empresaria?: No.

- ¿Tienen implementados Informes de Sustentabilidad?: No

- ¿ ¿Han recibido inspecciones de las autoridades de aplicación en el último año?: No.

- $\quad$ Ordene de mayor a menor importancia (siendo mayor 1 y menor 5) los siguientes puntos en relación al porqué de la implementación de la Gestión Ambiental en su Industria: La implementación de la Gestión Ambiental en la industria la realizan exclusivamente para tratar de cumplir mínimamente la reglamentación y no tener problemas a la hora de que los inspeccionen.

- En qué situaciones se comprometen la/s mayor/es autoridad/es de la Empresa con la Gestión Ambiental: El compromiso aparece en el caso de una inspección y que en la misma le imputen infracciones. También en el caso de que le llegue una multa o carta documento por parte de la autoridad de aplicación.

- $\quad$ En cuanto al cumplimiento de la normativa, su Industria se encuentra en base a las presentaciones obligatorias ante OPDS y ADA: Se adeudan algunos trámites. Las autoridades de la empresa conocen la situación, pero la respuesta es que por ahora no van a realizar más trámites de los mínimos que están haciendo. 
- ¿En qué rango de facturación anual se encuentra su Empresa? (en millones de pesos): menos de 5 millones de pesos al año.

- ¿En qué rango se encuentra el gasto anual que destinan a la Gestión Ambiental? (en miles de pesos): Menos de 100 mil pesos al año.

- $\quad$ Entre las limitaciones que pueden presentarse para no llevar una Gestión Ambiental eficiente en su Industria, ¿cuáles considera que serían las posibles causas?: la limitación se basa en la falta de decisión empresarial en función del costo.

- ¿ ¿Reciben auditorías ambientales de sus clientes / proveedores?: No.

- ¿Se ha visto perjudicada la relación con clientes y/o proveedores como consecuencia de incumplimientos de la Gestión Ambiental?: No.

- ¿Han tenido conflictos con la comunidad como consecuencia de problemas en la Gestión Ambiental?: No.

- ¿Conoce las responsabilidades civiles y/o penales de los puestos clave de la Gestión Ambiental en las Industrias?: conocen las responsabilidades de la empresa en función a las sanciones económicas que puedan recibir, pero desconocen la responsabilidad de los responsables de la gestión ambiental.

\subsubsection{Industria B:}

Se realizó la entrevista al Gerente de Calidad de la empresa.

- Rubro general de la industria: fabricación de autopartes de plástico para automotrices

- $\quad$ Cuidad: Berazategui

- $\quad$ Cantidad de Operarios: 300

- Cantidad de Recursos Humanos Internos dedicados a la Gestión Ambiental: 1

- Cantidad de Recursos Humanos internos dedicados a la Gestión Ambiental en forma exclusiva: ninguno

- ¿Cuál es su categorización de Industria?: segunda

- ¿ ¿Tienen Estudio de Impacto Ambiental presentado?: Sí. Fue evaluado y aprobado por OPDS. Luego de que les emitieran el Certificado de Aptitud Ambiental, pasaron dos años y se presentó la correspondiente Auditoría de Renovación en septiembre de 2013. Hasta el momento, no se ha 
tenido novedades del trámite por parte de OPDS. En abril de 2015, se presentó una actualización del EIA por modificaciones que realizó la empresa en relación a los procesos productivos.

- ¿Cuentan con Certificado de Aptitud Ambiental (CAA) vigente?: No. Se solicitó la renovación del mismo pero no ha habido respuesta por parte de OPDS.

- Sus Aparatos Sometidos a Presión (ASP), ¿están habilitados y cuentan con las renovaciones periódicas?: cuentan con 3 equipos habilitados y con las renovaciones al día. Tienen 15 equipos más en distintas máquinas inyectoras y sopladoras, que compensan la falta de aire a presión que puedan tener en algún momento del proceso. Estos equipos, están al límite de la normativa en relación a si corresponde o no habilitarlos. Se hizo la averiguación a OPDS en relación a esto, respondiendo que sí correspondía realizar el trámite. La decisión de la empresa es ir haciendo de a poco las habilitaciones, comenzando este año con 5 de esos equipos. Saben que no estarán cumpliendo la normativa y que están propensos a ser sancionados por tal decisión.

- ¿Cuentan con las renovaciones de Residuos Especiales correspondientes?: Sí, cuentan con la renovación al día. Realizan aproximadamente 8 envíos al año de residuos especiales.

- ¿Han solicitado el Permiso de Descarga de Efluentes Gaseosos a la Atmósfera?: Sí. Por más que no tengan conductos, luego de consultarse al área específica de OPDS se procedió a solicitar este permiso realizando mediciones de calidad de aire para posibles contaminantes producidos en el sector matricería, gracias a los procesos de soldadura que se realizan.

- ¿Cuentan con el Permiso de Descarga de Efluentes Gaseosos a la Atmósfera?: No. Se realizó la presentación en marzo de 2013 y no hay novedades al respecto por parte de OPDS.

- ¿Cuál es la periodicidad de los monitoreos de aire y/o conductos?: bianual.

- ¿Están inscriptos en el Banco Único de Datos de Usuarios de los Recursos Hídricos (BUDURH)?: Sí, con las renovaciones al día.

- ¿Tienen presentaciones solicitando el Permiso de Explotación del Recurso Hídrico Subterráneo de los pozos de extracción de agua?: sí, de 
un pozo de explotación. Tienen otro del que no han solicitado el permiso. Conocen las autoridades esta situación pero no deciden poner en regla la misma.

- ¿ ¿Cuentan con el Permiso de Explotación del Recurso Hídrico Subterráneo vigente?: No. Por parte de ADA no hubo respuesta todavía a la presentación realizada en agosto de 2013.

- ¿Tienen presentaciones solicitando la Factibilidad Hidráulica?: no corresponde.

- ¿ ¿Cuentan con la Factibilidad Hidráulica vigente?: No corresponde.

- ¿Tienen planta de tratamiento de efluentes líquidos?: No se generan efluentes líquidos.

- ¿Han solicitado el Permiso de Vuelco al Recurso Hídrico?: No corresponde.

- ¿Cuentan con el Permiso de Vuelco al Recurso Hídrico vigente?: No corresponde.

- ¿ ¿Qué servicios externos contratan para mantener la Gestión Ambiental?: Servicios de consultoría general y análisis de laboratorio.

- ¿ ¿Tienen implementados Sistemas de Gestión ISO?: Sí.

- $\quad$ En caso de ser "Si", especifique cuál: cuentan con certificación ISO 9001 y 14001.

- Considera que obtuvieron beneficios asociados con: La certificación de ambas normas les abrió la posibilidad de trabajar con las grandes automotrices. De no contar con las mismas, no podrían ser sus proveedores.

- ¿ ¿Tienen implementados Planes de Responsabilidad Social Empresaria?: No. Manifiestan la idea de hacer acciones con la comunidad pero no saben de qué manera llevarlo a cabo.

- ¿ ¿Tienen implementados Informes de Sustentabilidad?: No, y no saben a qué se refiere la pregunta. Desconocen completamente el tema.

- ¿ ¿Han recibido inspecciones de las autoridades de aplicación en el último año?: Sí.

- Las mismas fueron: Al menos una vez al año reciben visitas de inspectores de OPDS para controlar las presentaciones realizadas.

- $\quad$ Ordene de mayor a menor importancia (siendo mayor 1 y menor 5) los siguientes puntos en relación al porqué de la implementación de la 
Gestión Ambiental en su Industria: La base de la implementación de la Gestión Ambiental se relaciona en cumplir con toda la normativa obligatoria, para poder mantener la norma ISO 14.001 al día. Eso les permite poder seguir siendo proveedores de las grandes empresas con las que quieren trabajar. Más allá de eso, ven que para cumplir algunos trámites obligatorios, la cuestión económica termina resultando determinante.

- En qué situaciones se comprometen la/s mayor/es autoridad/es de la Empresa con la Gestión Ambiental: En situaciones de visita de inspectores y más aún cuando hay alguna sanción y/o pedido de realización de trámites que no tenían en cuenta.

- En cuanto al cumplimiento de la normativa, su Industria se encuentra en base a las presentaciones obligatorias ante OPDS y ADA: Al día con la mayoría de los trámites, sabiendo que en algunos temas tienen cosas pendientes.

- ¿En qué rango de facturación anual se encuentra su Empresa? (en millones de pesos): entre 10 y 20 millones de pesos al año.

- ¿En qué rango se encuentra el gasto anual que destinan a la Gestión Ambiental? (en miles de pesos): entre 100 y 200 mil pesos al año.

- Entre las limitaciones que pueden presentarse para no llevar una Gestión Ambiental eficiente en su Industria, ¿cuáles considera que serían las posibles causas?: principalmente con la explicación de los responsables de la empresa en relación al gasto que implican los distintos trámites. Es difícil que los responsables autoricen erogaciones para temas ambientales si no son extremadamente necesarios.

- ¿Reciben auditorías ambientales de sus clientes / proveedores?: Sí. Periódicamente reciben visitas de los clientes para ver si cumplen con sus estándares necesarios.

- ¿ ¿Se ha visto perjudicada la relación con clientes y/o proveedores como consecuencia de incumplimientos de la Gestión Ambiental?: Nunca se vieron perjudicados por este tema, pero saben que deben estar al día para prevenir problemas con los clientes.

- ¿Han tenido conflictos con la comunidad como consecuencia de problemas en la Gestión Ambiental?: No. 
- ¿Conoce las responsabilidades civiles y/o penales de los puestos clave de la Gestión Ambiental en las Industrias?: Sí.

\subsubsection{Industria C:}

Se realizó la entrevista a uno de los hijos de dueño, que se encarga de la gestión general de la planta, principalmente en el área de Calidad.

- Rubro general de la industria: Realiza autopartes (proceso de inyección), siendo una planta industrial que abastece solamente a otra planta de fabricación de baterías de automotor de la misma empresa.

- Cuidad: Ayacucho

- $\quad$ Cantidad de Operarios: 120

- Cantidad de Recursos Humanos Internos dedicados a la Gestión Ambiental: Ninguno

- Cantidad de Recursos Humanos internos dedicados a la Gestión Ambiental en forma exclusiva: Ninguno

- ¿Cuál es su categorización de Industria?: Segunda

- ¿ ¿Tienen Estudio de Impacto Ambiental presentado?: Tienen presentado en 2006 el EIA y una actualización del mismo en 2012. Hubo un inconveniente en el trámite ya que desde OPDS enviaron el Expediente al municipio para hacer una consulta a la empresa, y desde el mismo nunca notificaron tal observación. Por este motivo y porque en el municipio no lo enviaron nuevamente a OPDS, quedó "parado" el trámite por 5 años. Posteriormente, se reactivó por insistencia de la Empresa y se encuentra en OPDS para su evaluación.

- ¿Cuentan con Certificado de Aptitud Ambiental (CAA) vigente?: No, se explicó en el punto anterior la situación actual del trámite.

- Sus Aparatos Sometidos a Presión (ASP), ¿están habilitados y cuentan con las renovaciones periódicas?: Sí, cuentan con un equipo habilitado y con las renovaciones periódicas al día.

- ¿Cuentan con las renovaciones de Residuos Especiales correspondientes?: Sí, cuentan con las renovaciones al día y realizan uno o dos envíos de Residuos Especiales al año.

- ¿Han solicitado el Permiso de Descarga de Efluentes Gaseosos a la Atmósfera?: Sí. 
- ¿Cuentan con el Permiso de Descarga de Efluentes Gaseosos a la Atmósfera?: Sí, otorgaron el mismo y cuentan con la renovación al día.

- ¿Cuál es la periodicidad de los monitoreos de aire y/o conductos?: Anual.

- ¿Están inscriptos en el Banco Único de Datos de Usuarios de los Recursos Hídricos (BUDURH)?: No, saben que deben realizarla pero no lo han hecho. Está proyectada para la finalización del 2015.

- ¿Tienen presentaciones solicitando el Permiso de Explotación del Recurso Hídrico Subterráneo de los pozos de extracción de agua?: No tienen pozos de explotación, solo utilizan agua de red para baños y vestuarios.

- ¿ ¿Cuentan con el Permiso de Explotación del Recurso Hídrico Subterráneo vigente?: No realizan vuelco.

- ¿Tienen presentaciones solicitando la Factibilidad Hidráulica?: No corresponde.

- ¿Cuentan con la Factibilidad Hidráulica vigente?: No corresponde.

- ¿ ¿Tienen planta de tratamiento de efluentes líquidos?: No corresponde ya que no generan efluentes líquidos.

- ¿Han solicitado el Permiso de Vuelco al Recurso Hídrico?: No corresponde.

- ¿Cuentan con el Permiso de Vuelco al Recurso Hídrico vigente?: No corresponde.

- ¿ ¿Qué servicios externos contratan para mantener la Gestión Ambiental?: Servicio general de asesoramiento y gestión más análisis de laboratorio.

- ¿ ¿Tienen implementados Sistemas de Gestión ISO?: Sí.

- $\quad$ En caso de ser "Si", especifique cuál: ISO 9001.

- Considera que obtuvieron beneficios asociados con: Proveedores y clientes. Y principalmente en el manejo interno general.

- ¿ ¿Tienen implementados Planes de Responsabilidad Social Empresaria?: No.

- ¿Tienen implementados Informes de Sustentabilidad?: Desconocen el concepto.

- ¿Han recibido inspecciones de las autoridades de aplicación en el último año?: No. Hace más de 4 años que no reciben visitas de OPDS, ADA ni Municipio. 
- $\quad$ Ordene de mayor a menor importancia (siendo mayor 1 y menor 5) los siguientes puntos en relación al porqué de la implementación de la Gestión Ambiental en su Industria: Para evitar sanciones por parte de la autoridad de aplicación (multas, clausuras).

- En qué situaciones se comprometen la/s mayor/es autoridad/es de la Empresa con la Gestión Ambiental: cuando hay inspecciones, multas y/o clausuras.

- En cuanto al cumplimiento de la normativa, su Industria se encuentra en base a las presentaciones obligatorias ante OPDS y ADA: Con la mayoría de los trámites al día. Saben que están en falta en algunos, pero quieren solucionar ese tema.

- ¿En qué rango de facturación anual se encuentra su Empresa? (en millones de pesos): entre 10 y 20 millones de pesos al año.

- ¿ ¿En qué rango se encuentra el gasto anual que destinan a la Gestión Ambiental? (en miles de pesos): Menos de 100 mil pesos al año.

- Entre las limitaciones que pueden presentarse para no llevar una Gestión Ambiental eficiente en su Industria, ¿cuáles considera que serían las posibles causas?: El costo de la misma.

- ¿ ¿Reciben auditorías ambientales de sus clientes / proveedores?: No.

- ¿Se ha visto perjudicada la relación con clientes y/o proveedores como consecuencia de incumplimientos de la Gestión Ambiental?: No.

- ¿Han tenido conflictos con la comunidad como consecuencia de problemas en la Gestión Ambiental?: No.

- ¿Conoce las responsabilidades civiles y/o penales de los puestos clave de la Gestión Ambiental en las Industrias?: Sí las civiles, desconocen las penales.

\subsubsection{Industria D:}

Se realizó la entrevista al Presidente de la Empresa.

- Rubro general de la industria: procesos de destilación de petróleo crudo.

- Cuidad: Pilar

- Cantidad de Operarios: 25

- Cantidad de Recursos Humanos Internos dedicados a la Gestión Ambiental: 1. 
- Cantidad de Recursos Humanos internos dedicados a la Gestión Ambiental en forma exclusiva: Ninguno.

- ¿Cuál es su categorización de Industria?: Tercera.

- ¿ ¿Tienen Estudio de Impacto Ambiental presentado?: Sí, y actualizado.

- ¿Cuentan con Certificado de Aptitud Ambiental (CAA) vigente?: Sí, tuvieron un problema al emitirles el certificado por el cual salió mal expresado el rubro, así que se encuentran en proceso de resolver ese error interno de ODPS.

- Sus Aparatos Sometidos a Presión (ASP), ¿están habilitados y cuentan con las renovaciones periódicas?: Sí, cuentan con una caldera y un compresor habilitados y al día en OPDS.

- ¿Cuentan con las renovaciones de Residuos Especiales correspondientes?: Sí, realizan envíos periódicos.

- ¿Han solicitado el Permiso de Descarga de Efluentes Gaseosos a la Atmósfera?: Sí, actualmente desde el área correspondiente de OPDS les solicitaron nueva documentación e información para actualizar lo presentado.

- ¿Cuentan con el Permiso de Descarga de Efluentes Gaseosos a la Atmósfera?: No, se está en proceso de actualización de datos para que OPDS pueda emitir el mismo.

- ¿Cuál es la periodicidad de los monitoreos de aire y/o conductos?: semestral.

- ¿Están inscriptos en el Banco Único de Datos de Usuarios de los Recursos Hídricos (BUDURH)?: Sí, cuentan con la inscripción y renovaciones al día.

- ¿Tienen presentaciones solicitando el Permiso de Explotación del Recurso Hídrico Subterráneo de los pozos de extracción de agua?: Sí, se solicitó en 2012, y al momento no hubo respuesta de ADA.

- ¿ ¿Cuentan con el Permiso de Explotación del Recurso Hídrico Subterráneo vigente?: No.

- ¿Tienen presentaciones solicitando la Factibilidad Hidráulica?: No corresponde.

- ¿ ¿Cuentan con la Factibilidad Hidráulica vigente?: No corresponde. 
- ¿ ¿Tienen planta de tratamiento de efluentes líquidos?: Sí, están incluso construyendo actualmente una nueva planta de tratamiento para que el proceso sea más efectivo.

- ¿ ¿Han solicitado el Permiso de Vuelco al Recurso Hídrico?: Sí, se solicitó en 2013 y todavía no hay respuesta por parte de ADA.

- ¿Cuentan con el Permiso de Vuelco al Recurso Hídrico vigente?: No. Están esperando a terminar la nueva planta de tratamiento para poder agilizar el trámite.

- ¿ ¿Qué servicios externos contratan para mantener la Gestión Ambiental?: Servicios de asesoramiento y gestión integral, así como análisis de laboratorio.

- ¿ ¿Tienen implementados Sistemas de Gestión ISO?: No.

- ¿ ¿Tienen implementados Planes de Responsabilidad Social Empresaria?: Realizan algunas acciones aisladas con la población cercana a la planta industrial. No es programado ni organizado.

- ¿ ¿Tienen implementados Informes de Sustentabilidad?: No.

- ¿Han recibido inspecciones de las autoridades de aplicación en el último año?: Sí, reciben inspecciones periódicas por parte de OPDS (al menos una cada dos meses) y de ADA (una vez al año). El municipio va más periódicamente.

- Las mismas fueron: de rutina, con motivos de denuncias de vecinos, para actualizar datos y comprobar funcionamiento de procesos.

- $\quad$ Ordene de mayor a menor importancia (siendo mayor 1 y menor 5) los siguientes puntos en relación al porqué de la implementación de la Gestión Ambiental en su Industria: Principalmente para cumplir con la normativa y evitar sanciones. También, para evitar problemas con los vecinos.

- En qué situaciones se comprometen la/s mayor/es autoridad/es de la Empresa con la Gestión Ambiental: cuando hay inspecciones y sanciones (multas y/o clausuras).

- En cuanto al cumplimiento de la normativa, su Industria se encuentra en base a las presentaciones obligatorias ante OPDS y ADA: Al día.

- ¿En qué rango de facturación anual se encuentra su Empresa? (en millones de pesos): entre 30 y 50 millones de pesos al año. 
- ¿En qué rango se encuentra el gasto anual que destinan a la Gestión Ambiental? (en miles de pesos): entre 200 y 300 mil pesos al año.

- Entre las limitaciones que pueden presentarse para no llevar una Gestión Ambiental eficiente en su Industria, ¿cuáles considera que serían las posibles causas?: Burocracia de las autoridades de aplicación. Exigencias distintas de áreas distintas de OPDS.

- ¿ ¿Reciben auditorías ambientales de sus clientes / proveedores?: No.

- ¿ ¿Se ha visto perjudicada la relación con clientes y/o proveedores como consecuencia de incumplimientos de la Gestión Ambiental?: Sí, en los casos en que la planta estuvo clausurada.

- ¿Han tenido conflictos con la comunidad como consecuencia de problemas en la Gestión Ambiental?: Sí, hubo un derrame de hidrocarburos que generó protestas de la comunidad cercana.

- ¿Conoce las responsabilidades civiles y/o penales de los puestos clave de la Gestión Ambiental en las Industrias?: Sí.

\subsubsection{Industria E:}

Se realizó la entrevista al Gerente de Producción de la Empresa.

- Rubro general de la industria: fraccionamiento de Gas Licuado a Presión (GLP).

- $\quad$ Cuidad: Chivilcoy

- $\quad$ Cantidad de Operarios: 40

- Cantidad de Recursos Humanos Internos dedicados a la Gestión Ambiental: Uno pero solo como contacto con la planta industrial para pedido de documentación y/o información.

- Cantidad de Recursos Humanos internos dedicados a la Gestión Ambiental en forma exclusiva: Ninguno

- ¿ ¿Cuál es su categorización de Industria?: Tercera

- ¿ ¿Tienen Estudio de Impacto Ambiental presentado?: Sí, presentado en 2012 y sin actualizar.

- ¿Cuentan con Certificado de Aptitud Ambiental (CAA) vigente?: No, han solicitado una serie de aclaraciones al EIA, y todavía no se ha respondido. 
- $\quad$ Sus Aparatos Sometidos a Presión (ASP), ¿están habilitados y cuentan con las renovaciones periódicas?: Sí, cuentan con 6 equipos habilitados y con las renovaciones al día.

- ¿Cuentan con las renovaciones de Residuos Especiales correspondientes?: Sí, realizan no más de un envío al año.

- ¿Han solicitado el Permiso de Descarga de Efluentes Gaseosos a la Atmósfera?: Sí, han realizado la solicitud y actualizaciones.

- ¿Cuentan con el Permiso de Descarga de Efluentes Gaseosos a la Atmósfera?: Sí.

- ¿ ¿Cuál es la periodicidad de los monitoreos de aire y/o conductos?: Anual.

- ¿Están inscriptos en el Banco Único de Datos de Usuarios de los Recursos Hídricos (BUDURH)?: Sí, y las renovaciones al día.

- ¿Tienen presentaciones solicitando el Permiso de Explotación del Recurso Hídrico Subterráneo de los pozos de extracción de agua?: Sí, se realizó la solicitud en 2012 de dos pozos de explotación. Todavía no hubo respuesta por parte de ADA.

- ¿ ¿Cuentan con el Permiso de Explotación del Recurso Hídrico Subterráneo vigente?: No.

- ¿Tienen presentaciones solicitando la Factibilidad Hidráulica?: No corresponde.

- ¿Cuentan con la Factibilidad Hidráulica vigente?: No corresponde.

- ¿ ¿Tienen planta de tratamiento de efluentes líquidos?: Sí, una planta muy sencilla por la cual tratan líquido una vez que se lavan garrafas que ingresan a la planta, y previo a su envasado.

- ¿Han solicitado el Permiso de Vuelco al Recurso Hídrico?: No, tiene proyectado realizar esto para fines de 2015.

- ¿ ¿Cuentan con el Permiso de Vuelco al Recurso Hídrico vigente?: No.

- ¿ ¿Qué servicios externos contratan para mantener la Gestión Ambiental?: Asesoramiento y gestión general, y análisis de laboratorio.

- ¿ ¿Tienen implementados Sistemas de Gestión ISO?: No.

- ¿ ¿Tienen implementados Planes de Responsabilidad Social Empresaria?: No.

- ¿ ¿Tienen implementados Informes de Sustentabilidad?: No.

- ¿ ¿Han recibido inspecciones de las autoridades de aplicación en el último año?: No. 
- $\quad$ Ordene de mayor a menor importancia (siendo mayor 1 y menor 5) los siguientes puntos en relación al porqué de la implementación de la Gestión Ambiental en su Industria: para cumplir con la normativa y evitar sanciones por parte de las autoridades de aplicación.

- En qué situaciones se comprometen la/s mayor/es autoridad/es de la Empresa con la Gestión Ambiental: En caso de multas y/o clausuras. Para definir el presupuesto anual que destinarán a la misma.

- En cuanto al cumplimiento de la normativa, su Industria se encuentra en base a las presentaciones obligatorias ante OPDS y ADA: Al día con casi todos, salvo situaciones explicadas anteriormente y a sabiendas del no cumplimiento por parte de las autoridades.

- ¿En qué rango de facturación anual se encuentra su Empresa? (en millones de pesos): entre 20 y 30 millones de pesos al año.

- ¿En qué rango se encuentra el gasto anual que destinan a la Gestión Ambiental? (en miles de pesos): Menos de 100 mil pesos al año.

- Entre las limitaciones que pueden presentarse para no llevar una Gestión Ambiental eficiente en su Industria, ¿cuáles considera que serían las posibles causas?: La complejidad por parte de la comunicación interna entre Gerentes y dueños de la empresa, a la hora de aprobar presupuestos para la Gestión Ambiental.

- ¿Reciben auditorías ambientales de sus clientes / proveedores?: No, pero sí de Secretaría de Energía de Nación, que los limita a la hora de tener beneficios.

- ¿ ¿Se ha visto perjudicada la relación con clientes y/o proveedores como consecuencia de incumplimientos de la Gestión Ambiental?: No.

- ¿Han tenido conflictos con la comunidad como consecuencia de problemas en la Gestión Ambiental?: No.

- ¿Conoce las responsabilidades civiles y/o penales de los puestos clave de la Gestión Ambiental en las Industrias?: Sí.

\subsubsection{Industria F:}

Se realizó la entrevista a uno de los hijos de dueño, que se encarga de la gestión general de la planta, principalmente en el área de Calidad.

- Rubro general de la industria: fabricación de baterías de automotor. 
- $\quad$ Cuidad: Ayacucho.

- Cantidad de Operarios: 130.

- Cantidad de Recursos Humanos Internos dedicados a la Gestión Ambiental: Uno, parcialmente.

- Cantidad de Recursos Humanos internos dedicados a la Gestión Ambiental en forma exclusiva: Ninguno.

- ¿ ¿Cuál es su categorización de Industria?: Tercera.

- ¿ ¿Tienen Estudio de Impacto Ambiental presentado?: Sí, se presentó en 2003 y además se cuenta con una actualización del mismo al día. No hubo noticias por parte de OPDS en relación a su evaluación.

- ¿Cuentan con Certificado de Aptitud Ambiental (CAA) vigente?: No.

- Sus Aparatos Sometidos a Presión (ASP), ¿están habilitados y cuentan con las renovaciones periódicas?: Sí, cuentan con 4 equipos habilitados y con las renovaciones al día.

- ¿Cuentan con las renovaciones de Residuos Especiales correspondientes?: Sí, y realizan un envío de residuos especiales al año.

- ¿Han solicitado el Permiso de Descarga de Efluentes Gaseosos a la Atmósfera?: Sí.

- ¿Cuentan con el Permiso de Descarga de Efluentes Gaseosos a la Atmósfera?: Sí, otorgado en noviembre de 2014.

- ¿Cuál es la periodicidad de los monitoreos de aire y/o conductos?: Semestral.

- ¿Están inscriptos en el Banco Único de Datos de Usuarios de los Recursos Hídricos (BUDURH)?: Sí, con las renovaciones anuales al día.

- ¿Tienen presentaciones solicitando el Permiso de Explotación del Recurso Hídrico Subterráneo de los pozos de extracción de agua?: Sí, se solicitó en 2006 y todavía no hay respuesta por parte de ADA:

- ¿ ¿Cuentan con el Permiso de Explotación del Recurso Hídrico Subterráneo vigente?: No.

- ¿Tienen presentaciones solicitando la Factibilidad Hidráulica?: No corresponde.

- ¿Cuentan con la Factibilidad Hidráulica vigente?: No corresponde.

- ¿Tienen planta de tratamiento de efluentes líquidos?: Sí, construida a fines de 2014 como consecuencia de modificaciones en el proceso que hace que generen efluentes líquidos. 
- ¿Han solicitado el Permiso de Vuelco al Recurso Hídrico?: Están en proceso de actualizar toda la documentación presentada anda ADA según la reciente Resolución ADA 734/14.

- ¿ ¿Cuentan con el Permiso de Vuelco al Recurso Hídrico vigente?: No.

- ¿ ¿Qué servicios externos contratan para mantener la Gestión Ambiental?: Asesoramiento y gestión integral, y análisis de laboratorio.

- ¿ ¿Tienen implementados Sistemas de Gestión ISO?: Sí.

- En caso de ser "Si", especifique cuál: ISO 9001 y con intenciones de certificar durante 2016 la ISO 14001.

- Considera que obtuvieron beneficios asociados con: principalmente con la gestión interna, y con clientes.

- ¿ ¿Tienen implementados Planes de Responsabilidad Social Empresaria?: Sí, informalmente.

- $\quad$ En caso de ser "Si", especifique cuál: Se hacen algunas contribuciones a la comunidad cercana.

- Considera que obtuvieron beneficios asociados con: La comunidad en general.

- ¿ ¿Tienen implementados Informes de Sustentabilidad?: No.

- ¿ ¿Han recibido inspecciones de las autoridades de aplicación en el último año?: Sí, de OPDS.

- Las mismas fueron: De rutina, por control de documentación y del área de efluentes gaseosos para emitir el certificado correspondiente.

- $\quad$ Ordene de mayor a menor importancia (siendo mayor 1 y menor 5) los siguientes puntos en relación al porqué de la implementación de la Gestión Ambiental en su Industria: Para evitar sanciones de las autoridades de aplicación.

- En qué situaciones se comprometen la/s mayor/es autoridad/es de la Empresa con la Gestión Ambiental: En caso de problemas con la comunidad y de sanciones de las autoridades.

- En cuanto al cumplimiento de la normativa, su Industria se encuentra en base a las presentaciones obligatorias ante OPDS y ADA: Al día.

- ¿En qué rango de facturación anual se encuentra su Empresa? (en millones de pesos): entre 30 y 40 millones de pesos al año.

- ¿En qué rango se encuentra el gasto anual que destinan a la Gestión Ambiental? (en miles de pesos): Entre 200 y 300 mil pesos al año. 
- Entre las limitaciones que pueden presentarse para no llevar una Gestión Ambiental eficiente en su Industria, ¿cuáles considera que serían las posibles causas?: Falta de respuesta de las autoridades de aplicación en relación a las solicitudes y/o trámites realizados.

- ¿Reciben auditorías ambientales de sus clientes / proveedores?: Sí, de clientes.

- ¿ ¿Se ha visto perjudicada la relación con clientes y/o proveedores como consecuencia de incumplimientos de la Gestión Ambiental?: No.

- ¿Han tenido conflictos con la comunidad como consecuencia de problemas en la Gestión Ambiental?: Sí, como consecuencia de un derrame accidental y que tuvo repercusión en la comunidad.

- ¿Conoce las responsabilidades civiles y/o penales de los puestos clave de la Gestión Ambiental en las Industrias?: Sí. 


\section{Conclusiones}

\subsection{Influencia de la gestión ambiental en la toma de decisiones de las empresas.}

Para poder caracterizar la influencia de la gestión ambiental en la toma de decisiones de la empresa, se diseñó un índice que determina el Grado de Compromiso de la Gestión Empresarial con la Gestión Ambiental, denominado "Grado de Compromiso" (desarrollado en el ítem 7.2.1.5 del presente trabajo). El mismo está representado por el análisis de cinco variables y se caracteriza por tomar valores entre 1 y 5 en función de un menor o mayor compromiso respectivamente.

Para cualificar este indicador, se determina que si toma valores entre 1 y 2.33 el Grado de Compromiso es "bajo", entre 2.34 y 3.66 es "medio", entre 3.67 y 5 es "alto" como se muestra en la Tabla 5.

Tabla 5. Cualificación de Grados de Compromiso.

\begin{tabular}{|c|c|}
\hline Grado de Compromiso & Rango de valores obtenidos \\
\hline Medio & 1 y 2.33 \\
\hline Alto & 2.34 y 3.66 \\
\hline
\end{tabular}

Al analizar los Grados de Compromiso por Categoría, se observa en el Gráfico 44 que a medida que aumenta la complejidad de la industria, aumentan las industrias con Grado de Compromiso Alto y disminuyen las de Grado de Compromiso Bajo. Asimismo, las industrias de tercera categoría, son las que muestran en mayor cantidad, Grado de Compromiso Medio. 


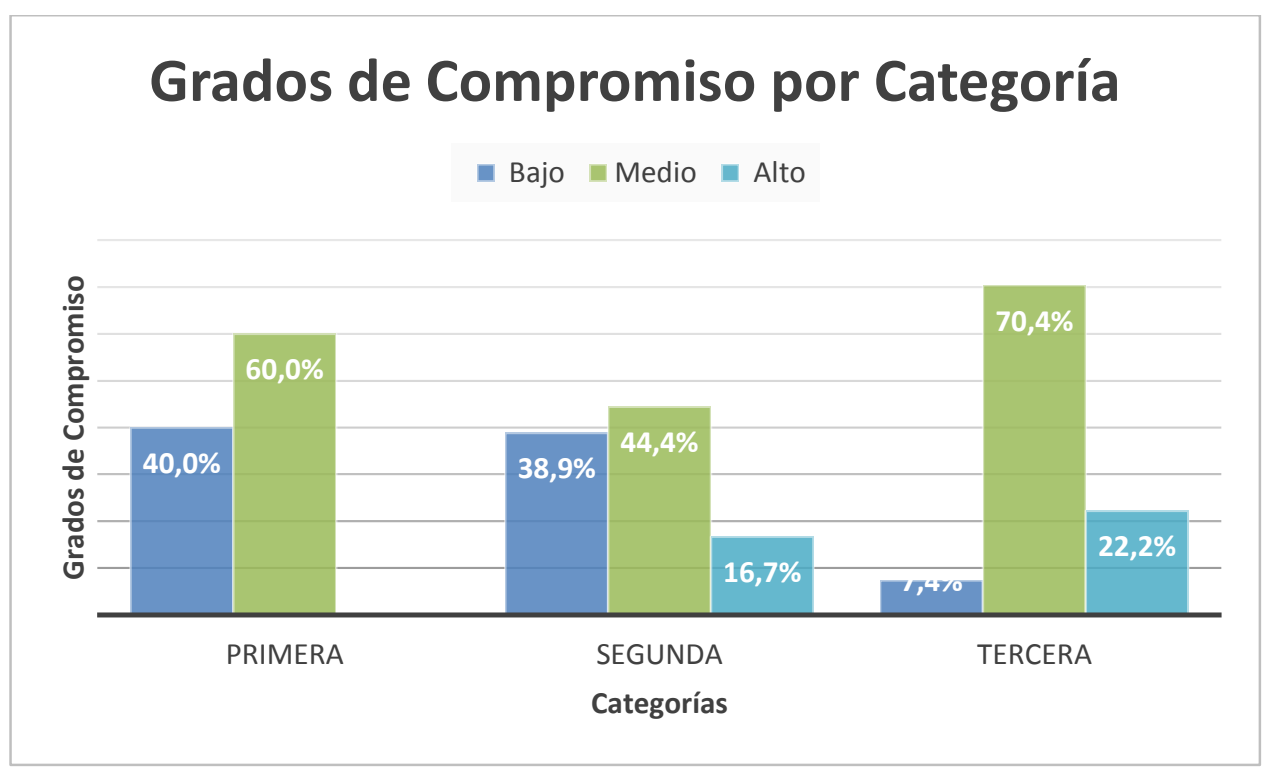

Gráfico 42. Grados de Compromiso por Categorías.

Las industrias de tercera categoría, en promedio, presentan valores de Grado de Compromiso mayores (3.07), las de segunda medios (2.51) y las de primera menores (2.22) como se puede observar en la Tabla 6. Asimismo, los valores de desvío estándar expresados en función de los datos obtenidos para cada categoría, fueron de 0.81 para las de primera categoría, 0.86 para las de segunda y 0.64 para las de tercera. En el análisis general, para todas las industrias en estudio, el promedio de Grados de Compromiso fue de 2.80, siendo su desvío estándar de 0.80 .

Por lo tanto, analizando los promedios en función de los desvíos estándar, se encuentra que el $68.3 \%$ de las industrias en general (porcentaje que se encuentra a un desvío estándar del promedio), está en valores de Grados de Compromiso entre 2 y 3.6. Al desglosar este análisis en las distintas categorías, se expresa que para la tercera categoría se encuentran entre 2.43 y 3.71 (Grado de Compromiso entre Medio y Alto); las de segunda categoría entre 1.65 y 3.37 (Grado de Compromiso entre Bajo y Medio) y las de primera categoría entre 1.41 y 3.03 (Grado de Compromiso entre Bajo y Medio). 
Tabla 6. Grados de Compromiso del 68,3\% de las industrias por Categoría.

\begin{tabular}{|c|c|c|}
\hline \multirow{2}{*}{ Categoría de Industria } & \multicolumn{2}{|c|}{$\begin{array}{l}\text { Grado de Compromiso del } 68,3 \% \text { de las } \\
\text { Industrias }\end{array}$} \\
\hline & Rango de valores & Cualificación \\
\hline Primera & 1.41 y 3.03 & Bajo - Medio \\
\hline Segunda & 1.65 y 3.37 & Bajo - Medio \\
\hline Tercera & 2.43 y 3.71 & Medio - Alto \\
\hline
\end{tabular}

\subsection{Causas del compromiso que toma la gestión general de la empresa con la gestión ambiental.}

Como se detallara anteriormente, las Gestiones Empresariales generales expresan mediante distintas acciones que realizan (o dejan de realizar), un mayor o menor compromiso con la Gestión Ambiental. Existe una variación significativa en cuanto a los valores del índice "Grado de Compromiso" que toman las distintas industrias que se analizaron.

Se enuncian a continuación posibles causas que, en relación a las decisiones que se tomen en cada empresa, explicarían los distintos Grados de Compromiso:

- Mayor Grado de Compromiso

\section{Mayor/res}

Participación por parte de las máximas autoridades.

Entendimiento de la normativa.

Exigencia por parte de proveedores y/o clientes.

Conciencia por el cuidado del ambiente y de la salud de los empleados.

Presión de la comunidad en general.

\section{Suficientes}


Controles por parte de las autoridades de aplicación ambiental.

Recursos Humanos dedicados.

Recursos Económicos destinados.

Costos destinados a la Gestión Ambiental vistos como Inversiones

- Menor Grado de Compromiso

\section{Menor/es o nula/o}

Participación por parte de las máximas autoridades.

Entendimiento de la normativa.

Exigencia por parte de proveedores y/o clientes.

Conciencia por el cuidado del ambiente y de la salud de los empleados.

Presión de la comunidad en general.

\section{Insuficientes}

Controles por parte de las autoridades de aplicación ambiental.

Recursos Humanos dedicados.

Recursos Económicos destinados.

\section{Costos destinados a la Gestión Ambiental vistos como Gastos}

Como se expresara, existen distintas causas por las cuales la Gestión Empresarial general presenta distintos grados de compromiso con la Gestión Empresarial.

Se destaca que las pequeñas o medianas industrias, que facturan menos y tienen una complejidad ambiental menor, sienten una mayor presión por parte de los trámites obligatorios. Esta presión, se traduce directamente en la 
proporción del costo para mantener una Gestión Ambiental eficiente, en relación a la facturación.

Otra situación de importancia, es la falta de respuesta por parte de las Autoridades de Aplicación. Se han identificado que pueden pasar varios años para que se evalúen trámites y de este modo las Industrias puedan contar con los trámites al día y no solo con la presentación por mesa de entradas del inicio del mismo. Esta situación se vio reflejada en los distintos trámites que se deben presentar ante OPDS y ADA.

En este sentido, se identifican también insuficiencias en los controles por parte de las Autoridades de Aplicación, principalmente en las Industrias de menor complejidad. Salvo que sucedan situaciones problemáticas puntuales (denuncias, derrames, explosiones, etc.), prácticamente no reciben visitas periódicas que permitan auditar el funcionamiento. Por lo tanto, al no recibir estas fiscalizaciones, se ven en situación de estar menos controlados y por este motivo incumplir con la normativa.

Por último, vale enfatizar que las Organizaciones no Gubernamentales (ONG), Defensor del Pueblo o asociaciones vecinales, están ejerciendo mayores presiones sobre las actividades industriales.

Por lo tanto, las Gestiones Empresariales generales, llevadas a cabo por las máximas autoridades, deberían acentuar el compromiso con la Gestión Ambiental. No solo por el mero cumplimiento de la normativa, para mejorar la imagen o ganar nuevos mercados, sino para cuidar y respetar el ambiente en que está instalada la Industria, y de esta manera no solo hacerlo con sus empleados, sino también a la comunidad en general.

\subsection{Gestión ambiental y ventajas competitivas empresariales}

Una Gestión Ambiental implementada de manera eficiente puede generar ventajas competitivas generales en la Empresa. Esta afirmación se puede justificar desde varios aspectos, ya que permite: 
- Evitar sanciones por incumplimientos en la normativa. Estas podrían ir desde multas, hasta clausuras parciales o totales del establecimiento. No solo se verá afectada la parte económica de la empresa, sino que también influirá de manera negativa en la relación con los clientes, proveedores, empleados y la comunidad en general.

- Limitar posibles impactos negativos que se produzcan en los empleados así como en el ambiente general, y de este modo no tener que realizar acciones de reparación, remediación y/o compensación en ese sentido. Esto no solo nuevamente se verá reflejado en reducción de costos, sino en no tener una imagen negativa ante clientes, proveedores, empleados y la comunidad en general.

- Conocer al detalle los trámites, gestiones y seguimientos que se deban realizar, optimizando de este modo las contrataciones de proveedores y redundando directamente en un menor costo asociado.

- Optimizar procesos, obteniendo beneficios asociados a la eficiencia en la utilización de materia prima e insumos y de este modo una reducción de los residuos e impactos negativos generados.

- Abrir mercados internos y externos gracias a la implementación de normas ISO (principalmente la 14.001 de Gestión Ambiental, de la mano con la 9.001 de Gestión de Calidad), ya que muchas empresas exigen para sus proveedores este requisito.

- Demostrar un mayor compromiso con la comunidad, desde la base del respeto al ambiente, y de este modo mejorar y optimizar la imagen institucional. Esto se verá reflejado más aún, en el caso de implementar informes formales de Sustentabilidad, como lo son por ejemplo los Global Reporting Initiative (conocidos por su sigla GRI). 


\section{Bibliografía}

- Albano, Osvaldo O. "Inconstitucionalidad del tipo penal genérico, en la aplicación de la ley de residuos peligrosos", J.A. 1994, p. 787.

- Bekerman, M., La economía y las prioridades sociales, en Diario Página $12,28 / 11 / 2004$.

- Bertonatti, C. y J. Corcuera. 2000. Situación Ambiental Argentina 2000. Fundación Vida Silvestre Argentina. Buenos Aires. 440 pp.

- Boatright, J., Ethics and the Conduct of Business, Prentice Hall, 1993.

- Boulding, K. (1966) The economics of the coming spaceship earth, pp.: 3-15 en $\mathrm{H}$. Jarrett (ed.): Environmental quality in a growing economy, John Hopkins, Baltimore.

- Bowen, H., Social Responsabilities of the Businessman, New York, Harper \& Row, 1953.

- Brañes, Raúl "La formación en derecho ambiental a nivel universitario" Ed. Gedisa Barcelona 1994.

- Bunge, M. (1972) Teoría y realidad, Ed. Ariel, Barcelona.

- Cámara Federal de Apelaciones de La Plata -Sala $2^{\circ}$ - "Asociación Coordinadora de Usuarios, Consumidores y Contribuyentes c. Enre Edesur s/cese de obra de cableado y traslado de subestación transformadora" 08/07/03.

- Cámara Federal de San Martín (Sala $1^{\circ}$ ) 16-10-92 "Wentzel, Jochen E y otro" JA 1993-III-10

- Cámara Federal de San Martín (Sala $1^{\circ}$ ) sentencia del 26/8/92 "Constantini y otros s/Averiguación de contaminación Río Reconquista"

- Cámara Federal San Martín -Sala 1ำ "Averiguación presunta infracción a la Ley 24.051, Felici Octavio, Felici Nicolás" sentencia 14-06-2005

- Camerlinck, G. y Lyon Cahen, G., Droit du travail, Dalloz, París,1980, citados por Martínez Vivot, J., en "El compromiso de información por 
parte del empresario en la Ley 25.250, con particular referencia al balance social", en Trabajo y Seguridad Social, 2002.

- Cano, Guillermo. 1979. Recursos naturales y energía. Derecho, política y administración. La Ley. Fondo Editorial de Derecho y Economía. Buenos Aires.

- Cappelletti, B., Actores sociales y formación en Argentina, Aportes para el diálogo social y formación, Oficina Internacional del Trabajo, Cinterfor, Montevideo, 2000.

- Castello, L. (1996). Desarrollo sostenible, terminología, conceptos y afines, mimeo

- Clark, C. W. (1974). The economics of overexploitation, Science 181: 630-634.

- Clark, C. W. y R.E. Munn - eds.- (1986). Sustainable development of the biosphere, IIASA, Cambridge Univ. Press.

- Comisión Económica para América Latina y el Caribe CEPAL, El cambio social y la política de desarrollo social en América Latina, ONU, New York, pág. 187, 1969.

- Corradetti, S; Deibe, E.; Fontana, B.; lacona, J.; Peralta, M.; Rial, N.; y Treviño, S., El Trabajo Decente: El caso argentino, X Encuentro Grupo Bologna - Castilla La Mancha, año 2001.

- Davis, K., Can Business Afford to Ignore Social Responsabilities?, en California Management Review, número 2, 1960.

- Derecho Laboral, número extraordinario, La Reforma Laboral, Ley 25.250, RubinzalCulzoni, 2000.

- Donaldson, T., Ethical Issues in Business, 1999.

- Dourojeanni, Axel. 1999. La Dinámica del desarrollo sustentable y sostenible. Documento del XV Congreso Venezolano de la Ciencia del Suelo, Barquisimeto, Venezuela. 
- Drucker, P., The New Meaning of Corporate Social Responsibility, en California Management Review, 1984, número 26.

- Enzensberger, H. M. (1974). Para una crítica de la ecología política, Ed. Anagrama, Barcelona.

- Epstein, E., The Corporate Social Policy Process, Beyond Business Ethics, Corporate Social Responsibility, and Corporate Social Responsiveness, en California Mangement Review, 1987.

- Estrada Oyuela, R. y M. C. Zeballos de Sisto (1993) Evolución reciente del derecho ambiental internacional, Ed. A-Z, Bs. As.

- Etala, C., La Reforma Laboral de la Ley 25.877, LexisNexis, Buenos Aires, 2004.

- Frederick, W., The Growing Concern Over Business Responsibility, en California Management Review, número 2, 1960.

- Freeman, R., Strategic Management: A Stakeholder Aprroach, Boston, Pitman, 1984.

- Frías, Pedro. 1980. Introducción al Derecho Público Provincial, Depalma, Buenos Aires.

- Friedman, M., Friedman Doctrine. The Social Responsability of Business is to Increase its Profits, en The New York Times Magazine,1970, pág. $32 / 33$.

- Funtowicz, S. y J. Ravetz (1994). The worth of a songbird: ecological economics as a post-normal science, Ecological Economics 10: 197-207.

- Gallart, M., Escuela-empresa: un vínculo difícil y necesario, en Boletín Educación y

- Gallart, M., Reflexiones para la vinculación con Empresas por parte de Escuelas Técnicas, Programa Vinculación Empresa-Escuela, Buenos Aires, 2004.

- Gallego, M., El balance social como herramienta de auditoría social, en Revista Universidad Eafit, julio-agosto-septiembre, 1999. 
- Gambier Beltrán y Lago Daniel "El medio ambiente y su reciente recepción constitucional” en E.D. 1163-727.

- García, E. (1995). Notas sobre desarrollo sustentable y propósito consciente, Ecología Política 10: 45-58, Barcelona.

- Ge orgescu-Roegen, N. (1971). The entropy law and the economic process, Harvard University Press.

- Gnecco, L., Contratos de formación y derecho del trabajo, Astrea, Buenos Aires, 2002.

- Goin, F. y R. Goñi (eds.). 1993. Elementos de Política Ambiental. Honorable Cámara de Diputados de la Provincia de Buenos Aires.

- Goñi, Ricardo y Francisco Goin. 2006. El desarrollo sustentable en tiempos interesantes. Editorial Scalabrini Ortiz. La Plata.

- Gould, S. J. (1994). La regla áurea: una escala apropiada para nuestra crisis ambiental, pp. 38-47, en: S. J. Gould: Ocho cerditos. Reflexiones sobre historia natural, Crítica, Barcelona.

- Grisolía J. e Hierrizuelo D., Ley de Ordenamiento Laboral - Reforma 2004 - Ley 25.877 Análisis Teórico Práctico, Quantum, Buenos Aires, 2004.

- Grisolía, J., Derecho del Trabajo y de la Seguridad Social, LexisNexis, Buenos Aires, 2004.

- Holdgate, M. (1992). Políticas globales para la conservación, Actualización Política 7: 9-18, Buenos Aires.

- Hurrel, A. y Woods, N., Inequality, Globalization and World Politics, New York, Oxford University Press, 1999.

- Hutchinson, Tomás en obra colectiva "Daño Ambiental" T.1 Rubinzal Culzoni, Santa Fe 1999 p.285

- Imbach, A.; E. Dudley; N. Ortiz y H. Sánchez (1996). MARPS - Mapeo analítico, participativo y reflexivo de la sustentabilidad. Una aproximación 
integral al monitoreo y evaluación de los avances hacia la sustentabilidad, UICN, edición provisional, 36 p.

- Introducción a la G4. La nueva generación de memorias de sostenibilidad. Global Reporting Initiative. Mayo 2013. www.globalreporting.org

- ISO - Febrero 2010/1 500 - ISBN 978-92-67-30518-5 Traducciòn realizada por COPANT bajo su responsabilidad.

- ISO Lic. Elda Monterroso UN Lujan http://www.unlu.edu.ar/ ope20156/normasiso.htm

- Javiller, J., Ordenamiento jurídico, relaciones profesionales y flexibilidad. Enfoques comparativos e internacionales, Revista Trabajo y Seguridad Social, Tomo XIV, 1987.

- Kapstein, E., Directions Report, World Lindk, 2000.

- Kuhn, T.S. (1970). The structure of scientific revolutions, Univ.of Chicago Press, 2nd. ed.

- Lozano, J., Etica y empresa, Madrid, Trotta,1999.

- Malgariño, F., La responsabilidad social de la empresa en Italia, Roma, 2001.

- Martínez Alier, J. (1995). Indicadores de sustentabilidad y conflictos distributivos ecológicos, Ecología Política 10: 35-43, Barcelona.

- Martínez Alier, J. y K. Schlüpmann (1991). La ecología y la economía, Fondo de Cultura Económica, México, 1991.

- Mathews J. y Hakim, P., prólogo al Disenso de Washington, citado en Kliksberg, B., Hacia una nueva visión de la política social en América Latina: Desmoronando mitos, La Plata, ponencia presentada en el Programa de Gerencia Social para el Desarrollo Humano, 2002.

- Mauricio Libster "Delitos Ecológicos" p 177 Ed. Desalma Bs As 1993 pág. 177. 
- Meadows, D. et al. (1972). Los límites del crecimiento, Fondo de Cultura Económica, México.

- Melnick, S. (1980). Principales escuelas, tendencias y corrientes de pensamiento, pp.: 236-287, en: O. Sunkel y N. Gligo (comps.): Estilos de desarrollo y medio ambiente en la América Latina, Fondo de Cultura Económica, México, tomo 1.

- Munda, G. (1995). Multicriteria evaluation in a fuzzy environment. Theory and applications in ecological economics, Physica Verlag, Heidelberg, $255 \mathrm{p}$.

- Neffa, J., ¿Qué hacer para mejorar la competitividad de las Pyme argentinas?, Asociación Trabajo y Sociedad - Programa de Investigaciones Económicas sobre Tecnología, Trabajo y Empleo (CEIL - PIETTE CONICET), Buenos Aires, 2000.

- Norgaard, R. (1994). Development betrayed, Routledge, Londres.

- Odum, H. T. (1971). Environment, power and society, Wiley, New York.

- OIT, Por una globalización justa, crear oportunidades para todos, informe de la Comisión Mundial sobre la Dimensión social de la Globalización, 2004.

- Ojeda, R., Crisis, concertación y representación de los nuevos actores sociales, en el Primer Encuentro sobre Diálogo Social y Trabajo Decente - Red Académica para el Diálogo Social, Mar del Plata, 2003.

- Olabe, A., Indicadores de sustentabilidad en el ámbito de la responsabilidad social de la empresa, Jornadas sobre Responsabilidad Social, junio, 2002.

- Paladino, M., La responsabilidad de la empresa en la sociedad. Construyendo la sociedad desde la tarea directiva, Buenos Aires, Ariel Sociedad Económica, 2004. 
- Pastorino, Leonardo. 1995. Los recursos naturales y la distribución de competencias, según la reforma constitucional. Revista del Colegio de Abogados de La Plata. №56, p. 9.

- Pearce, D. (1976). Environmental economics, Longman, Londres. (Versión consultada: Economía ambiental, Fondo de Cultura Económica, México, 1985).

- Pigretti, Eduardo. 1971. Derecho de los recursos naturales. La Ley. Buenos Aires.

- Pigretti, Eduardo. 2005. Derecho Ambiental profundizado. La Ley. Buenos Aires.

- Podetti, H., Política social, Astrea, Buenos Aires, 1982.

- Ramón Martín Mateo, "Tratado de Derecho Ambiental" 1991. Pág. 219.

- Rodríguez Larreta, H., Responsabilidad Social Empresaria, un desafío cultural para la Argentina, Grupo Sophia, Buenos Aires, 2003.

- Rojas, A. (1993). ¿Desarrollo sustentable o desarrollo de la sustentabilidad ecológica y social?, pp: 61-101, en: Medio Ambiente en desarrollo, Santiago.

- Schmidheiny, S. (1992). Cambiando el rumbo: una perspectiva global del empresariado para el desarrollo y el medio ambiente, Fondo de Cultura Económica, México.

- Schumacher, E. (1978). Lo pequeño es hermoso, H. Blume Ed., Barcelona.

- Sethi, S., Dimensions of Corporate Social Performance: An Analytical Framework, en California Management Review, número 17, 1975. 36

- Sheldon, O., The Philosophy of Management, Londres, Sir Isaac Pitman \& Sons, 1923.

- Stein, G., Management y el arte de gobernar según P. Drucker, Harvard Desuto Review, marzo-abril 2000, número 95. 
- Sunkel, O. y N. Gligo - comps.- (1980). Estilos de desarrollo y medio ambiente en la América Latina, Fondo de Cultura Económica, México, 2 tomos.

- Trabajo, Red Latinoamericana de Educación y Trabajo CIID - CENEP, Año 7, número 1, Buenos Aires, 1996. 35

- UICN - PNUMA - WWF (1993). Cuidar la Tierra. Una estrategia para el futuro de la vida, Gland, Suiza.

- Vázquez Vialard, A., Reflexiones respecto de las expectativas creadas por el Mensaje del Poder Ejecutivo Nacional y logros alcanzados por la Ley 25.250, en Revista de

- Vázquez Vialard, A., Tratado de derecho del trabajo, Buenos Aires, Astrea, 1982-1996.

- Vitousek, P. (1994). Beyond global warming: ecology and global change, Ecology 75 (7): 1861-1876.

- Vitousek, P.M., P.R. Ehrlich, A. H. Ehrlich y P. A. Matson (1986). Human appropriation of the product of photosynthesis, BioScience 36: 368-373.

- Winograd, M. (1995). Indicadores ambientales para Latinoamérica y el Caribe: hacia la sustentabilidad en el uso de tierras, IICA, San José de Costa Rica, 84 p.

- WRI - UICN - PNUMA (1992). Estrategia global para la biodiversidad, $243 p$. 


\section{Referencias y anexos}

\subsubsection{Referencias}

\subsubsection{1 Índice de Tablas}

Tabla 1. Detalle de posibles valores para tabular variables en la determinación del Grado de Compromiso por Industria. 100

Tabla 2. Determinación del Grado de Compromiso por Industria. 102

Tabla 3. Promedio, desvío estándar y varianza de valores de grados de compromiso por tipo de industrias. 104

Tabla 4. Resumen de características de industrias seleccionadas para la realización de entrevistas. 105

Tabla 5. Cualificación de Grados de Compromiso 124

Tabla 6. Grados de Compromiso del $68,3 \%$ de las industrias por Categoría. 126

\subsubsection{2 Índice de gráficos}

Gráfico 1. Trámites obligatorios a presentar ante OPDS.jError! Marcador no definido.

Gráfico 2. Trámites obligatorios a presentar ante ADA. ¡Error! Marcador no definido.

Gráfico 3. Evolución de la norma ISO 14001 en Argentina. Fuente: Encuesta ISO 2913.

Gráfico 4. Industrias relevadas según Categorización de OPDS............. 77

Gráfico 5. Presentación de EIA's de Industrias de $1^{\circ}$ y $2^{\circ}$ Categoría. ..... 78

Gráfico 6. Presentación de EIA's de Industrias de $3^{\circ}$ Categoría. ............. 78

Gráfico 7. Otorgamiento de CAA a Industrias de $1^{\circ}$ y $2^{\circ}$ Categoría......... 79

Gráfico 8. Otorgamiento de CAA a Industrias de $3^{\circ}$ Categoría................. 79 
Gráfico 9. Presentación de trámites de Aparatos Sometidos a Presión (ASP), Residuos Especiales (RREE) y Efluentes Gaseosos de Industrias de $1^{\circ}$ y $2^{\circ}$ Categoría.

Gráfico 10. Presentación de trámites de Aparatos Sometidos a Presión (ASP), Residuos Especiales (RREE) y Efluentes Gaseosos de Industrias de $3^{\circ}$ Categoría. 80

Gráfico 11. Certificado de Descarga de Efluentes Gaseosos a la Atmósfera vigente, de las Industrias que han solicitado el mismo.

Gráfico 12. Periodicidad de monitoreos de Efluentes Gaseosos.

Gráfico 13. Inscripción en el BUDURH.

Gráfico 14. Solicitud del Permiso de Explotación del Recurso Hídrico Subterráneo.

Gráfico 15. Permiso de Explotación del Recurso Hídrico Subterráneo vigente.

Gráfico 16. Cuentan con planta de tratamiento de efluentes líquidos.

Gráfico 17. Solicitud del Permiso de Vuelco de Efluentes Líquidos previamente tratados.

Gráfico 18. Otorgamiento del Permiso de Vuelco de Efluentes Líquidos previamente tratados.

Gráfico 19. Implementación de Sistemas de Gestión ISO 85

Gráfico 20. Sistemas de Gestión ISO implementados. 85

Gráfico 21. Obtención de beneficios en relación a la implementación de Sistemas de Gestión ISO. 86

Gráfico 22. Beneficios obtenidos en relación a la implementación de Sistemas de Gestión ISO. 86

Gráfico 23. Implementación de Planes de RSE y/o Sustentabilidad. 87

Gráfico 24. Tipos de planes de RES y/o Sustentabilidad implementados. 
Gráfico 25. Beneficios obtenidos en relación a la implementación de planes de RSE y/o Sustentabilidad. 88

Gráfico 26. RRHH dedicados a la Gestión Ambiental en Industrias de Segunda Categoría.

Gráfico 27. RRHH dedicados a la Gestión Ambiental en Industrias de Tercera Categoría.

Gráfico 28. Servicios contratados para el mantenimiento de la Gestión Ambiental.

Gráfico 29. Realización de inspecciones de las autoridades de aplicación ambiental en el último año.

Gráfico 30. Motivos por los cuales recibieron inspecciones. 92

Gráfico 31. Porcentaje de inspecciones por Categoría, que recibieron inspecciones.

Gráfico 32. Motivos por los cuales realizan una Gestión Ambiental. 93

Gráfico 33. Situaciones en las que se comprometen las mayores autoridades de la Empresa con la Gestión Ambiental. 94

Gráfico 34. Situación actual en relación al cumplimiento de los trámites obligatorios de la Gestión Ambiental en Industrias de $1^{\circ}$ y $2^{\circ}$ Categoría. 95

Gráfico 35. Situación actual en relación al cumplimiento de los trámites obligatorios de la Gestión Ambiental en Industrias de $3^{\circ}$ Categoría. 95

Gráfico 36. Comparativa de presentaciones de trámites obligatorios según facturación anual. 96

Gráfico 37. Gastos de Gestión Ambiental en relación a facturación anual. 96

Gráfico 38. Limitaciones para una Gestión Ambiental eficiente. 97

Gráfico 39. Reciben auditorías de clientes y/o proveedores. 98

Gráfico 40. Afectación negativa de la relación con clientes y/o proveedores como consecuencia de una Gestión Ambiental ineficiente. 98 
Gráfico 41. Presencia de conflictos con la comunidad como consecuencia de una Gestión Ambiental ineficiente. 98

Gráfico 42. Conocimiento de responsabilidades civiles y/o penales en los puestos clave de la Gestión Ambiental. 99

Gráfico 43. Dispersión de valores de Grados de Compromiso por Industrias.

Gráfico 44. Grados de Compromiso por Categorías. 125

Gráfico 45. Causas de mayor y menor Grado de Compromiso de la Gestión Empresarial general con la Gestión Ambiental. ¡Error! Marcador no definido.

\subsubsection{Anexos}

10.1.2.1 Anexo I: Encuesta

Rubro general de la industria*

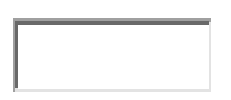

Cuidad $^{*}$

\section{Cantidad de Operarios*}
Menos de 50
Entre 50 y 100
Entre 100 y 200
Entre 200 y 300
Más de 300

Cantidad de Recursos Humanos Internos dedicados a la Gestión Ambiental ${ }^{*}$.

Cantidad de Recursos Humanos internos dedicados a la Gestión Ambiental en forma exclusiva ${ }^{*}$ 
En cuanto a presentaciones ante el Organismo Provincial para el Desarrollo Sostenible (OPDS)

¿Cuál es su categorización de Industria?*
1. Primera
2. Segunda
3. Tercera ¿Tienen Estudio de Impacto Ambiental presentado?*
A. Sí, y está actualizado
B. Sí, pero no está actualizado
C. No

¿Cuentan con Certificado de Aptitud Ambiental (CAA) vigente?*

- $\frac{\mathrm{S} i ́}{\mathrm{~N}}$

Sus Aparatos Sometidos a Presión (ASP), ¿están habilitados y cuentan con las renovaciones periódicas?* ${ }^{*}$

- $\frac{r}{r}$ Ní

¿Cuentan con las renovaciones de Residuos Especiales correspondientes?*

- C sí

- $\mathrm{C}$ No

- $\mathrm{N}$ No aplica ¿Han solicitado el Permiso de Descarga de Efluentes Gaseosos a la Atmósfera?*

- $\mathrm{C}$ sí

- $\mathrm{No}$

- $\mathrm{N}$ No aplica ¿Cuentan con el Permiso de Descarga de Efluentes Gaseosos a la Atmósfera? 
- $\frac{r}{\text { sí }}$

¿Cuál es la periodicidad de los monitoreos de aire y/o conductos?*

- Mensual

- $\mathrm{C}$ Trimestral

- $\mathrm{C}$ Cuatrimestral

- $\mathrm{C}$ Semestral

- $r$ Anual

- O Otro:

En cuanto a presentaciones ante la Autoridad del Agua (ADA)

¿Están inscriptos en el Banco Único de Datos de Usuarios de los Recursos Hídricos (BUDURH)? *

- $\frac{\mathrm{C}}{\mathrm{C}} \mathrm{i}$

¿Tienen presentaciones solicitando el Permiso de Explotación del Recurso Hídrico Subterráneo de los pozos de extracción de agua?*

- C sí

- $\mathrm{C}$ No

- No aplica

¿Cuentan con el Permiso de Explotación del Recurso Hídrico Subterráneo vigente?

- S Sí

- No

¿Tienen presentaciones solicitando la Factibilidad Hidráulica?*

- $\frac{\mathrm{C} \text { sí }}{\mathrm{C} \text { No }}$ - No aplica

¿Cuentan con la Factibilidad Hidráulica vigente? 
- $\frac{r}{r}$ sí

¿Tienen planta de tratamiento de efluentes líquidos?*

- $\quad$ Sí

- $\mathrm{No}$

¿Han solicitado el Permiso de Vuelco al Recurso Hídrico?*

- Sí

- $\mathrm{r}$ No

- $\quad$ No aplica

¿Cuentan con el Permiso de Vuelco al Recurso Hídrico vigente?

- S sí

- No

¿Qué servicios externos contratan para mantener la Gestión Ambiental?*

- $\quad$ Consultoría y Asesoramiento integral

- Consultoría y Asesoramiento para cada tema puntual

- $\quad$ Laboratorio de análisis ambientales

- $\square$ Implementación y mantenimiento de Sistemas de Gestión ISO

- $\Gamma$ Implementación y mantenimiento de Planes de Responsabilidad Social Empresaria

- $\quad$ Implementación y mantenimiento de Informes de Sustentabilidad

- $\square$ Ninguno

- Otro:

¿Tienen implementados Sistemas de Gestión ISO?*

- $\mathrm{C}$ sí

- $\mathrm{No}$

En caso de ser "Si", especifique cuál: 


\section{Considera que obtuvieron beneficios asociados con: ${ }^{*}$}

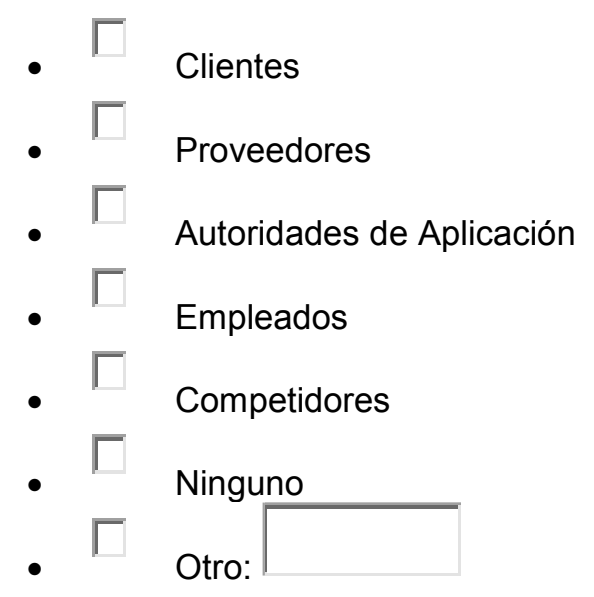

¿Tienen implementados Planes de Responsabilidad Social Empresaria?*

- $\quad$ Sí

- $\mathrm{C}$ No

En caso de ser "Si", especifique cuál:

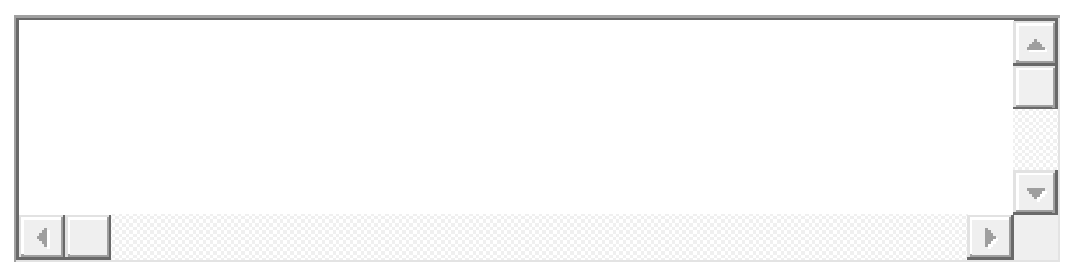

\section{Considera que obtuvieron beneficios asociados con: ${ }^{*}$}

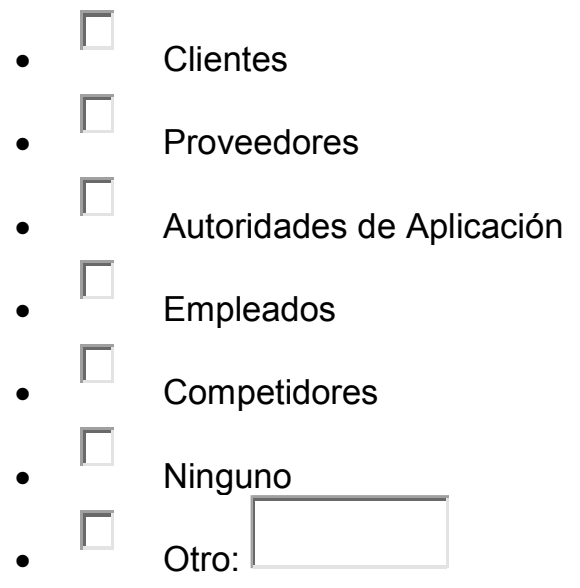

¿Tienen implementados Informes de Sustentabilidad?*-

- $\quad$ Sí 
- No

En caso de ser "Si", especifique cuál:

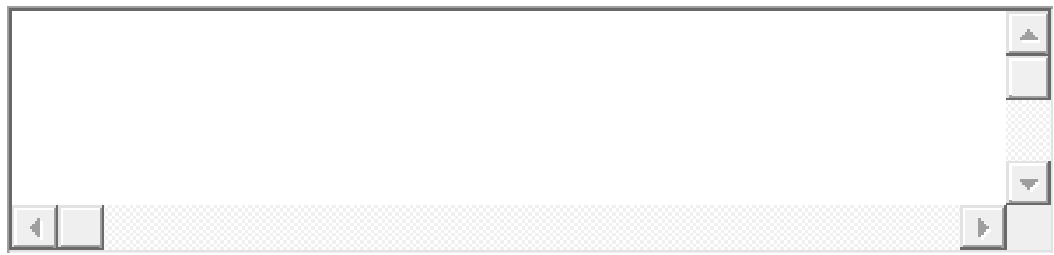

Considera que obtuvieron beneficios asociados con:*

- Clientes

- $\quad$ Proveedores

- $\quad$ Autoridades de Aplicación

- $\quad$ Empleados

- $\quad$ Competidores

- Ninguno

- $\quad$ Otro:

¿Han recibido inspecciones de las autoridades de aplicación en el último año?*

- $\quad$ Sí

- No

Las mismas fueron:

- $\quad$ De rutina

- $\Gamma$ Por denuncias de vecinos

- $\quad$ Para corroborar datos presentados

- Otro:

Ordene de mayor a menor importancia (siendo mayor 1 y menor 5) los siguientes puntos en relación al porqué de la implementación de la Gestión Ambiental en su Industria*.

$\begin{array}{lllll}1 & 2 & 3 & 4 & 5\end{array}$

Para cumplir

con la

normativa y

P.

evitar 


$\begin{array}{lllll}1 & 2 & 4 & 5\end{array}$

sanciones

Para

mantener /

mejorar la

imagen con

C

C

C

$P$

la comunidad

\section{Para}

diferenciarse

de los

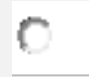

P

C

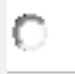

competidores

Para

mantener

acotados los

riesgos

ambientales

Por

exigencias

de clientes /

proveedores

¿En qué situaciones se comprometen la/s mayor/es autoridad/es de la Empresa con la Gestión Ambiental?*

- $\mathrm{C}$ Nunca

- Cuando hay sanciones (multas / clausuras)

- Cuando hay inspecciones / intimaciones

- $\quad$ Solicitan informes periódicos

- La conocen al detalle

En cuanto al cumplimiento de la normativa, su Industria se encuentra en base a las presentaciones obligatorias ante OPDS y ADA: ${ }^{*}$

- $\quad$ Al día

- $\quad$ Se adeudan algunas 
- Se adeudan la mayoría

- $\quad$ No se ha realizado ninguna

¿En qué rango de facturación anual se encuentra su Empresa? (en millones de pesos) ${ }^{*}$

- Menos de 5

- $\quad$ Entre 5 y 20

- $\quad$ Entre 20 y 50

- $\quad$ Entre 50 y 100

- Más de 100

¿En qué rango se encuentra el gasto anual que destinan a la Gestión Ambiental? (en miles de pesos) ${ }^{*}$

- $\quad$ Menos de 100

- $\quad$ Entre 100 y 200

- $\quad$ Entre 200 y 300

- $\quad$ Entre 300 y 500

- Más de 500

Entre las limitaciones que pueden presentarse para no llevar una Gestión Ambiental eficiente en su Industria, ¿cuáles considera que serían las posibles causas?*

- Falta de recursos económicos

- Falta de recursos humanos capacitados

- $r$ Falta de asesoramiento

- $\mathrm{D}$ Decisión empresarial

- $\mathrm{O}$ Otro:

¿Reciben auditorías ambientales de sus clientes / proveedores?*

- S Sí

- $C$ No

¿Se ha visto perjudicada la relación con clientes y/o proveedores como consecuencia de incumplimientos de la Gestión Ambiental?*

- $\frac{r}{r}$ Ní 
¿Han tenido conflictos con la comunidad como consecuencia de problemas en la Gestión Ambiental?*

- Sí, y se generaron gastos económicos adicionales

- $\quad$ Sí, pero no se generaron gastos económicos adicionales

- No

¿Conoce las responsabilidades civiles y/o penales de los puestos clave de la Gestión Ambiental en las Industrias?*

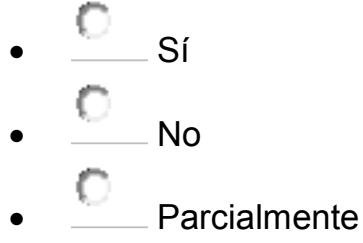

